University of South Florida

DIGITAL COMMONS

Digital Commons @ University of

@ UNIVERSITY OF SOUTH FLORIDA

South Florida

USF Tampa Graduate Theses and Dissertations

USF Graduate Theses and Dissertations

10-30-2009

\title{
Hemocompatibility Assessment of 3C-SiC for Cardiovascular Applications
}

Norelli Schettini

University of South Florida

Follow this and additional works at: https://digitalcommons.usf.edu/etd

Part of the American Studies Commons

\section{Scholar Commons Citation}

Schettini, Norelli, "Hemocompatibility Assessment of 3C-SiC for Cardiovascular Applications" (2009). USF Tampa Graduate Theses and Dissertations.

https://digitalcommons.usf.edu/etd/3679

This Dissertation is brought to you for free and open access by the USF Graduate Theses and Dissertations at Digital Commons @ University of South Florida. It has been accepted for inclusion in USF Tampa Graduate Theses and Dissertations by an authorized administrator of Digital Commons @ University of South Florida. For more information, please contact digitalcommons@usf.edu. 
Hemocompatibility Assessment of 3C-SiC for Cardiovascular Applications

by

\author{
Norelli Schettini \\ A dissertation submitted in partial fulfillment \\ of the requirements for the degree of \\ Doctor of Philosophy \\ Department of Electrical Engineering \\ College of Engineering \\ University of South Florida \\ Co-Major Professor: Stephen E. Saddow, Ph.D. \\ Co-Major Professor: Mark Jaroszeski, Ph.D. \\ Anne Curtis, M.D. \\ Karl E. Muffly, Ph.D. \\ Andrew Hoff, Ph.D. \\ Jing Wang, Ph.D. \\ Date of Approval: \\ October 30, 2009
}

Keywords: cubic silicon carbide, thrombogenicity, platelet adhesion, circularity, cell proliferation

(C) Copyright 2009, Norelli Schettini 


\section{Dedication}

To those that in the lack of motivation provided me with inspiration....

To the ones that kept me awake, sane.

To the ones that didn't give up on me.

To the ones that nourished my dreams.

To the ones that helped me find the path.

To the ones that were with me when I lost the path...

... when I lost the patience.

To those that in the lack of inspiration provided me with strong motivations... 


\section{Acknowledgments}

In the first place, I would like to express my gratitude to Dr. S. Saddow, who has supported this project intellectually, morally and financially, he offered me the opportunity to work in his group, started me in the area of biotechnology and provided me with a sense of belonging, motivations, a working environment and infinite hours of academic discussion that resulted in this document. My gratitude also goes to Dr. M. Jaroszeski, he accepted to be my co- major professor, and provided the right tools and necessary support to develop this research. I am also indebted to my committee members Dr. A. Curtis, Dr. K. E. Muffly, Dr. A. Hoff and Dr. J. Wang, it has been an honor to work with them and they have provided very valuable suggestions through the course of this research. Next, I would like to thank especially Mr. L. West and Dr. K. E. Muffly who became pivotal for the development of this research; I owe most of my biotechnology knowledge to them. Additionally, I would like to thank the FCoE-BITT fellowship and Dr. T. Vickerson for all her support.I would like to acknowledge Dr. L. Ondrovic and the staff of the Department of Comparative Medicine (USF Vivarium) for our blood and tissues supply. Finally, I would like thank my friends and colleagues for their valuable help and support: Dr. Coletti, Dr. Reyes, Dr. Walker, Dr. Frewin, Dr. Benjamin, Dr. Short, C. Locke, I. Haselbarth, A. Oliveros, E. Murphy, our visitors Dr. A. Severino and R. Anzalone (AFM), to R. Connelly, J. Rey, J. Jiménez and especially to J. Elliott to whom I owe the survival of my cell cultures. 


\section{Table of Contents}

List of Tables ......................................................................................................... ii

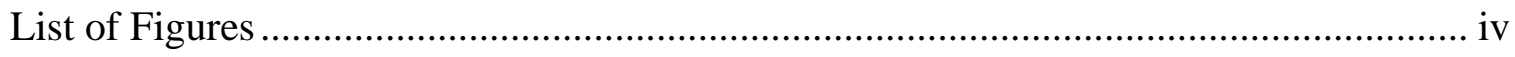

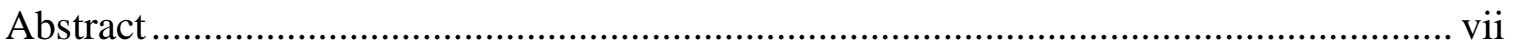

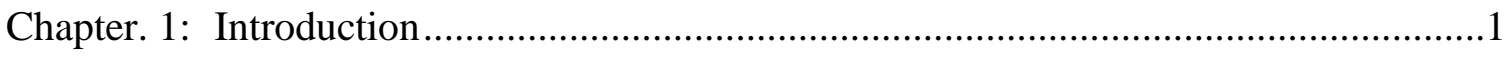

1.1 Research Objective and Motivation ........................................................2

1.1.1 Thrombus Formation .............................................................4

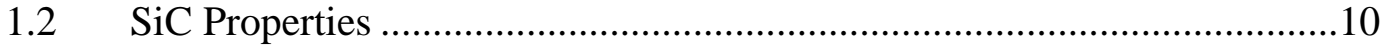

1.2.1 SiC a Promising Material for Biosensing Applications in the Blood Stream................................................................12

1.3 Summary and Dissertation Organization .............................................21

Chapter. 2: Biocompatibility of Materials ...........................................................22

2.1 Biocompatibility of Materials with Blood: Hemocompatibility ................23

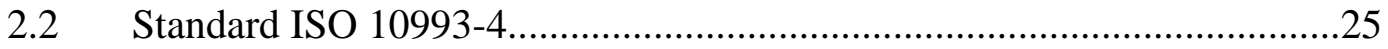

2.3 Perspectives in Hemocompatibility Assessment .....................................27

2.3.1 The Platelet Adhesion and Activation Assessment

Perspective ..............................................................................30

2.3.2 The Protein Adsorption Assessment Perspective .........................32

2.3.3 The Endothelial Cell Proliferation Perspective...............................33

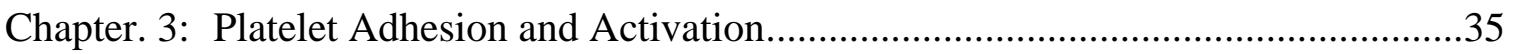

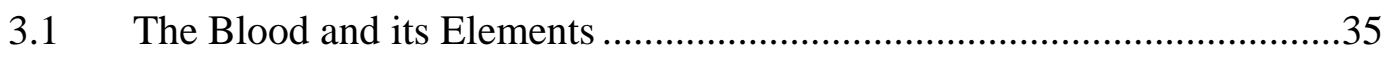

3.2 Platelet Adhesion and Activation Assessment Protocol ...........................41

3.2.1 The Impact of Surface Roughness ...........................................51

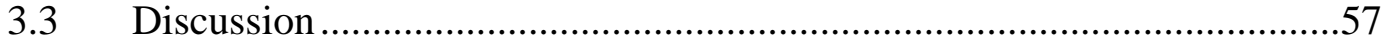

Chapter. 4: Protein Adsorption to Surfaces ..................................................................58

4.1 The Aggregation and Activation of Platelets ........................................58

4.2 The QCM Technology .............................................................60

4.3 Protein Adsorption Assessment Using QCM-D ....................................62

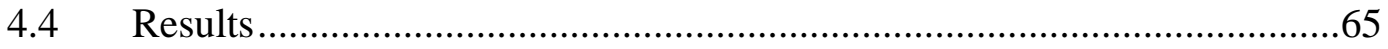




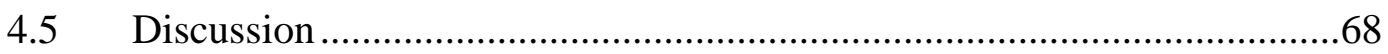

Chapter. 5: Microvascular Endothelial Cell Proliferation on Semiconductor

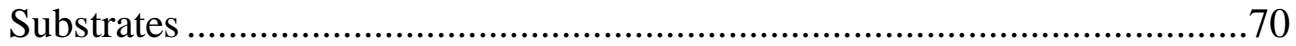

5.1 Microvascular Endothelial Cells and the Vessel Internal Lumen...............70

5.2 Cell Proliferation in Vitro: Experimental Protocol .......................................73

5.3 MTT Assay and Fluorescent Microscopy Results ......................................78

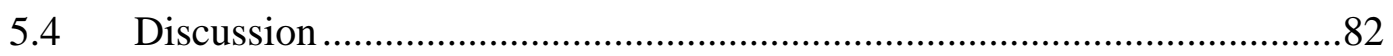

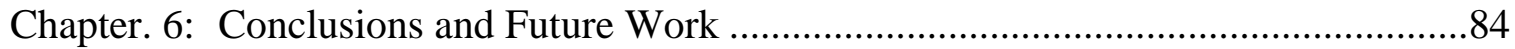

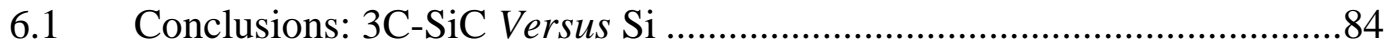

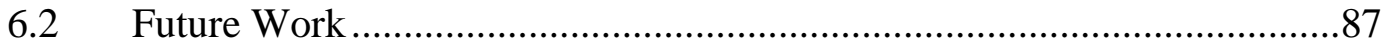

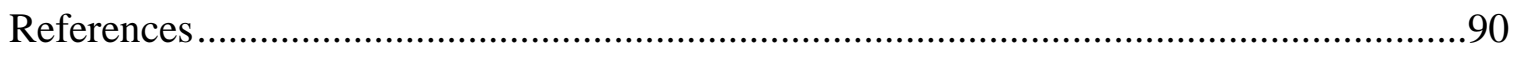

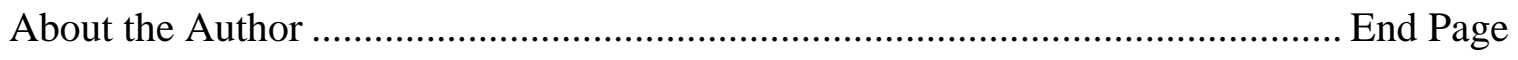




\section{List of Tables}

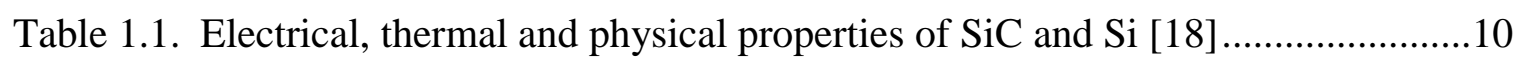

Table 2.1. A sample of primary in vitro tests, Adapted from [51] ................................26

Table 3.1. Summary of samples roughness expressed as [average roughness $(\mu)+$ standard deviation of the mean $(\sigma)]$ in nanometers $(\mathrm{nm})$...... 


\section{List of Figures}

Figure 1.1. (Top) Flow diagram of the clotting cascade showing both, extrinsic and intrinsic pathways [6]....................................................................

Figure 1.2. Platelet lamellipodia and filopodia after activation on a surface.

Adapted from [6].

Figure 1.3. Sequence of events that leads to formation of fibrous capsules around sensors [16].

Figure 1.4. Fluorescent micrographs of (a) B16 melanoma cells (b) BJ fibroblast cells and (c) $\mathrm{HaCaT}$ keratinocyte cells on $\mathrm{SiC}$ substrates 72 hours after seeding [9].

Figure 1.5. Fluorescent micrographs of (a) B16 melanoma cells (b) BJ fibroblast cells and (c) $\mathrm{HaCaT}$ keratinocyte cells on Si substrates 72 hours after seeding [9].

Figure 1.6. Histogram of cell proliferation of B16, BJ and $\mathrm{HaCaT}$ cells, normalized to the control sample, expressed as $x \pm \sigma$ measured via MTT assays at the third day.

Figure 1.7. Histogram representing results of neuronal $\mathrm{H} 4$ and PC12 cell proliferation tests.

Figure 1.8. $45 \times 45$ um AFM micrographs of $\mathrm{H} 4$ cells deposited on different substrates.

Figure 2.1. Scanning electron micrographs showing platelet morphology of $\mathrm{Si}$ (left) and $\mathrm{SiO}_{2}$ (right).

Figure 2.2. Number of adhered platelets per $15 \mathrm{~mm}^{2}$ for $\mathrm{Si}$, Si-based materials, SU-8, parylene and polyurethane.

Figure 2.3. Fibrinogen promoting platelet-platelet adhesion by binding glycoprotein IIb-IIIa (GPIIb-IIIa).

Figure 2.4. SEM micrographs showing endothelial cells on three types of $\mathrm{Cr}$ -

DLC. Cr is 1,5 and $10 \%$ [62]

Figure 3.1. Diagram of a red blood cell (erythrocyte) shape, .36 
Figure 3.2. Classification of the 5 types of white cells [75].

Figure 3.3. Scanning electron microscope images of resting (left), partially

(center) and fully activated (right) human platelets.

Figure 3.4. Diagram of a tube of anticoagulated blood that has settled,

illustrating the separation of blood into three layers.

Figure 3.5. Preparation of platelet concentrates using the PRP and BC techniques [15].

Figure 3.6. Illustration of the image analysis process for platelets seeded on a Si sample.

Figure 3.7. Fluorescent micrographs comparing adhered platelets on 3 different $\mathrm{SiC}$ polytypes and $\mathrm{Si}$.

Figure 3.8. Fluorescent micrographs revealing activated platelet clumps (left), non- clumped activated platelets (center) and a large non-activated platelet clump on the surface of $4 \mathrm{H}-\mathrm{SiC}$ samples.

Figure 3.9. Statistical analysis of particle circularity on 3 different SiC polytypes and $\mathrm{Si}$.

Figure 3.10. Statistical analysis of particle counts on 3 different SiC polytypes and Si..

Figure 3.11. Statistical analysis of particle size on 3 different $\mathrm{SiC}$ polytypes and Si..

Figure 3.12. Fluorescent micrographs comparing Si (left) and 3C-SiC (right) samples revealing higher degree of thrombogenicity in Si than in $3 \mathrm{C}$ $\mathrm{SiC}$.

Figure 3.13. AFM micrograph taken in tapping mode. .52

Figure 3.14. AFM micrograph taken in tapping mode. .52

Figure 3.15. AFM micrograph taken in tapping mode. .53

Figure 3.16. AFM micrograph taken in tapping mode. ............................................53

Figure 3.17. AFM micrograph taken in tapping mode. .............................................54

Figure 3.18. Fluorescent micrograph comparison of two low-roughness surfaces. .55

Figure 3.19. Fluorescent micrograph comparison of two high-roughness polycrystalline $3 \mathrm{C}-\mathrm{SiC}$ surfaces. .56 
Figure 3.20. Fluorescent micrograph of platelet adhesion on a low-roughness silicon(100) surface.

Figure 4.1. Platelet aggregation mediated by the action of fibrinogen and von Willebrand Factor (vWF) [87].

Figure 4.2. Diagram of a quartz crystal sensor [91]

Figure 4.3. Sequence of steps of a typical hemocompatibility assesment using a Q-sense device..

Figure 4.4. Histogram of the fribrinogen and GPIIb-IIIa adsorption to gold, silicon and $4 \mathrm{H}-\mathrm{SiC}$ substrates.

Figure 4.5. ANOVA tables of the statistical data for Fibrinogen (top) and GPIIbIIIa (bottom).

Figure 4.6. Histogram of the fribrinogen and GPIIb-IIIa mass $\left(\mathrm{ng} / \mathrm{cm}^{2}\right)$ adsorption to gold, silicon and $4 \mathrm{H}-\mathrm{SiC}$ substrates.

Figure 5.1. Fluorescent micrographs illustrating the pavement-like pattern of the endothelial cells.

Figure 5.2. Diagram of a small artery in cross section.

Figure 5.3. Schematic representation of sample position for cell plating experiments.

Figure 5.4. (Top) Histogram displaying the normalized results (respect to the treated wells) of the MTT assay after 72 hours. .78

Figure 5.5. Fluorescent micrographs of HMVEC proliferation on various substrates (treated well, non treated well, $3 \mathrm{C}-\mathrm{SiC}$ and $\mathrm{Si}$ ) after 72 hours.

Figure 5.6. (Top) Histogram displaying the normalized results (respect to the treated wells) of the MTT assay after 120 hours.

Figure 5.7. Fluorescent micrographs of HMVEC proliferation on various substrates (treated well, non treated well, 3C-SiC and Si) after 120 hours.

Figure 5.8. (Top) Histogram displaying the normalized results (respect to the treated wells) of the MTT assay after 168 hours.

Figure 5.9. Fluorescent micrographs of HMVEC proliferation on various substrates (treated well, non treated well, 3C-SiC and $\mathrm{Si}$ ) after 168 hours. 


\title{
Hemocompatibility Assessment of 3C-SiC for Cardiovascular Applications
}

\author{
Norelli Schettini
}

\begin{abstract}
The hemocompatibility of crystalline Silicon Carbide (SiC), in its cubic form (i.e., $3 \mathrm{C}-\mathrm{SiC})_{2}$ has been evaluated and compared to Silicon ( $\left.\mathrm{Si}\right)$, the leading material in biosensing applications. Silicon carbide $(\mathrm{SiC})$ is a hard, chemically robust material, very well suited for harsh environment applications, and has been suggested to have very good biocompatibility. Additionally, $\mathrm{SiC}$ in its amorphous form, has been used as a coating for medical implantable devices such as bone prosthetics and cardiovascular stents. However, assessment of single crystal 3C-SiC for cardiovascular applications has not been reported. In this research we have studied the interactions of single crystal 3C-SiC with platelets and human microvascular endothelial cell (HMVEC) to assess the degree of hemocompatibility of 3C-SiC.

The more hemocompatible a material is, the less platelet adhesion would be expected. Using fluorescence microscopy higher platelet adhesion was statistically observed on $\mathrm{Si}$ than on $\mathrm{SiC}$. In addition 3C-SiC surfaces showed less platelet reactivity, measured by the degree of platelet adhesion, aggregation and activation, with mostly circular morphology of adhered platelets while Si showed an elevated presence of nonactivated (Circular) platelet clumps.
\end{abstract}


Additionally, HMVEC proliferation assessment suggest that $3 \mathrm{C}-\mathrm{SiC}$ performs comparably to high attachment culture wells with enhanced proliferation, without affecting cell morphology.

These results suggest that $3 \mathrm{C}-\mathrm{SiC}$ is a promising candidate for applications in the blood stream due to its low thrombogenic characteristics and good hemocompatibility. 


\section{Chapter. 1: Introduction}

Biocompatibility is the required property of materials and systems that are intended to be in contact with biological matter to perform according to the system design but without interfering with the integrity of the tissues and biological matter that such material is in contact with and without generating any adverse reactions [1].

Silicon ( $\mathrm{Si}$ ) has been long used in the construction of Microelectromechanical systems, MEMS, devices. Subsequently; the question of whether silicon is or is not a biocompatible/suitable material for biotechnology applications or implantable devices is a crucial question in the area of microfabrication and biomedical sensing devices. Although this question seems a simple one, and the kind that one should be able to solve with some literature search, this search usually tends to provide answers as complex as the biological systems that we try to work with.

First, one cannot talk about a biocompatible material in an absolute way, as a material that performs extraordinarily well for some biological matter can be devastating for others and additionally there is a lot of uncertainty about the mechanisms that determine biocompatibility as there as many ways in which tissues and materials interact [2]. In the case of silicon previous research shows that the material can perform well for certain tissues but can be cytotoxic for others [1] [3] [4]. Many limitations have been reported for devices fabricated with $\mathrm{Si}$, including carcinogenic effects due to the presence of minute silicate particulates, inflammatory responses and device encapsulation.

The limitations of how compatible a material is when in contact with tissues is limited by the application, e.g., issue engineering, implantable sensors, drug delivery, etc. If the 
application to be developed requires the proliferation of cells on the surface of a device, such as grafts, cell viability can be considered a pretty good measurement of a material's biocompatibility, but if the material is going to be in contact with blood then we need measurements of the degree of thrombogenicity, defined as the tendency of a material in contact with blood to produce or induce thrombus formation [1] [5].

Biocompatibility is also defined in terms of behaviors that are desirable for a material in contact with biological matter, e.g., a material being non-toxic, non-immunogenic, non carcinogenic, non irritant and so on. Another factor of supreme importance is the implant life time. In the case of short term implants advanced biopolymers offer excellent biocompatible surfaces, but this solution is not suitable for long term implants as these biopolymers tend to degrade in the harsh environment of the human body. In addition, polymers also lack the sensing capabilities that semiconductor materials have, this is especially important in the case on bio-sensing implantable devices.

The particular case of material biocompatibility with blood (and the cardiovascular system in general) is called hemocompatibility and this research explores different aspects of the biocompatibility of single crystal $3 \mathrm{C}-\mathrm{SiC}$ as a potential material for future cardiovascular applications due to its less bioreactive nature when in contact with biological samples and its high degree of proven chemical resilience.

\subsection{Research Objective and Motivation}

Heart failure and stroke are two of the leading causes of death in the United States every year. Today, patients with cardiovascular conditions can benefit from new medications, improved means of cardiovascular monitoring and treatments which were unavailable in the past; however there is still room for improved cardiovascular 
therapeutic devices based on biotechnology, ranging from real-time detection and monitoring of cardiac event markers to accurately timed drug delivery and dosage. Unfortunately, current technology does not allow for their realization due to the insufficient performance of the present biomaterials. Clearly, there is a critical need for a new class of biomaterials that are hemocompatible and that could also allow the fabrication of MEMS-based sensing devices.

Developing a sensor that operates in real-time and in vivo represents a challenge dominated by the hemocompatibility of the materials used and the successful accomplishment of different requirements such as matching blood flow dynamics, duration of blood contact, selection of an appropriate sensor geometry, and sensor surface quality (in terms of surface roughness) and chemistry (i.e., specific adhesion of the target molecule). The formerly mentioned requirements are necessary to avoid device-induced thrombus formation which can be life threatening either because of device failure or because of thrombi embolization [6] [7].

Silicon carbide $(\mathrm{SiC})$ is a hard, chemically robust material, very well suited for harsh environment applications such as implantable devices in the human body [8] [9]. Recent assessment of the single crystal form of this material (by Dr. C. Coletti and Dr. C. Frewin in the $\mathrm{SiC}$ and Drug and Gene Delivery laboratories at USF), suggests that it has very good biocompatibility [9] [10] [11]. Moreover, $\mathrm{SiC}$, in its amorphous form, has been used previously as a coating for medical implantable devices such as bone prosthetics and cardiovascular stents [8] [12]. However, assessment of single crystal $\mathrm{SiC}$ for cardiovascular applications has not been reported and is the focus of this dissertation research. 
Single crystalline $\mathrm{SiC}$ grows in many crystal forms, but only one form of $\mathrm{SiC}$ is both cubic and can be grown on single crystal Si substrates - 3C-SiC. Single crystal 3C-SiC is highly resistant to harsh environments and it is chemically inert. It can be grown heteroepitaxially on silicon substrates and standard silicon processing can be used to micro-machine this material [13]. However, in order to exploit these material properties for a blood-stream implantable device, its biocompatibility with blood and vascular endothelial lining must be assessed.

This research looks for establishing whether or not single crystal $3 \mathrm{C}-\mathrm{SiC}$ is a hemocompatible material suitable for cardiovascular applications, through the explorations of its platelet adhesion and biocompatibility with human microvascular endothelial cells.

Next, an introduction to thrombus formation, biocompatibility testing and the biocompatibility of $3 \mathrm{C}-\mathrm{SiC}$ is presented to further understand the processes behind thrombogenicity and the rationale behind the different aspects that we have chosen to evaluate to determine the degree of hemocompatibility of 3C-SiC.

\subsubsection{Thrombus Formation}

Device hemo-in-compatibility occurs when a blood-contacting man-made device induces thrombus formation [6]. Almost immediately after injury or the introduction of a foreign material into the body clotting factors become activated (see figure 1. Top) and induce the generation of an enzyme called thrombin [14]. Thrombin converts the soluble protein fibrinogen into insoluble fibrin. The formed fibrin provides the scaffold for the entrapment of platelets, blood cells, and plasma proteins (indeed this is critical for patient survival as it is the mechanism behind blood clotting). 
In the case of a blood-contacting device, key blood proteins, such as fibrinogen and von Willebrand's factor, that can trigger the clotting cascade (Figure 1. Top), adsorb onto the surface of the device (Figure 1. Bottom), This is followed by the adhesion of platelets to these proteins on the surface of the implanted probe, through key receptors on the surface of platelets that bind fibrinogen and von Willebrand's factor, as well as platelet activation; such binding to surface-adsorbed proteins plays an important role in the clotting cascade [15] [16] [17].

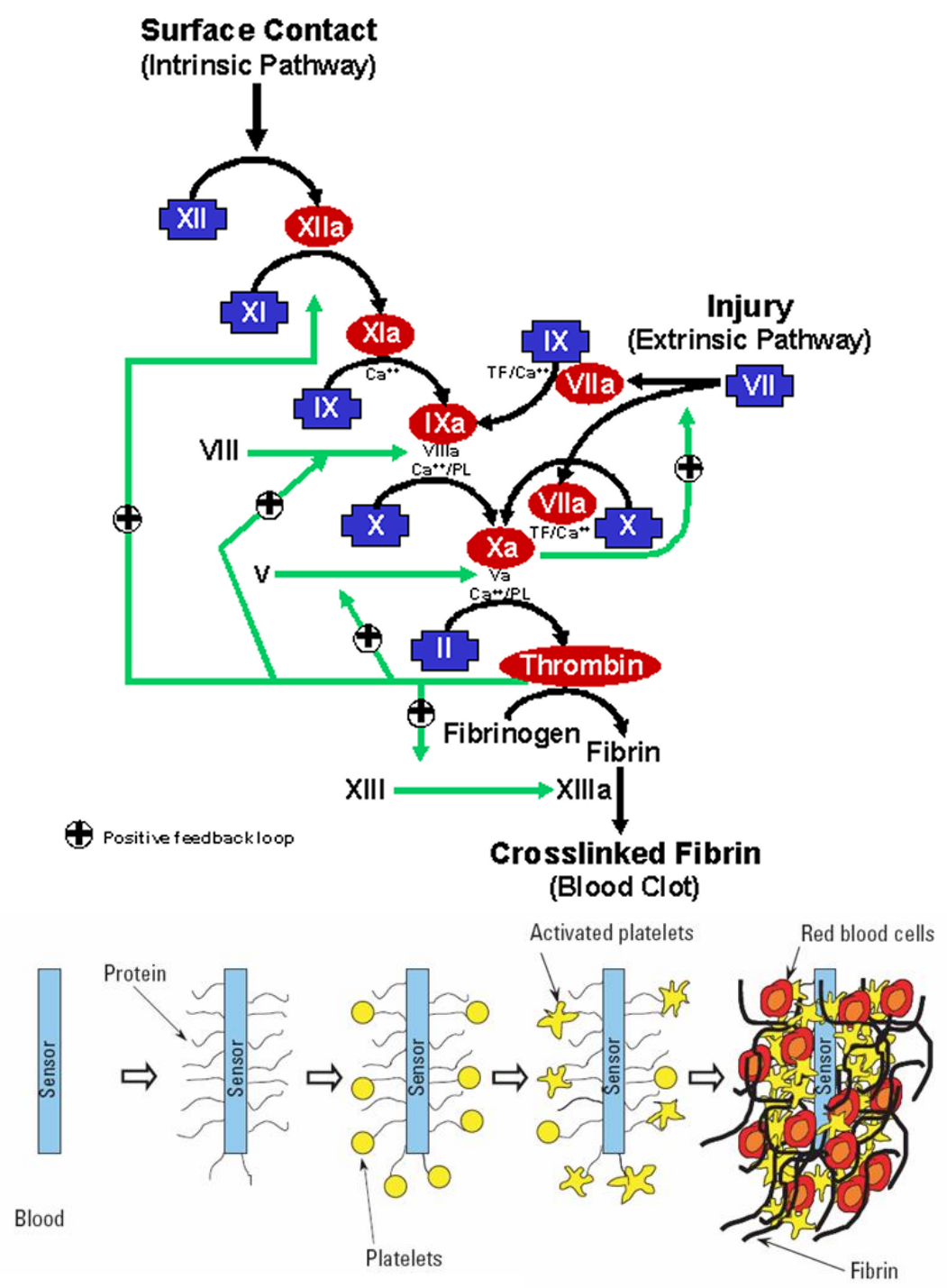

Figure 1.1. (Top) Flow diagram of the clotting cascade showing both, extrinsic and intrinsic pathways [6]. (Bottom) Sequence of events that leads to thrombus formation on the surface of a man-made material placed within the blood stream [16]. 
The platelet's main function is to seal openings in the vascular tree. It is necessary, subsequently, that the initiation signal for platelet deposition and activation is exposure of the underlying vessel wall, that are normally hidden from circulating platelets by a noncompromised endothelial lining [15].

Additional parameters determining platelet response are the depth of the injury, the vascular bed, age of the individual, hematocrit value (blood volume occupied by red cells), the speed of blood flow and the size of the blood vessel [15].

For platelet plug formation to occur, platelets must undergo adhesion, activation and aggregation [18] [19]. Most platelet activators are released or synthesized at the place of the vascular injury. Additionally, biochemical interactions between platelets and erythrocytes (red cells) also enhance platelet activation. Adhesion of platelets to subendothelial structures may lead itself to platelet activation [6] [15].

Once activated, platelets suffer a change in their discoid shape which occurs in response to many different agents, resulting in a transformation to a spiny sphere with long, thin filopodia extending several micrometers out from the membrane surface [15].

When platelets adhere to surfaces, they generally undergo spreading and activation which depends on the protein surface on which they spread to, with collagen inducing the most activation. Platelet spreading results in the development of broad lamellipodia rather than spike-like filopodia (see Figure 2) which is accompanied by granule secretion [15].

Intravascular placement is the most desirable for most chemical measurement. However, platelet role in the vascular tree healing process, as well as the processes that intervene in platelet adhesion, spreading, aggregation and activation, all must be considered when studying the issue of device implantation. In addition there is the role 
played by platelet activators and glycoprotein ligands, platelets changes and surface proteomics. These are complicated bio-physical processes that must be well understood before considering the placement of a man-made sensor or material into the cardiovascular system. The biological response of the body to foreign materials determines the success of implantable biosensors and the degree of their bio/hemocompatibility.

Once the blood clot is formed, the clot itself promotes more clotting; the platelet thrombi appear capable of rapidly recruiting tissue factor (thromboplastin) from the blood which is associated with P-selectin glycoprotein ligand (PSGL-1), a ligand for the Pselecting expressed on the surface of activated platelets. Activated platelets also recruit neutrophils and monocytes expressing PSGL-1 [15].

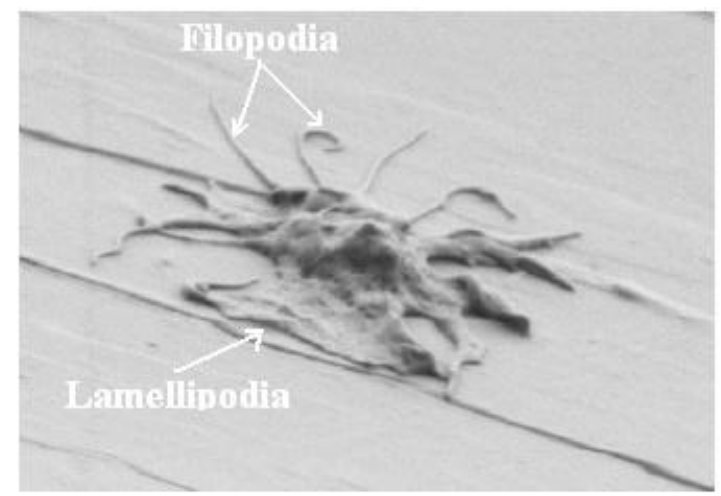

Figure 1.2. Platelet lamellipodia and filopodia after activation on a surface. Adapted from [6]

Activation of the clotting cascade by intravascular sensors presents risks to the patient in that emboli may be shed and clog blood vessels elsewhere in the body [6]. Therefore, careful selection of suitable hemocompatible material is the first step that must be undertaken before developing any sensor for the cardiovascular system. 
From the sensor device data-collection perspective, the presence of activated platelets on the surface of an implanted chemical sensor can create a local chemical environment that differs from that of bulk blood. Even in the absence of complete thrombus formation on the surface of the device, a monolayer of active cells can cause significant measurement errors; hence, the activity of cells adhered to the surface of any implanted sensor can act like an immobilized enzyme catalyst to create a similar local change in key analyte levels [16]. The former implies the need for a material for sensor device fabrication that not only reduces thrombus formation (or eliminates it in the best case scenario); by controlling protein activity on the surface of the device, but also that minimizes platelet adhesion.

The use of an immobilized heparin coating on the surface of the implanted device, which is the current strategy used by most researchers [20], is not a solution either, because such coatings have been shown to not reduce platelet activation and adhesion on foreign materials. Heparin coatings as an anticoagulant does reduce the size of the thrombus formed on the device by locally inhibiting the activities of thrombin and Factor $\mathrm{Xa}$, however it will not significantly diminish the presence of adhered, metabolically active cells [16] and, moreover, it will be consumed over time, so it is clearly not a good option for long-term implantable devices.

Implantable sensors are subject to an acute inflammatory response that involves the release of fluid and plasma proteins followed by recruitment of leukocytes to the implant site. 


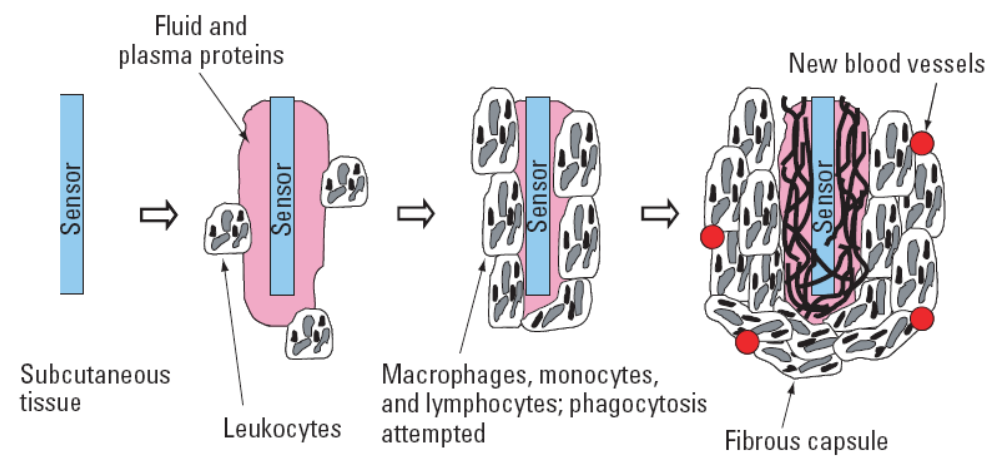

Figure 1.3. Sequence of events that leads to formation of fibrous capsules around sensors [16].

Leukocytes (mainly neutrophils and monocytes) migrate to the implanted device and adhere to the surface in an attempt to begin the process of phagocytosis. Finally, a fibrous capsule composed mainly of macrophages and collagen forms around the implanted device. The capsule can alter local analyte levels via metabolic reactions [16].

Different approaches can be used to determine and modify the degree of thrombogenicity of MEMS materials, including biomolecular surface interactions. For vascular implants, human microvascular endothelial cells and platelets must be used to assess the hemocompatibility of any foreign material inserted into the vascular system.

Endothelial cells relate directly to platelet interactions and bio/hemocompatibility of materials; the inner lining of the endothelium constitutes the blood's natural compatible surface and does not promote platelet attachment. The interactions of both endothelial cells and platelets with a desirable material for device implantation must be studied to get a full insight on the material's biocompatibility, as well as the blood protein interactions with these foreign surfaces [21]. 


\subsection{SiC Properties}

$\mathrm{SiC}$ is a wide-bandgap (great sensing potential), optically transparent semiconducting material that exhibits great electrical properties in harsh environments, such as high temperature elasticity and chemical inertness [22].

Table I displays some of the various properties of silicon carbide. Its electrical, mechanical and chemical properties (i.e., resistance to corrosion and wear, etc.) make it an ideal candidate for sensing applications, such as MEMS devices.

Table 1.1. Electrical, thermal and physical properties of $\mathrm{SiC}$ and $\mathrm{Si}$ [18]

\begin{tabular}{|l|l|l|l|l|}
\hline & $3 \mathrm{C}-\mathrm{SiC}$ & $4 \mathrm{H}-\mathrm{SiC}$ & $6 \mathrm{H}-\mathrm{SiC}$ & $\mathrm{Si}$ \\
\hline Bandgap (eV) & 2.36 & 3.23 & 3.0 & 1.12 \\
\hline Breakdown field $\left(\mathrm{MV} \mathrm{cm}^{-1}\right)$ & 1 & $3-5$ & $3-5$ & 0.25 \\
\hline $\begin{array}{l}\text { Electron Mobility }\left(\mathrm{cm}^{2} \mathrm{~V}^{-1} \mathrm{~s}^{-1}\right) \\
\text { at 300K }\end{array}$ & $<800$ & $<900$ & $<400$ & 1500 \\
\hline $\begin{array}{l}\text { Hole Mobility } \\
\left(\mathrm{cm}^{2} \mathrm{~V}^{-1} \mathrm{~s}^{-1}\right) \\
\text { at 300K }\end{array}$ & $<320$ & $<120$ & $<90$ & 450 \\
\hline $\begin{array}{l}\text { Thermal conductivity } \\
(\mathrm{W} / \mathrm{cm}-\mathrm{K})\end{array}$ & 5 & 4.9 & 4.9 & 1.5 \\
\hline $\begin{array}{l}\text { Thermal expansion @ 300 K } \\
\text { @ } 1500-1600 \mathrm{~K}\left(10^{-6} \mathrm{~K}-1\right)\end{array}$ & 3.8 & NA & $\begin{array}{l}4.3 \perp c \\
\text { axis } \\
4.7 \\
\text { axis }\end{array}$ & 2.6 \\
\hline Young's Modulus $(\mathrm{GPa})$ & 5.5 & 300 to 700 & & $4.56-4.6$ \\
\hline
\end{tabular}

$\mathrm{SiC}$ forms in three main crystal orientations; cubic (3C-SiC), hexagonal (4H-SiC and $6 \mathrm{H}-\mathrm{SiC})$, and rhombohedral (15R-SiC) where $4 \mathrm{H}-, 6 \mathrm{H}-$, and $3 \mathrm{C}-\mathrm{SiC}$ are the main polytypes of practical and commercial interest [22]. As SiC is not a chemical compound normally found in nature it must be artificially generated. One of the methods used for the creation of single crystal, high quality $\mathrm{SiC}$ material is provided through the use of a 
chemical vapor deposition (CVD) on a bulk crystal which is performed at high temperatures [23].

$3 \mathrm{C}-\mathrm{SiC}$ is the only single crystal form of $\mathrm{SiC}$ that can be grown heteroepitaxially using $\mathrm{Si}$ as a substrate, due to the similarities in the crystal lattice structures (i.e., crystal lattice). In addition 3C-SiC is already a well established semiconductor and MEMS material [22] [24]. 3C-SiC also has the benefit of being compatible with most $\mathrm{Si}$ micromachining techniques, such as reactive ion etching (RIE) and ion implantation [24] [25].

To date, few crystalline semiconductor materials have been assessed for their biocompatibility. $\mathrm{Si}$, the leading material in the MEMS field, has been shown to be cytotoxic, due to the formation of silica and silicates in aqueous solutions [3] [26] [27] [28] [29]. Other materials, which do not undergo hemo-in-compatibility problems, but that are not suitable for sensing applications, have been used as coatings for short-term contact applications.

Materials such as polymers are consumed over time when implanted in the body, so they do not offer an alternative for long-term implantable applications even though they are the most developed material for this application. One advantage of such materials is their very low cost, which is important for short-time, high-volume (device quantity) implantable applications.

There is evidently a need for a crystalline material with suitable characteristics for sensing applications in harsh environments, such as in bodily fluids, which also provides a bio/hemocompatible surface. 
$\mathrm{SiC}$, in its amorphous form, has been used successfully as a coating for prosthetic devices, it is one of the most used materials for cardiovascular applications, and has been shown to be highly effective in vivo clinical trials as a coating for heart stents [8] [12] [21] [26] [30] [31] [32] [33]. The literature also reveals that collagen deposition on SiC whiskers is non progressive and that it generates an inflammatory response that decreases gradually after implantation [32]

All of the above suggest attractive bio/hemocompatibility properties of this material in its amorphous form and one could suspect that $3 \mathrm{C}-\mathrm{SiC}$, in its single crystal form, should evidence the same properties; however, before the research conducted by Dr. C. Coletti of the SiC group at the University of South Florida, no previous research on the biocompatibility of single crystal 3C-SiC had been reported in the literature [9] [10] [34].

\subsubsection{SiC a Promising Material for Biosensing Applications in the Blood Stream}

$\mathrm{SiC}$ is a polymorphic material, having approximately 170 different crystal organizations, but sharing a common stoichiometry (i.e., all forms contain bi-layers of $\mathrm{Si}$ and C) [22]. Two of the hexagonal polytypes, $4 \mathrm{H}-\mathrm{SiC}$ and $6 \mathrm{H}-\mathrm{SiC}$, have been fashioned in the past into electrode myocardial sensors and have shown low biofouling, nontoxicity and in general good biocompatibility [35] [36]. Amorphous and polycrystalline forms of silicon carbide, a-SiC and poly-SiC, have been used as coatings for many implantable biomedical devices, and clinical studies for bone prosthetics and heart stents have confirmed its biocompatibility.

Dr. C. Coletti researched the in vitro biocompatibility of three lines of cells, namely B16-F10 mouse melanoma cells (ATCC CRL6475), BJ human fibroblasts (ATCC CRL2522) and human keratinocytes (HaCaT) by plating and culturing them in the 
appropriate media onto the surfaces of the main polytypes of $\mathrm{SiC}$ : $3 \mathrm{C}-\mathrm{SiC}, 4 \mathrm{H}-\mathrm{SiC}$, and $6 \mathrm{H}-\mathrm{SiC}$, and assessing cell morphology, attachment to the substrate surface, successful cellular binding and proliferation [9].

In her research, Coletti used Si and standard culture plates, as negative and positive controls respectively, which served as benchmarks for biocompatibility comparisons [9]. These three different cells lines were selected for their different adhesion properties, i.e., B16 melanoma cells are very aggressive, proliferate at a fast rate and adhere indifferently on substrates with different degrees of biocompatibility, conversely, BJ fibroblasts are much more selective as to a preferred substrate for adherence and should provide more information regarding a substrate's degree of biocompatibility [9].
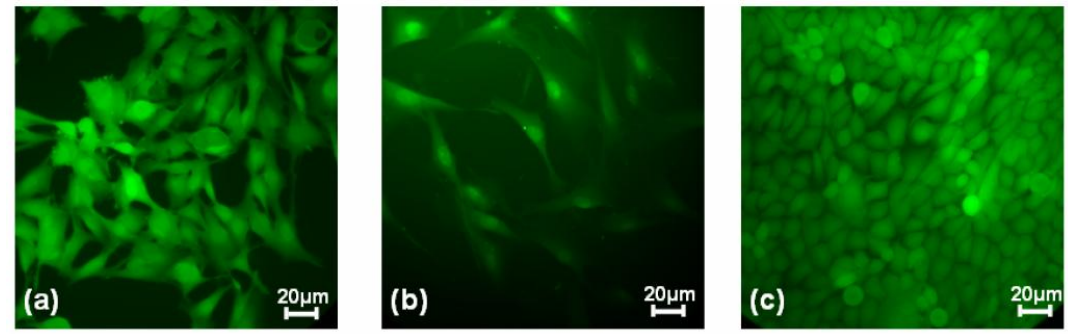

Figure 1.4. Fluorescent micrographs of (a) B16 melanoma cells (b) BJ fibroblast cells and (c) HaCaT keratinocyte cells on $\mathrm{SiC}$ substrates 72 hours after seeding [9].
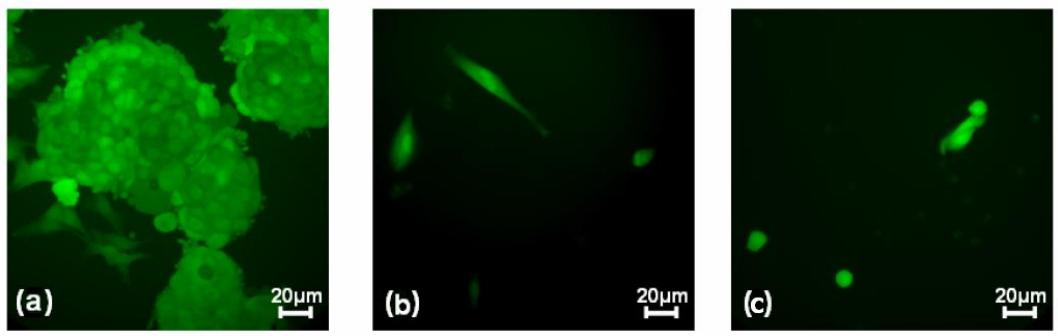

Figure 1.5. Fluorescent micrographs of (a) B16 melanoma cells (b) BJ fibroblast cells and (c) HaCaT keratinocyte cells on Si substrates 72 hours after seeding [9]. 


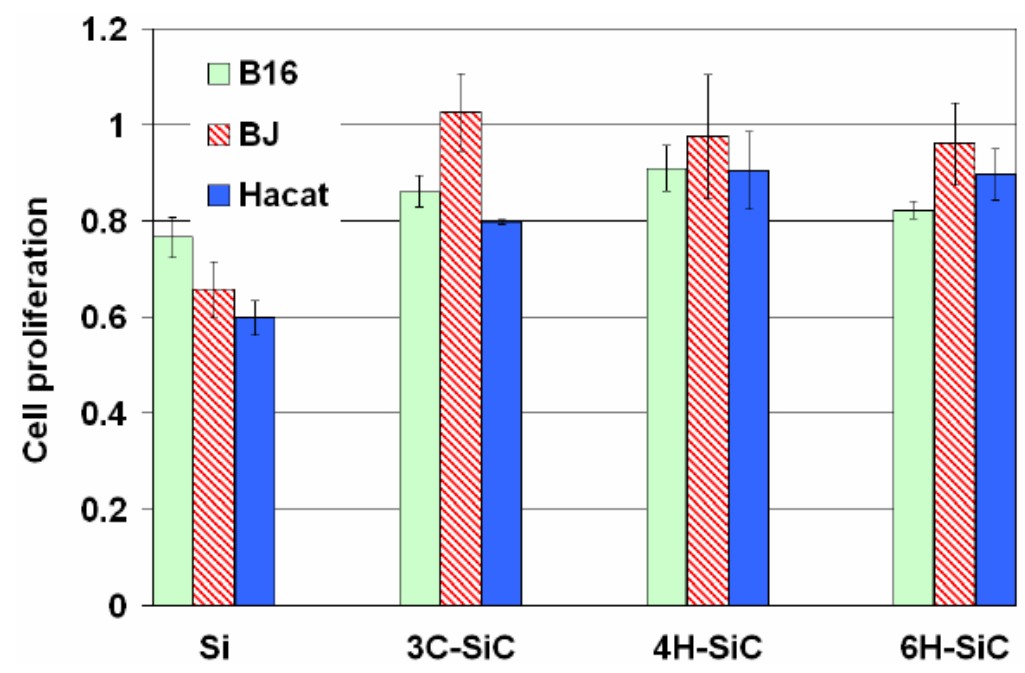

Figure 1.6. Histogram of cell proliferation of $\mathrm{B} 16, \mathrm{BJ}$ and $\mathrm{HaCaT}$ cells, normalized to the control sample, expressed as $x \pm \sigma$ measured via MTT assays at the third day. Note that cell proliferation is greater on $\mathrm{SiC}$ than on $\mathrm{Si}[9]$.

In Coletti's study, the viability and proliferation of the cultured cells was assessed using separate MTT [3-(4,5-Dimethylthiazol-2-Yl)-2,5-Diphenyltetrazolium Bromide] assays for the three different cell lines. The adherent cell morphology was studied using fluorescence microscopy. SiC samples, $\mathrm{Si}$ samples, and cell-culture wells were plated and the cell morphology was inspected after 4, 24, 48, 72 hours for the B16 cells and 4, 24, 48, 72, 96 and 120 for the $\mathrm{BJ}$ and $\mathrm{HaCaT}$ cells. The cells were fluorescently labeled with CMFDA (5- chloromethylfluorescein diacetate) cell tracker dye (Molecular Probes, Eugene, OR) [9].

Optical inspection revealed that both the B16 and BJ cells were well distributed on the $\mathrm{SiC}$ surfaces after 4 hours of incubation, elongated and flattened against the surface after 24 hours, and became confluent after 3 days (B16) and 5 days (BJ and $\mathrm{HaCaT}$ ) independently of polytype used, and chemical composition [9]. Images of B16, BJ and HaCaT cells cultured on $\mathrm{SiC}$ (72 hours after seeding), where the adherent cells appear to 
be flattened and stellate-shaped, maximizing the contact area with the substrate and similar to that observed in culture wells, are shown in Figure 4 ( $a, b$ and c). The lack of $\mathrm{SiC}$ cytotoxicity was confirmed by the fact that the cells could be cultured to confluence on all the $\mathrm{SiC}$ substrates used [9].

The morphology and density of B16, BJ and $\mathrm{HaCaT}$ cells cultured on Si substrates under identical conditions revealed that B16 cells tended to form in clumps, while the adherent cell quantity, in the case of BJ fibroblasts and HaCaT keratinocytes, was drastically reduced (see Figure 5). In addition, the reduced contact area of the adherent cells (low adhesion force) suggests some degree of cytotoxicity for the Si substrates [9].

Figure 6 shows a histogram of the calculated cell viability from MTT assays, performed on the third day for the three different cell lines, which confirmed the optical inspection results. The histogram clearly shows that $\mathrm{SiC}$ is a high-quality surface for cell culture with significantly better performance than $\mathrm{Si}$. No statistically significant differences in cell proliferation were found among the different $\mathrm{SiC}$ polytypes [9].

An extremely satisfying proliferation was observed for BJ cells on SiC [9]. From the histogram it is also clear that the B16 cell proliferation is lower than the BJ cell proliferation on $\mathrm{SiC}$ substrates but always higher than on $\mathrm{Si}$.

As in this study the variation of roughness of the different substrates was very small compared to the cell dimensions. Therefore future work regarding surface roughness effects on the biocompatibility must be performed, with roughness values exceeding the cell diameter. Surface roughness also plays a role in hemocompatibility, as high surface roughness can lead to blood cells lysis and induce clotting. 
After the results of Dr. Coletti the biocompatibility of 3C-SiC seemed promising. Subsequently, Dr. Frewin, also in the USF SiC group, engaged in the research of the neuron-SiC interface and the development of Brain Machine Interface (BMI) devices. In his research Dr. Frewin proposed cubic silicon carbide (3C-SiC) as a solution to the biocompatibility problems of current implantable BMI devices. Dr. Frewin's study [11] showed that both materials possess good biocompatibility with neural cell lines (human neuroglioma and PC12 rat pheochromocytoma cell lines) that, in the worst case, is comparable to cell treated polystyrene and, in most cases, even surpasses polystyrene. Additionally, in this research the action potential of differentiated PC12 cells was activated using 3C-SiC within an electrode device.

H4 human neuroglioma and PC12 rat pheochromocytoma cell lines were used for the study, and polystyrene (PSt) and amorphous glass were used as controls or for morphological comparison. MTT assays were performed to determine general cell viability with each substrate and atomic force microscopy (AFM) was used to quantify the general cell morphology on the substrate surface along with the substrate permissiveness to lamellipodia extension. $3 \mathrm{C}-\mathrm{SiC}$ was the only substrate tested to have good viability and superior lamellipodia permissiveness with both cell lines, while nanocrystalline diamond (NCD) showed a good level of viability with the neural H4 line but a poor viability with the PC12 line and lower permissiveness than $3 \mathrm{C}-\mathrm{SiC}$. 


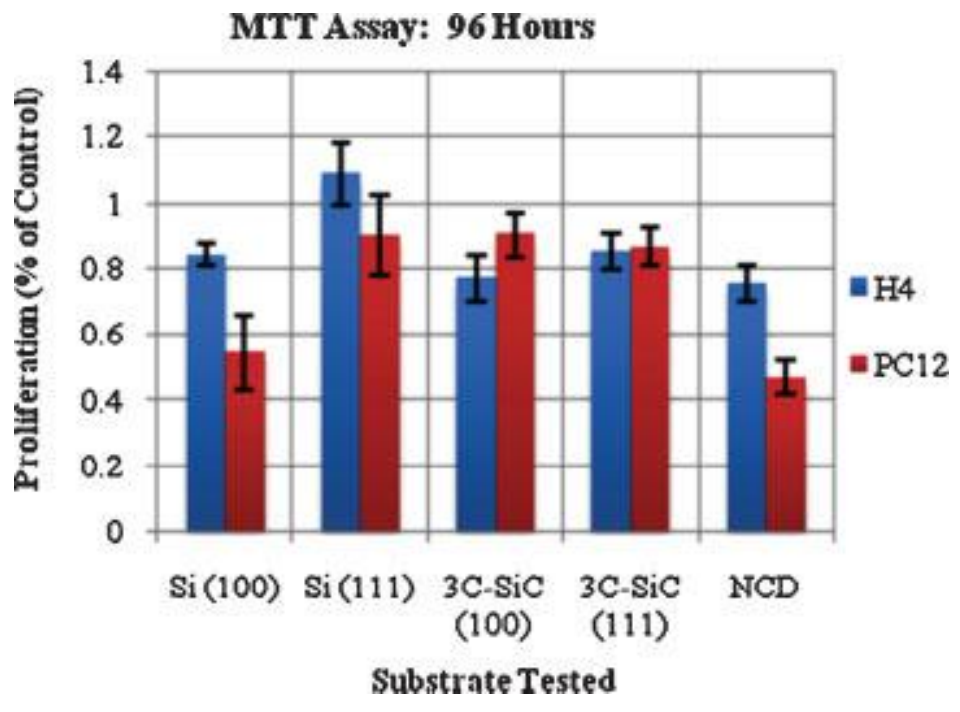

Figure 1.7. Histogram representing results of neuronal $\mathrm{H} 4$ and PC12 cell proliferation tests. The graph is expressed as the s.d.m., with error bars indicating the s.e.m., from the three MTT assays. From [11]

The MTT analysis results for both the H4 and PC12 cell lines are displayed in Figure 1.7. The $\mathrm{H} 4$ cell line shows a viability level of approximately $80 \% \pm 5 \%$ as compared to the PSt control for all samples excluding Si (111) which performed at $108 \% \pm 9 \%$. Si (100), 3C-SiC surfaces and NCD sample means were found to be statistically similar, as well as $\mathrm{Si}(111)$ and PSt. Statistically significant similarities were found between 3C-SiC samples and $\mathrm{Si}$ (111) when testing for PC12 proliferation, showing proliferation values of approximately $90 \%$ of the PSt control, while the NCD and Si (100) samples were found to be statistically similar with proliferations of 46 and $55 \%$, respectively.

The morphology and lamellipodia attachment quality were evaluated with AFM analysis. Figure 1.8 displays two selected AFM micrograph scans of the H4 cell line incubated on each of the tested substrates with one scan showing a living cell and the other a fixed cell. The H4 cells on PSt show a low level of attachment to the surface. Figure 1.8(a) indicates that $\mathrm{H} 4$ cells on PSt have microtubule extensions and the average 
lamellipodia extension over the whole cell group is $28.9 \%$ of the cell area while alive. Unfortunately, as seen in Figure 1.8(b), the lamellipodia coverage is reduced by $13.5 \%$ after cell fixation for. The $\mathrm{H} 4$ cells on glass, as seen in Figure 1.8(c) for the living cell and Figure 1.8(d) for the fixed cell, react similarly to the cells on PSt.

Although there are large expanses of lamellipodia present with many of the cells on the glass substrate, they show very little attachment to the surface, constituting an average of $45.5 \%$ of the cell in the living cell scans, and only $8.43 \%$ of the cell after fixation (a 27\% reduction). The $\mathrm{H} 4$ cells on the surface of Si (Figure 1.8(e) and 1.8(f)), on 3C-SiC (Figure 1.8(g) and 1.8(h)), and on NCD (Figure 1.8(i) and 1.8(j)) possess similar levels of cell attachment to the surface, but they show some differences in the lamellipodia attachment. The $\mathrm{H} 4$ cells flatten and expand over a larger surface area on these substrates. The $\mathrm{H} 4$ cells on Si show the lamellipodia extending from many parts of the cell accounting for an average of $36.4 \%$ of the cell area when measured alive and 26.4\% after fixation. NCD shows a slightly better lamellipodia extension and attachment level with $30.5 \%$ of the cell area before fixation and $22.4 \%$ cell area after fixation. 


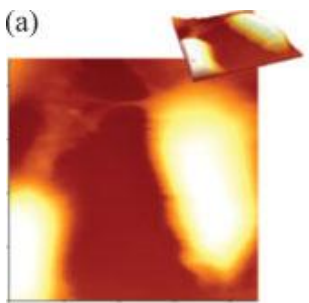

(c)

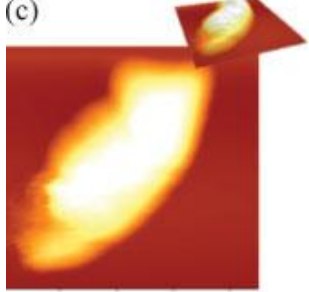

(e)

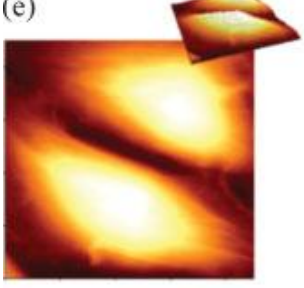

(g)

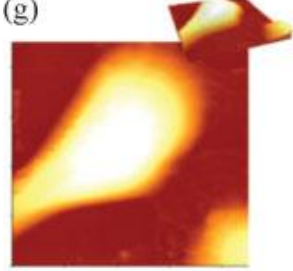

(i)

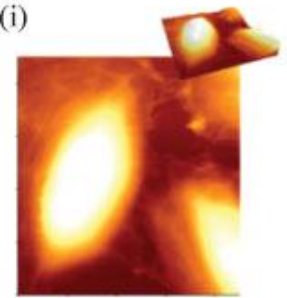

(b)

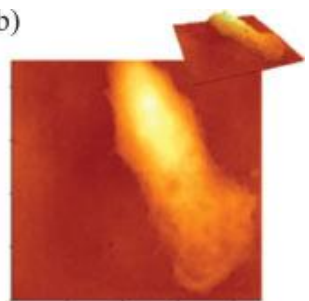

(d)

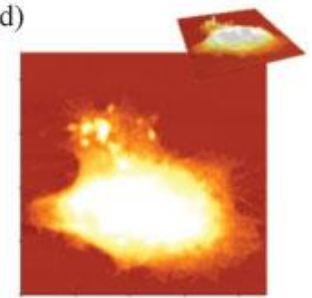

(f)

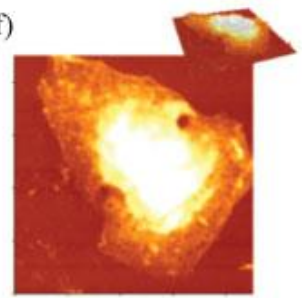

(h)

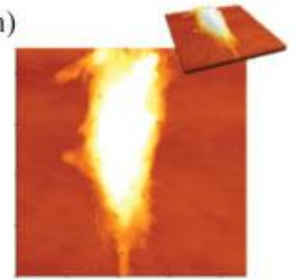

(i)

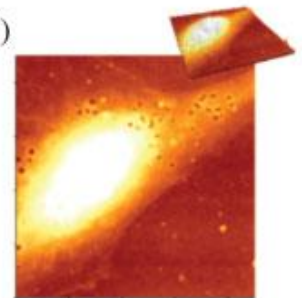

Figure 1.8. 45x45 um AFM micrographs of $\mathrm{H} 4$ cells deposited on different substrates. Each micrograph possesses a pseudo three-dimensional insert in the upper right hand corner to give some perspective on cell morphology. (a), (c), (e), (g), and (i) are H4 living cells measured in PBS deposited on polystyrene, glass, Si, 3C-SiC, and NCD. (b), (d), (f), (h), and (j) are $\mathrm{H} 4$ cells that have been fixed with $2 \%$ formaldehyde on polystyrene, glass, $\mathrm{Si}, 3 \mathrm{C}-\mathrm{SiC}$, and NCD. From [11]

3C-SiC has the smallest measured surface area for the lamellipodia, which measured $15.1 \%$ of the living cellular area, but was the only sample group that increased in area percentage and was $15.4 \%$ after the cell was fixed. $3 \mathrm{C}-\mathrm{SiC}$ cells also show multiple large 
projections of microtubule extensions on almost all of the cells measured. The lamellipodia reduction level for $\mathrm{Si}$ and $\mathrm{NCD}$ was 10 and $8.1 \%$, respectively, while 3C$\mathrm{SiC}$ shows a mean increase of $0.3 \%$.

The PC12 cells have much different attachment characteristics than the H4 cells and this is most likely due to the fact that they were not changed into peripheral neurons through the addition of neural growth factor (NGF). Glass, $\mathrm{Si}$, and NCD all show lower attachment characteristics for this cell line. Analysis of the cell height to area ratios and attachment angles for glass, $\mathrm{Si}$, and $\mathrm{NCD}$, indicated that the cells are trying to minimize their contact with these substrates which was confirmed as each of these substrates show poor lamellipodia attachment. Although Si shows good extensions of microtubules, it has a lamellipodia reduction of $10.2 \%$ area as indicated for the 25.0 and $14.8 \%$ live cell and fixed cell lamellipodia measurements.

The PC12 cells on $3 \mathrm{C}-\mathrm{SiC}$ have a slightly lower height to surface area ratio and a lower angle of attachment when compared to the previous three samples. The lamellipodia shows a much better attachment factor composing $29.3 \%$ of the cell area for the living cell and $24.8 \%$ of the cell area for the fixed cells which amounts to only a reduction of $4.5 \%$. Cells on $3 \mathrm{C}$-SiC also possess multiple large microtubule extensions. The PC12 cells showed a good permissiveness with PSt, this material allows the cell to project multiple microtubule extensions and had a $3.3 \%$ increase in lamellipodia attachment area due to the living cell area lamellipodia percentages were 25.9 and $29.2 \%$ for the living and fixed cells, respectively. 
Frewin's research also showed that after cell seeding and proliferation on the substrates, the Si surface suffered physical damage that was visible through AFM analysis of the samples, this was not the case for $3 \mathrm{C}-\mathrm{SiC}$.

\subsection{Summary and Dissertation Organization}

The demonstrated biocompatibility of 3C-SiC, together with its other properties, such as mechanical and chemical resilience, the capability to built sensing devices or patterned grafts using traditional microfabrication techniques, make this material an ideal candidate for cardiovascular applications.

However, such applications cannot be realized until it is known for certain if this material stimulates thrombogenic behavior that would induce thrombus formation. This research looks to assess the hemocompatibility of this material, so that its use in cardiovascular applications can be pursued.

The subsequent chapters explore the nature of blood, its formed elements (§3.1) and the formation of clots and how it relates to interactions with foreign surfaces $(\S 2.1)$; additionally we introduce the different techniques and rationales behind hemocompatibility testing ( $\$ 2.2$ and $\S 2.3)$, and finally the results of this research by exploring three different perspectives: platelet adhesion (\$3) protein adsorption (\$4) and interactions with microvascular endothelial cells (§5). 


\section{Chapter. 2: $\quad$ Biocompatibility of Materials}

A material, synthetic or natural, that is used in contact with a biological system and that is able to co-exist without causing an unacceptable degree of harm to the system is called a biomaterial [16].

Early biomaterials included silicone, polyurethanes, rubber, Teflon, nylon, titanium, and stainless steel. These early materials were used to develop various types of prosthetic devices such as biodegradable scaffolds, cochlear implants, breast implants, shoulder, hip and knee prostheses, dental and intraocular implants, etc. Biomaterials have improved the quality of life of many patients around the world and have provided alternatives to the limitations of tissue rejection or limited organ donors (for the cases in which it applies).

The development of biomaterials has been full of success but also of challenges related to material rejection or incompatibility. Most mammalian cells require attachment to an external surface or they will experience apoptosis. The interaction of the cells and the material at the interface must induce cell attachment and proliferation without inducing negative morphological changes or intoxicating the cell.

Although the interaction between cells and substrates is complex and it is regulated by the interactions of the material with the extracellular matrix, cell membrane, cell cytoskeleton etc., it is widely accepted that a cell in contact with a biocompatible material will attach to and spread out on the surface and then proliferate, thus making cell morphology and viability good measurements of biocompatibility [11] [37] [38]. Cells on a non-permissive surface will interact with the substrate by decreasing their attachment 
area due to flow back of actin filaments from the cytoskeleton into the central core of the cell [37] [39].

Unfortunately, the above concepts of viability and morphology as a measurement of biocompatibility cannot be extended to the interaction of materials and blood. If a blood contacting material allows blood organelles to attach and spread on its surface, this would alter the normal blood flow, create turbulence and ultimately induce thrombus formation. Thrombus formation has life threatening consequences for the patient due to thrombus embolization and must be avoided at all cost.

Therefore a new set of concepts to describe the biocompatibility of a substrate with blood must be utilized. The following sections of this chapter describe these concepts and the different perspectives on hemocompatibility evaluation.

\subsection{Biocompatibility of Materials with Blood: Hemocompatibility}

Hemocompatibility concerns to the properties of materials suitable for blood contacting applications. Blood contacting devices range from needles to vascular grafts, cardiopulmonary bypass and heart valves among others. Highly invasive devices usually extend the life of patients and perform reasonably well for periods of time before clinical complications can be observed. These devices also require post-implant clinical treatments, like the use of blood anticoagulants. Today's blood compatibility philosophy is to guarantee the safety of the implant and to minimize post-implant procedures which finally represent long term benefit for the patient. [1] [40] [41].

The most common device/material failures due to a lack of hemocompatibility are related to thromboembolic complications. Other complications of prosthetic devices in contact with the blood stream include erosion of the material, mechanical failure and 
nonstructural dysfunction, hemolysis and infection. However, for the purpose of studying hemocompatibility, it is important to focus on reactions that are specific to the placement of a material in contact with blood and not to those that may be the result the activation of the multiple defense mechanisms that the body has available in response to the presence of foreign devices [42] [43] [44]. These specific reactions are called thrombotic and thromboembolic complications. To study hemocompatibility is related to the study of the thrombogenic behavior of a material; a material with low thrombogenicity will be therefore more hemocompatible and will also reduce the risk of bleeding associated with the use of blood thinners [45] [46] [40].

To date a man-made material that is purely hemocompatible has not been reported, and the mechanisms behind surface-blood interactions have not been completely understood. Indeed, it may be this later point that has made the development of a truly hemocompatible material so difficult.

Smooth polymeric surfaces have been used as a coating for materials used in blood pumps and they have shown that roughness seems to play an important role in hemocompatibility. Since the introduction of these polymeric coatings, based on the use of anticoagulants like heparin or thrombin inhibitors [47] [48], two approaches have been used to address the subject of surface-blood interactions. First, the creation of a pseudointima formed from the blood lining and, second, the reduction of blood formed elements and protein interactions with the surface. A material that has a high compatibility with endothelial cells and that possesses low thrombogenicity, ultimately expressed in fewer platelet adsorption, aggregation and activation, would satisfy both 
approaches and would be desirable for the development of long-term cardiovascular devices [7] [46].

The ISO 10993-4 standard introduces the different rationales that must be used when evaluating a material for its hemocompatibility. Next we explore some of the key points of this important document.

\subsection{Standard ISO 10993-4}

The relevant standard for this research, ISO 10993, defines blood/device interaction as any interaction between blood or blood components and a device resulting in effects on the blood or on any organ or tissue, or on the device [49] [50].

When testing a material for its hemocompatibility, several considerations, such as duration of contact, temperature, sterility, flow conditions, sample collection/storage, enzymes, controls, surface to volume ratio and fluid dynamic conditions (flow rates), among others, have to be taken into account. Tests should be performed with minimal delay, usually within 4 hours of blood withdrawal, since some properties of the blood change rapidly after collection [51] [50].

Additionally, in the case of a specific geometry, the ratio of the test parameter to the exposed surface area must be evaluated (Concentration per unit volume/ $\mathrm{cm}^{2}$ ) [51] [50] [52].

The use of animal models for screening purposes is encouraged, but the interpretation of the results must be done carefully, considering that results may be different in human models, given the differences in blood reactivity between species, as well as the fact that differences between in vitro and in vivo models will most probably exist. For example in vitro hemocompatibility does not guarantee in vivo hemocompatibility [49] [51] [53]. 
ISO 10993-4 provides a test-selection system that is based on clinical concerns. The types of tests required by this standard depend on the blood contact category of the device or material (external communicating devices-blood path indirect, external communicating devices - circulating blood, and implant devices) [52]. For each contact category tests are recommended from the following list of general test categories: thrombosis, coagulation, platelets/platelet function, hematology, and immunology, as shown in Table 2.1 for in vitro testing [52].

Table 2.1. A sample of primary in vitro tests, Adapted from [51]. Copyright remains with ISO

\begin{tabular}{|c|c|c|}
\hline Test Category & Method & Comments \\
\hline Thrombosis & $\begin{array}{l}\text { Adhered platelets, } \\
\text { Platelet count, } \\
\text { leukocytes, aggregates, } \\
\text { erythrocytes, fibrin, etc. }\end{array}$ & $\begin{array}{l}\text { Light Microscopy or } \\
\text { Scanning Electron } \\
\text { Microscopy }\end{array}$ \\
\hline Coagulation & $\begin{array}{l}\text { Partial thromboplastin } \\
\text { time }\end{array}$ & \\
\hline Hematology & $\begin{array}{l}\text { Leukocyte count; } \\
\text { hemolysis (plasma } \\
\text { hemoglobin) }\end{array}$ & $\begin{array}{l}\text { Hemolysis is } \\
\text { performed to measure } \\
\text { the red blood cell } \\
\text { membrane fragility in } \\
\text { contact with materials } \\
\text { and devices. }\end{array}$ \\
\hline Hematology & $\begin{array}{l}\text { Leukocyte count and } \\
\text { differential; hemolysis } \\
\text { (plasma hemoglobin) }\end{array}$ & $\begin{array}{l}\text { Hemolysis screening } \\
\text { test is performed } \\
\text { because of its } \\
\text { measurement of red } \\
\text { blood cell membrane } \\
\text { fragility in contact } \\
\text { with materials and } \\
\text { devices. The method } \\
\text { used should be one of } \\
\text { the normative } \\
\text { standard test methods } \\
\text { for hemolysis. }\end{array}$ \\
\hline Immunology & $\begin{array}{l}\text { C3a, C5a, TCC, Bb, } \\
\text { iC3b, C4d, SC5b-9 }\end{array}$ & $\begin{array}{l}\text { A panel including the } \\
\text { last four tests } \\
\text { encompasses the } \\
\text { various complement } \\
\text { activation pathways. }\end{array}$ \\
\hline
\end{tabular}


In order to maximize the hemocompatibility information about a device, one or more tests from Table 2.1 should be performed. Unfortunately, in the absence of standardized and validated test methods, the requirement for testing across all categories is frequently ignored [52].

Complement activation is the most important immunology test for circulating-blood contact devices/materials; this test reveals the activation of the complement cascade [41].

ASTM F 756, a standardized ASTM hemolysis test method, is used to determine the hemolytic potential of a device or material; an increase in plasma hemoglobin correlates with lysis of red blood cells, thereby indicating hemolytic activity of the material exposed to the cells. A device's effect on blood coagulation may be measured in vitro by determining the rate of clot formation or the partial thromboplastin time (PTT) test of plasma exposed to the biomaterial or device during an incubation period. The reaction of white blood cells to materials can also be used as an effective hematology test [52].

However, the first step in determining the degree of hemocompatibility of a material is to evaluate thrombogenicity and compatibility with the cells of the blood vessels lining, as low thrombogenicity and low compatibility with the vessel cells would not justify testing for hemolysis, complement activation and immunologic responses or would require in-vivo or ex-vivo testing.

\subsection{Perspectives in Hemocompatibility Assessment}

Previous research regarding the bio and hemocompatibility of materials have shown interest in amorphous $\mathrm{SiC}$, porous $\mathrm{SiC}$, crystalline silicon, polysilicon, Diamond-like carbon (DLC), polymers, heparin coatings, titanium, chromium and different oxides [8] [12] [35] [46] [54] [55] [26] [56]. 
As both $\mathrm{Si}$ and $\mathrm{SiC}$ have shown good biocompatibility for tissue proliferation they have drawn interest for hemocompatibility research, however, most of all the documented research regarding hemocompatibility of $\mathrm{SiC}$ is limited to amorphous $\mathrm{SiC}, 4 \mathrm{H}-\mathrm{SiC}, 6 \mathrm{H}-$ $\mathrm{SiC}$ and porous $\mathrm{SiC}(4 \mathrm{H}-\mathrm{SiC}$ and $6 \mathrm{H}-\mathrm{SiC})$ [57]. Also, in many of these studies $\mathrm{SiC}$ is not compared directly to $\mathrm{Si}$ which is still the leading material for biomedical sensors.

To the best of our knowledge, this is the first research that directly compares single crystal 3C-SiC with $\mathrm{Si}$ (100), and explores if the low thrombogenic behavior of amorphous $\mathrm{SiC}$ extends to its single crystal (i.e., 3C-SiC) polytype.

Hemocompatibility of amorphous hydrogenated $\mathrm{SiC}(\mathrm{a}-\mathrm{SiC}: \mathrm{H})$ has been tested mostly as a coating made by Plasma Enhanced Chemical Vapor Deposition (PECVD) [8] [55], these coatings have shown less protein adhesion and aggregation when exposed to whole blood than Si and silicon-rich surfaces which tend to absorb more albumin [58]. Chances of protein biofouling directly associated with the capacity of a material to adsorb proteins, and protein adsorption seems to decrease with increased concentrations of carbon.

In [58] it was shown than silicon and silicon nitride had higher platelet adhesion than silicon dioxide, paralene or SU-8 polymers, unfortunately they did not include $\mathrm{SiC}$ in their study. Polyethylene glycol has been grafted to silicon in the past to decrease the protein binding and platelet adhesion of silicon surfaces [28] [59] [60]. It has been shown that amorphous $\mathrm{SiC}$ coatings have low levels of fibrinogen and fibrin (proteins that promote clot formation) adsorption when contacting blood, thus making $\mathrm{SiC}$ coatings, resistant to platelet adhesion [61] [21]. Consistent results have been found when comparing amorphous $\mathrm{SiC}$ coatings to Ti. It is not known if the clot resistance of PECVD 
deposited a-SiC coatings will translate to single crystal $3 \mathrm{C}-\mathrm{SiC}$ films grown on $\mathrm{Si}$ substrates.

In [54] a direct comparison of silicon wafers and a-SiC-coated (PECVD) silicon wafers was performed, In this study both materials seemed to be outperformed by diamond-like coated silicon wafers which presented less clot formation.

Additionally, a microvascular approach has been introduced in many hemocompatibility studies, as this is the level where the cellular interactions responsible for hemocompatibility take place. This microvascular approach is related to the assessment of microvascular endothelial cell proliferation on the surfaces of interest [21] [62] [63] [64]. DLC and Si doped DLC films and coatings have been shown to have good compatibility with human microvascular endothelial cells (HMVEC), and decreased platelet adhesion. It was also shown than graphitization of these films reduces HMVEC attachment and increases platelet adhesion [21].

The evaluation of endothelial cell proliferation has been used as a standard to evaluate the hemocompatibility of vascular grafts, and it has been used to evaluate $\mathrm{Si}$ and plasma modified polyethylenerephthalate (PET) substrates,

The study of the opposing but complementary nature of the behavior of platelets and endothelial cells for a particular biomaterial can therefore provide valuable insight about its hemocompatibility [21].

From all the above, it can be concluded that the perspectives in the evaluation of the hemocompatibility of a material can be classified, at least for initial exploration, into three types: 1) the evaluation of platelet adhesion and aggregation to the substrates of interest, 2) the evaluation of the adsorption of the protein related to platelet adhesion to 
the surfaces and 3) the study of microvascular endothelial cell proliferation on these surfaces.

\subsubsection{The Platelet Adhesion and Activation Assessment Perspective}

The deadly complications associated with the formation of a fibrin-platelet thrombus (i.e. arterial or pulmonary embolization) when inserting a blood contacting device into the blood stream, or the risk of device malfunction, make assessment of the behavior of platelets in contact with a material a topic that is gaining increased interest.

Platelet adhesion, lamellipodia and filopodia formation, aggregation, and spreading precede the formation of a thrombus and these markers have therefore been used as a measure of a material's thrombogenicity [58] [65] [66] [67] [68].
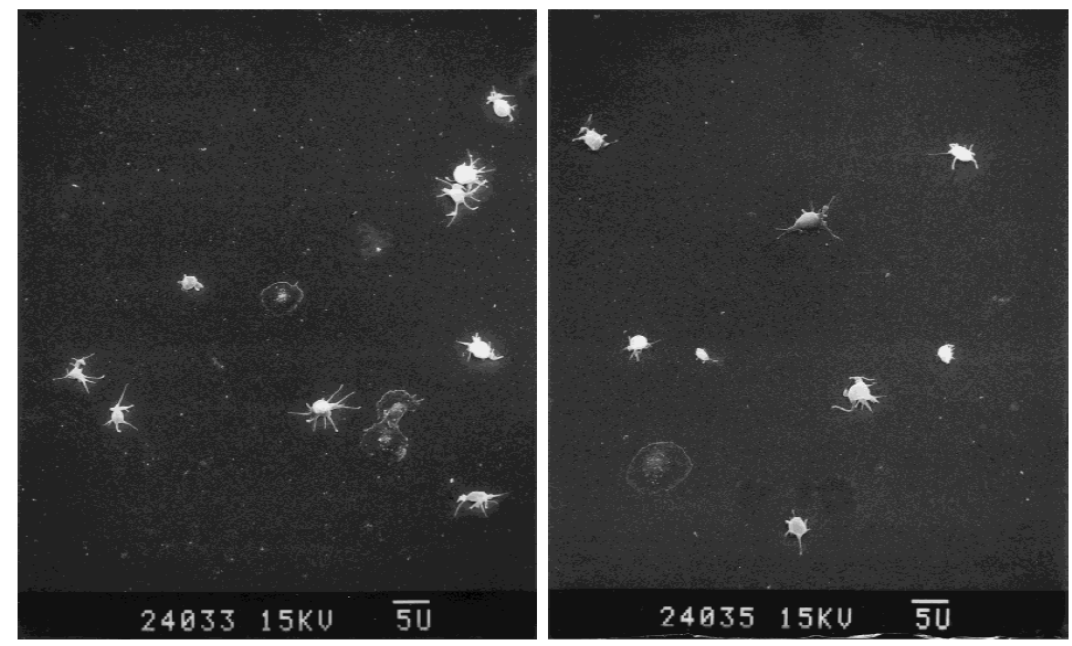

Figure 2.1. Scanning electron micrographs showing platelet morphology of Si (left) and $\mathrm{SiO}_{2}$ (right). Images taken at $1200 \times 0.15 \mathrm{kV}$ [58]

Figure 2.1 illustrates, from the study in [58], the adhesion of platelets to $\mathrm{Si}$ and $\mathrm{SiO}_{2}$. The images reveal morphological changes of platelets (pseudopods formation) that indicate activation and aggregation. 
Figure 2.2 shows how in [58] platelet adhesion was used to quantitatively compare various material used in Bio-MEMS devices. The results confirmed higher levels of thrombogenicity for $\mathrm{Si}$ and the lowest value of platelet adhesion for polyurethane [69]. platelet circularity and spreading (area) have also been reported as more specific measurements of hemocompatibility. When a platelet activates, it starts spreading on the surface and developing pseudopods, changing consequently its circular shape from the resting state. The less circular the platelets are that adhere to a surface, the more thrombogenic the material is [68].

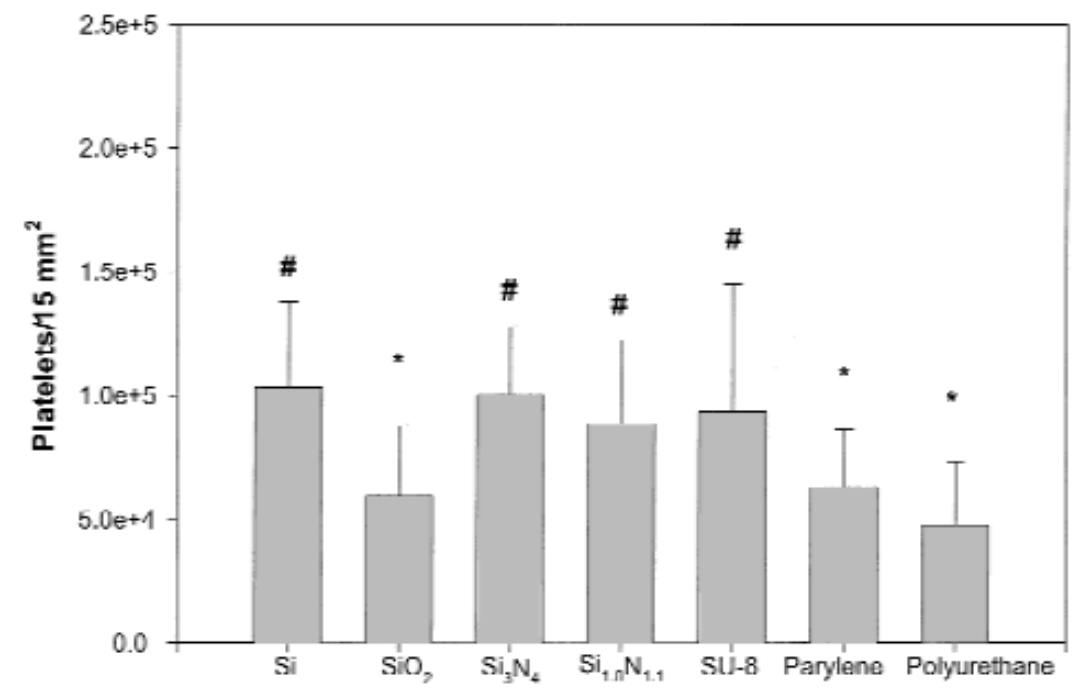

Figure 2.2. Number of adhered platelets per $15 \mathrm{~mm}^{2}$ for Si, Si-based materials, SU-8, parylene and polyurethane. \# Statistically different from Polyurethane and * statistically different from Si [58].

In contrast with other blood formed elements, platelets are not normally in stable contact with each other, but they develop such contacts once aggregation has started, limiting the escape of platelet activators from within the gaps between them. This helps to create and prevent the dissolution of the haemostatic plug [70]. Therefore the degree of 
aggregation also provides important information about the thrombogenic behavior of the material, even when activation is not present [71].

\subsubsection{The Protein Adsorption Assessment Perspective}

When injury is present in the vessel wall, it initiates the expression of tissue factor activity. Platelets rapidly accumulate on the endothelium, and fibrin can be observed at the platelet thrombus-vessel wall interface, at the leading edge of the thrombus. The same concept applies for thrombus formed on the surfaces of a material, with adhesion plasma proteins being adsorbed to the surface and fibrinogen being transformed to fibrin by the action of thrombin.

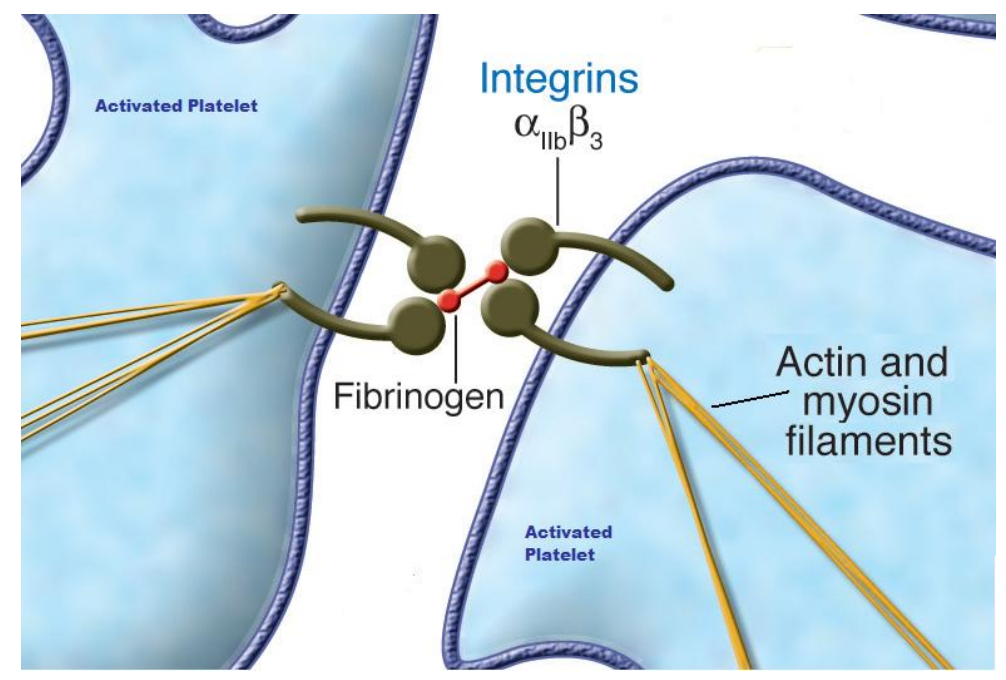

Figure 2.3. Fibrinogen promoting platelet-platelet adhesion by binding glycoprotein IIbIIIa (GPIIb-IIIa). Adapted from [70]

Fibrinogen and the Von Willebrand factor are thought to play a key role in plateletvessel wall interaction, particularly at low shear rates. Deficiencies in fibronectin delayed the formation of thrombus in in-vivo experiments performed on modified rats [70]. 
The short distance between platelets leads to aggregation when by direct interaction a multivalent adhesive proteins (i.e. Fibrinogen) link activated glycoprotein IIb-IIIa (GPIIb-IIIa, the major platelet membrane integrin) on the surface of platelets adjacent to other platelets or promoting platelet adhesion to artificial surfaces (see Figure 2.3).

However, there are multiple plasma proteins and participants of this platelet-surface (material or vessel wall) interaction, including albumin and collagen that are directly implied in thrombus formation [70] [14] [61] [72]. However in-vitro applications look for the minimum amount of variables possible and usually limits the study of plasma protein interactions with surfaces to either fibrinogen or fibronectin [72].

\subsubsection{The Endothelial Cell Proliferation Perspective}

Antithrombogenic polymeric coatings have been widely used to improve the hemocompatibility of materials [73]. However a new trend is to coat the material with the natural Antithrombogenic surface of the human body: Vascular endothelial cells.

As stated before the relationship between endothelial cells and platelets is opposite in nature but complementary. A material that has low platelet adhesion usually has very good endothelial cell proliferation, and these two requirements must be fulfilled for a material to be considered hemocompatible for real applications [74]. Endothelial coatings have been tested in the past on modified DLC surfaces with the purpose of using it in vascular grafts and heart valves but this requires the substrate in which the endothelial cells are been seeded to be compatible with these cells. 

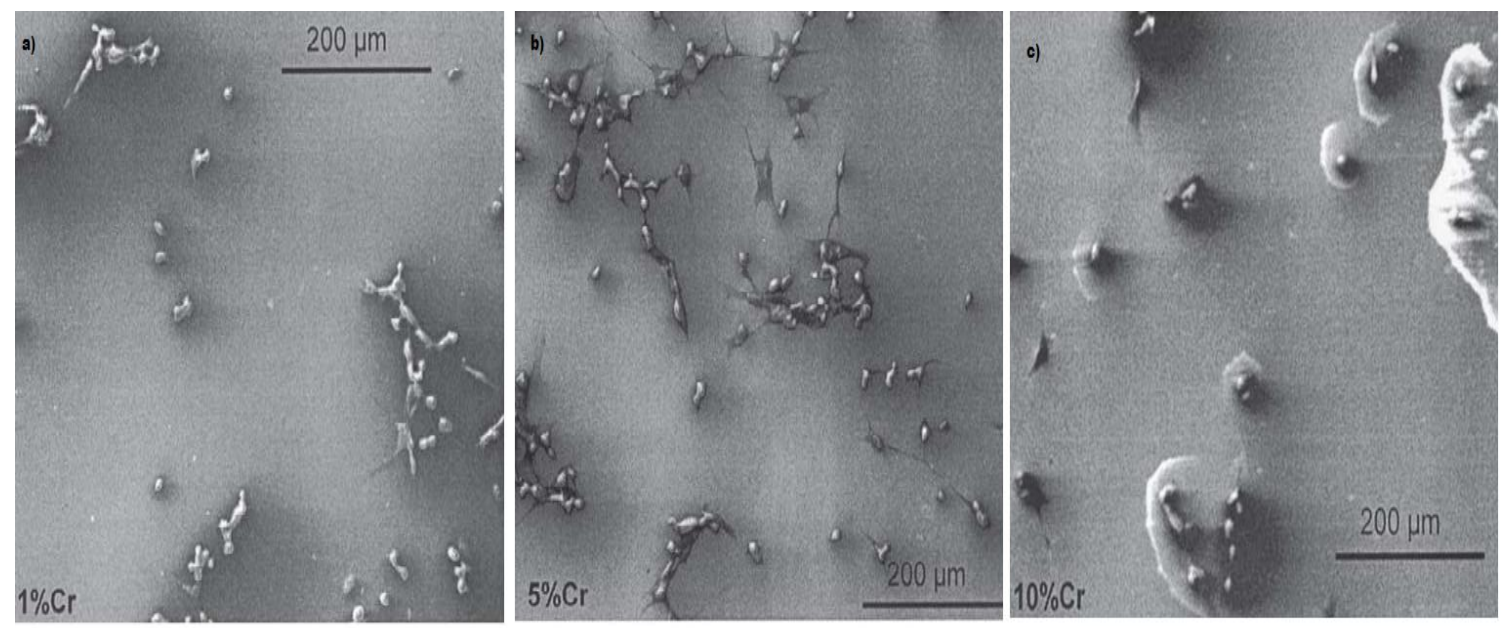

Figure 2.4.SEM micrographs showing endothelial cells on three types of Cr-DLC. Cr is 1,5 and $10 \%$ [62]

Cr-DLC compatibility with human vascular changes as a function of the percentage of chromium in the film has been studied in [62]. Figure 2.4 shows that DLC with $5 \%$ of Cr was the only for which endothelial cells presented good morphology. All the other percentages shown agglomerations, lack of spreading, and poor generation of lamellipodia and filopodia typical of HMVEC. Consistently, the surfaces with bad morphology presented lower proliferation. It was concluded that 5\% Cr-DLC is more hemocompatible than the other variations analyzed in this study. This is an example of how microvascular endothelial cell proliferation can be used to asses hemocompatibility. However, using only this information is incomplete, as good endothelial cell proliferation must complement low platelet adhesion for a hemocompatibility statement to be made. 


\section{Chapter. 3: Platelet Adhesion and Activation}

\subsection{The Blood and its Elements}

Blood is a bodily fluid that constitutes about $8 \%$ of the body's weight, it circulates through the heart and vessels transporting oxygen and nutrients to the different tissues and organs of the human body and transporting waste products away from them. It is through a blood mechanism called coagulation that the body heals itself and prevents excessive bleeding after injury. Blood also executes many immunological (activation of the complement system that leads to inflammation and foreign body encapsulation) and regulatory ( $\mathrm{pH}$ and temperature) functions in the human body [75] [15].

Blood is constituted of plasma (55\%) and formed elements or organelles (45\%). About $92 \%$ of the plasma is water and $7 \%$ proteins (albumin, globulin, fibrinogen, etc.) and the remaining are electrolytes, glucose, amino acids, fatty acids, organic nutrients and waste [75] [15].

The normal $\mathrm{pH}$ of arterial human blood is approximately 7.4. The term blood serum refers to plasma without clotting factors (i.e., fibrinogen). Blood formed elements include erythrocytes (red blood cells), leucocytes (white blood cells) and thrombocytes (platelets). About 99\% of the blood organelles are red cells [75] [15].

Mature red cells in mammals do not have a nucleus. Red cells are produced in the bone marrow and usually lose their nuclei when they are released into the blood stream, in order to provide more space for hemoglobin. After being released red blood cells live 
for about 100-120 days. Mammalian erythrocytes are flexible biconcave disks: flattened and depressed in the center, with a dumbbell-shaped cross section (see Figure 3.2). A typical human erythrocyte disk has a diameter of $6-8 \mu \mathrm{m}$ and a thickness of $2 \mu \mathrm{m}$, about one third of the volume of a red cell is hemoglobin, responsible for the transport of about $98 \%$ of the oxygen in the human body [75] [15].
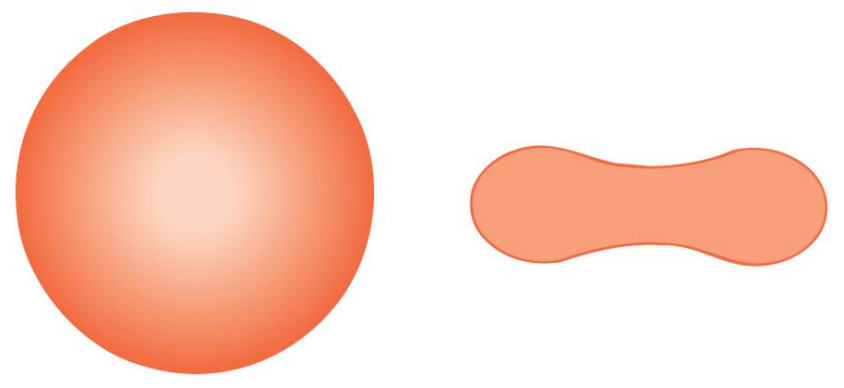

Figure 3.1. Diagram of a red blood cell (erythrocyte) shape, in plan and cross section [75].

White cells or leucocytes are the cells of the immune system and there are at least five types of them. Unlike red cells, white cells retain their nuclei. White cells are divided into granulocytes (also known as polymorphonuclear leucocytes) and mononuclear cells. There are three types of granulocytes and two types of mononuclear cells, see Figure 3.2.
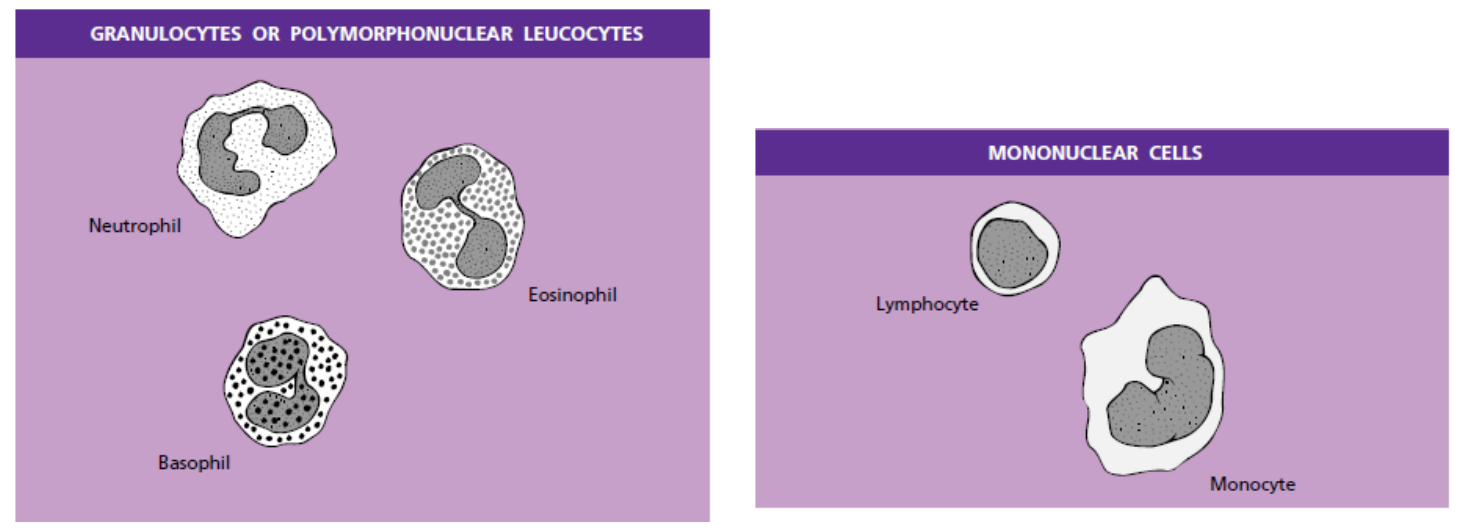

Figure 3.2. Classification of the 5 types of white cells [75]. 
Neutrophils are attracted to sites of infection (chemotaxis), and destroy the microorganisms (mainly bacteria and fungi) responsible for the infection by ingesting them through a process known as phagocytosis. Eosinophils target parasitic infections and also play a role in allergic reactions. Basophils have a role in immediate hypersensitive reactions and allergic and inflammatory responses.

Mononuclear cells include lymphocytes and monocytes. Lymphocytes mediate immune responses and are classified into three types: B, T and natural killers (NK). B lymphocytes secrete antibodies to work against antigens as part of the humoral immune response. $\mathrm{T}$ lymphocytes attack cells bearing foreign antigen and antibody coated cells playing a key role in the cell-mediated immunity. NK cells reject tumors and attack cells infected by viruses; they play a role in cell-mediated immunity and are a major component of the innate immune system.

Monocytes migrate to tissues where they differentiate into tissue resident macrophages or dentritic cells. Macrophages phagocytose cellular debris and pathogenic microorganisms and stimulate lymphocytes and other immune cells that respond to the pathogen. Dentritic cells present the antigens to the T lymphocytes in order to activate them.

Another formed element in the blood are platelets. Platelets are formed by the fragmentation of the protruding cytoplasm of megakaryocytes (large bone marrow cells) in the sinusoids of the bone marrow. Therefore they are not cells but fragments of cell cytoplasm of discoid shape. The average life span of a platelet is 7 days and they range from $2 \mu \mathrm{m}$ to $3 \mu \mathrm{m}$ in diameter by $0.5 \mu \mathrm{m}$ in thickness [76]. Their small size and discoid 
shape allows the blood flow to push them to the vessel edge, near the surface of the endothelium were they are ready to detect and respond to vascular damage.

Platelets play a key role in hemostasis leading to the formation of blood clots when in contact with activating factors. Clot formation requires platelets to undergo rapid morphological changes from a resting state to an activated state, as well as platelet aggregation, as shown in Figure 3.3.

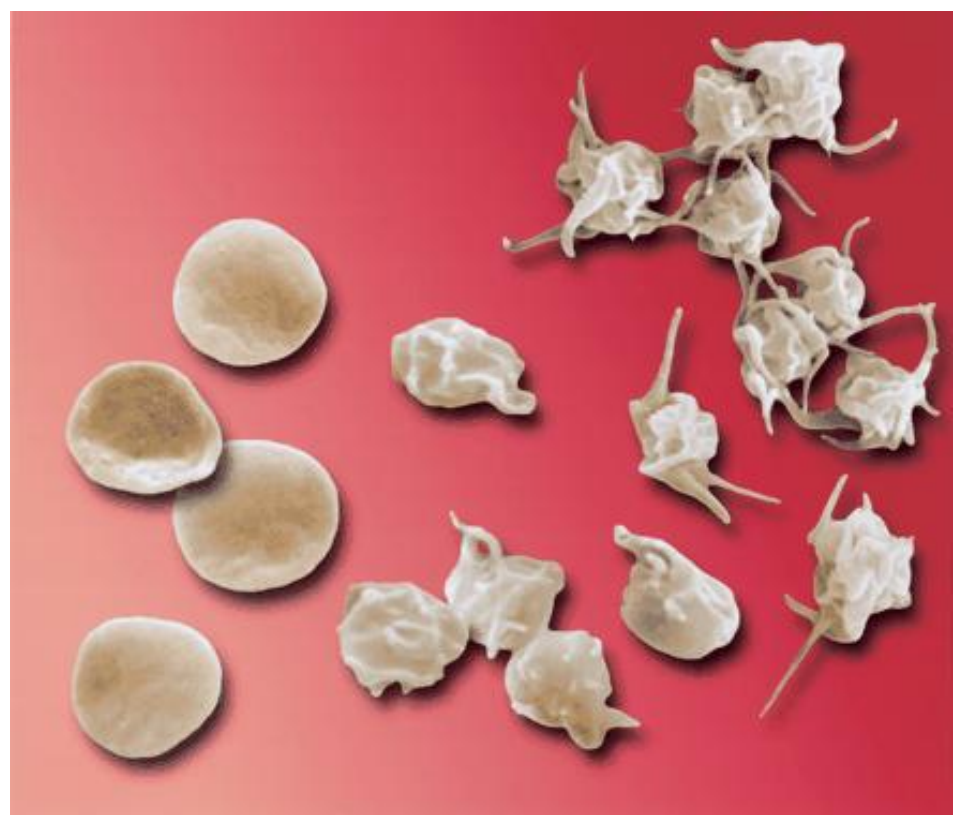

Figure 3.3. Scanning electron microscope images of resting (left), partially (center) and fully activated (right) human platelets. From [77].

The shape of the platelets is maintained by a sturdy and flexible internal cytoskeleton composed of actin and tubulin polymers and their associated proteins [5]. Remodeling of the cytoskeleton and assembly of new actin filaments allows for platelet shape changes. The surface of the platelets is featureless except for semi-selective conduits formed from membrane invaginations that allow small molecules to enter the platelet membrane. Platelet cytoplasm is composed of normal cellular organelles (lysosomes, mitochondria, etc.) and additionally contains specific platelet granules, the $\alpha$-granules, which store 
matrix adhesive proteins and have glycoprotein receptors in their limiting membranes in order to promote adhesion between platelets and the matrix.

When blood is collected in tubes containing anticoagulant solution (otherwise it would create a single solid clot) and it is allowed to settle, it separates into three layers, see Figure 3.3: The bottom layer is composed of red cells, the top layer is clear and pale yellow and is the blood plasma. In between is a narrow layer called the buffy coat composed mainly of white cells and platelets [75] [15].

If it is necessary to isolate platelets from whole blood, two major methods are available: the platelet rich plasma (PRP) and the buffy coat (BC) methods, illustrated in the diagrams of Figure 3.4.

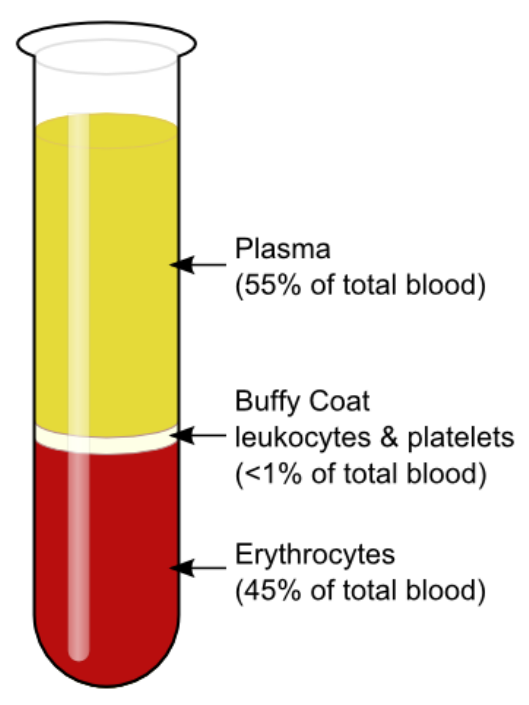

Figure 3.4. Diagram of a tube of anticoagulated blood that has settled, illustrating the separation of blood into three layers. Adapted from [75] 
PRP Preparation

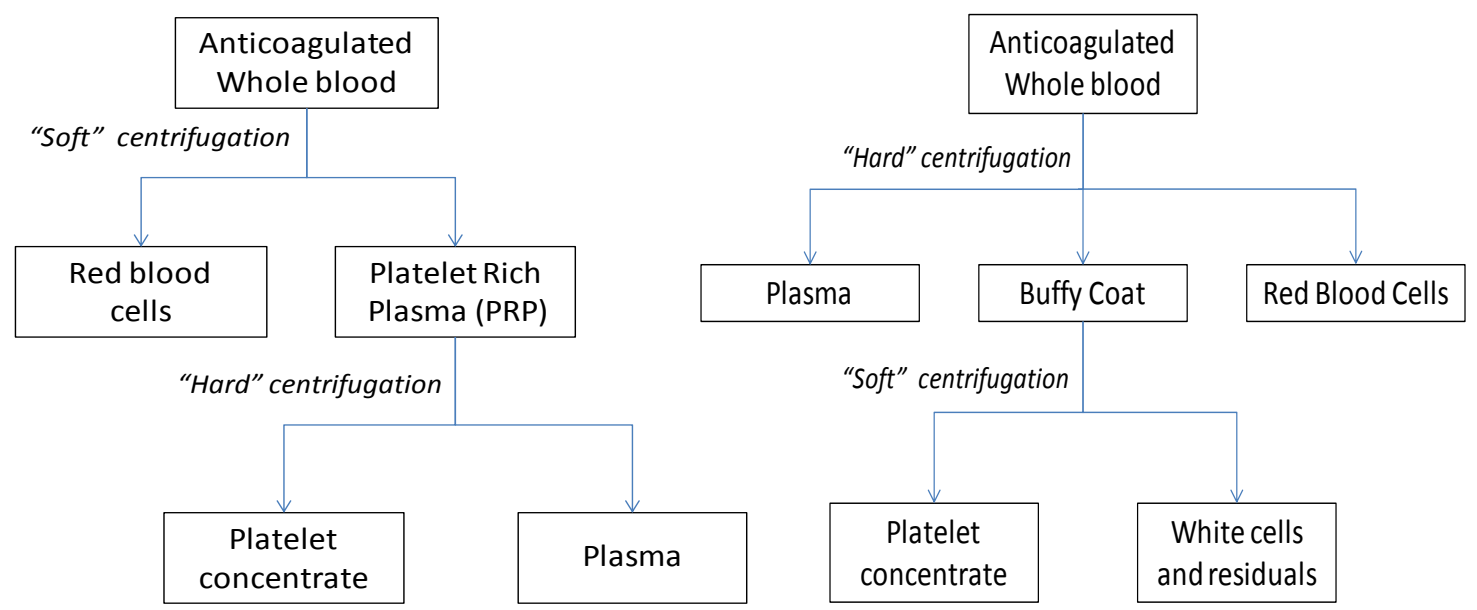

Figure 3.5. Preparation of platelet concentrates using the PRP and BC techniques [15].

Both techniques are based on the concept of differential sedimentation, which is manipulated via centrifugation. The sedimentation rate is influenced heavily by the physical properties of the cells and the viscosity of the medium, in this case, plasma [15].

In the PRP technique, anticoagulated whole blood first undergoes low G-force ("soft") centrifugation which results in a PRP supernatant that contains mostly suspended platelets( plus $30-50 \%$ of white cells and some red cells). The red cells form a pellet in the bottom of the test tube with the remaining white cells and some platelets. The PRP can be centrifuged at high $\mathrm{G}$, to separate platelet-poor plasma from the plateletconcentrate pellet that can be resuspended to the desired density [15].

High speed (hard) centrifugation separates blood differently from low speed centrifugation. At high speed, the white cells sediment with red cells initially, leaving in the top a PRP supernatant. Then red cells are packed closely and fall to bottom rapidly, which forces white cells upward at the plasma interface, which is a process that is followed by platelet sedimentation at the white cell layer. The former describes the first 
step of the BC method. Subsequently the buffy layer containing white cells and platelets is centrifuged at low g, resulting in dense platelet rich plasma [75] [15].

Appropriate selection of the centrifugation speed and centrifugation time may result in a PRP supernatant, an intermediate white cell layer and a red cell pellet.

\subsection{Platelet Adhesion and Activation Assessment Protocol}

Platelet reactivity, measured by the degree to which platelets in suspension adhere to a surface in vitro, has been proposed as a measure of thrombogenicity [58]. This includes the amount of platelet adhesion as well as changes in platelet morphology including increased area and development of pseudopods. Platelet circularity, C, is defined as $C=4 \pi \frac{A}{P^{2}}$, where $P$ is the perimeter of the platelet and $A$ is its area. When the platelet possesses perfect circularity $\mathrm{C}$ is equal to unity [78] [58].

It has been observed that an increase in platelet circularity on a material correlates with increased hemocompatibility of the material surface [58]. It has also been noted that an increase in platelet area represents a decrease in hemocompatibility of the surface (this is consistent with the above as the platelet tends to form a tight circular shape when not adhering to the surface thus minimizing its area). Therefore platelet spreading (i.e., increase in platelet area) and circularity have been reported as specific markers for surface hemocompatibility.

In order to evaluate platelet reactivity on $3 \mathrm{C}-\mathrm{SiC}, 4 \mathrm{H}-\mathrm{SiC}, 6 \mathrm{H}-\mathrm{SiC}$ and $\mathrm{Si}$ samples the following protocol was followed. Blood samples were obtained from young, healthy, female farm pigs weighting approximately $45 \mathrm{~kg}$, free of hepatitis or other blood borne disease. The blood samples were collected by routine phlebotomy using $4.5 \mathrm{ml} \mathrm{BD}$ 
Vacutainer blood collection tubes (blue stopper) containing $0.105 \mathrm{M}(3.2 \%)$ buffered sodium citrate $(12.35 \mathrm{mg}$ of sodium citrate / $2.21 \mathrm{mg}$ of citric acid) for anticoagulation. The anticoagulant effect of sodium citrate is reversible, allowing the platelets to activate when in contact with a thrombogenic (i.e., non hemocompatible) material.

Platelet rich plasma (PRP) was obtained from the blood samples via centrifuging the tubes for 20 minutes at $200 \mathrm{~g}$ and at room temperature. The platelet concentration was calculated using bright line counting chamber (hemocytometer) with reduced thickness from Hausser Scientific and a BD Unopette ${ }^{\mathrm{TM}}$ system, designed especially for platelets and leukocyte counts. The average platelet concentration was $4.38 \times 10^{5}$ platelets $/ \mathrm{ml}$. The PRP samples were then incubated for 30 minutes at $37^{\circ} \mathrm{C}$ to allow the platelets to recover their shape which is necessary for platelet interactions and activation.

Single crystal 3C-SiC samples grown on $\mathrm{Si}(100)$ and single crystal $\mathrm{Si}(100)$ wafer samples (die size $10 \mathrm{~mm}$ x $8 \mathrm{~mm}$ ) were cleaned for 10 minutes via piranha solution (organics removal) at 2:1 concentrations of $\mathrm{H}_{2} \mathrm{SO}_{4}: \mathrm{H}_{2} \mathrm{O}_{2}$, then rinsed three times with deionized water (DI-water) with a resistivity of at least $16 \mathrm{M} \Omega \cdot \mathrm{cm}$, followed by 5 minutes of $\mathrm{H}_{2} \mathrm{O}: \mathrm{HCl}$ in a 1:1 ratio, intended to eliminate any sulfur traces resulting from the piranha cleaning. Native surface oxide was removed by dipping the samples in a hydrofluoric acid solution $\left(50: 1 \quad \mathrm{H}_{2} \mathrm{O}: \mathrm{HF}\right)$ for 1 minute. The samples were then thoroughly rinsed in DI water and stored under ethanol. Just prior PRP exposure, the samples were rinsed three times with DI-water and manually blow dried with nitrogen.

$4 \mathrm{H}-\mathrm{SiC}$ and $6 \mathrm{H}-\mathrm{SiC}$ samples were obtained from wafers purchased from Cree Inc. $4 \mathrm{H}-\mathrm{SiC}, 6 \mathrm{H}-\mathrm{SiC}$ and $\mathrm{Si}$ samples underwent the same cleaning procedure already described for 3C-Sic samples. 
The clean and dry semiconductor material samples were them placed in BD Falcon 24-multiwell culture inserts and covered with $2 \mathrm{ml}$ of PRP. The multiwell plates were then placed in the incubator for 15 minutes at $37^{\circ} \mathrm{C}$ and $5 \% \mathrm{CO}_{2}$ and $95 \%$ relative humidity.

The wafer die were then removed and rinsed twice with PBS (Phosphate buffered saline) to remove non adherent platelets, and then the platelets were fixed using $4 \%$ paraformaldehyde in PBS. The samples were rinsed again two times and then dipped for 30 minutes in a $0.1 \%$ Triton- $\mathrm{X}$ solution in order to permeabilize the membrane of the adherent platelets. After rinsing, the fixed platelets were pre-incubated in PBS containing $1 \%$ BSA (bovine serum albumin) in order to reduce nonspecific background staining. Next, the F-Actin filaments of the platelets' cytoskeleton was stained using Rodhamine Phalloidin (R415 from Invitrogen ${ }^{\mathrm{TM}}$ ), a cellular structure probe made from a phalotoxin conjugated to the orange-fluorescent dye, tetramethylrhodamine (TRITC) also diluted in 1\% BSA solution. Cover slips were mounted over the samples using DAPI $\left(4^{\prime}, 6-\right.$ diamidino-2-phenylindole), a nucleic acid fluorescent stain, in order to differentiate platelets from any unintentionally present cells derived from the PRP separation process. Subsequently, the samples were imaged using a Leica DM IL inverted microscope at different levels of magnification, and the images were manually processed to enhance borders and backgrounds and then automatically processed (thresholding, noise reduction, etc.) and analyzed using ImageJ, a public domain image processing software developed at the NIH (National Institutes of Health) [79].

Previous research regarding platelet adhesion, and activation were usually performed in the absence of aggregation, either chemically manipulating the PRP (for example 
adding EDTA) or by exposing the surfaces to PRP only for 5 minutes [58] [80]. Additionally the PRP is diluted to guarantee a low number of platelets adhered to the surface and this way images of single activated platelets are easier to obtain [81]. Although this approach allows the acquisition of single activated platelet images it may be detrimental to the experiments as it can yield falsified results making it hard to know if low adhesion and activation is just a consequence of low platelet surface interaction, it also prevents one from getting a better picture of platelet clumping in the presence and absence of activation [81].

In this experiment the samples were exposed for longer times (15 minutes), at high platelet concentrations and without PRP manipulation to avoid aggregation, in order to get a better insight into the thrombogenic behavior of the studied surfaces. Subsequently, these conditions resulted in a higher level of difficulty when analyzing the images, as the presence of clumps and the facts that platelets do not have a constant size and that their shape is discoid required more complex image processing (manual and automatic) in order to facilitate particle differentiation when possible (see Figure 3.6).
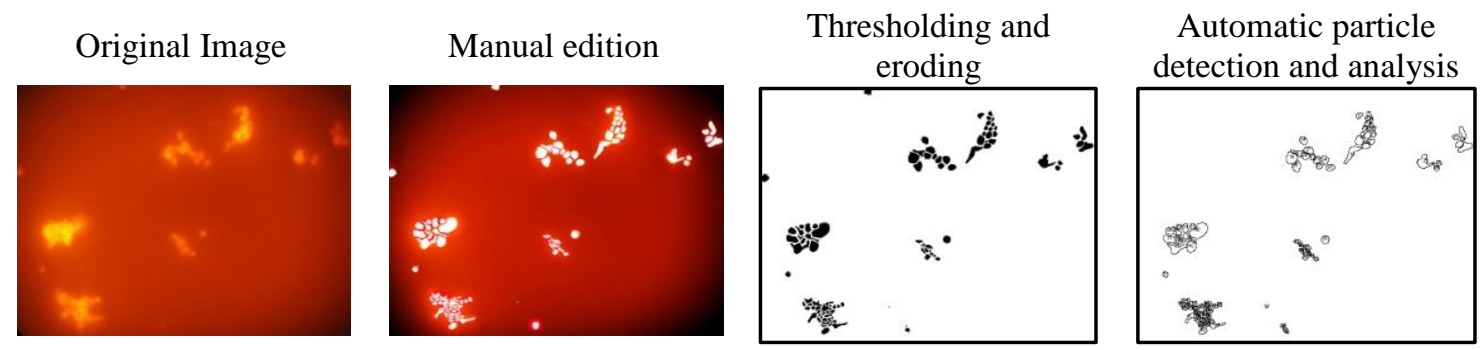

Figure 3.6. Illustration of the image analysis process for platelets seeded on a Si sample. The original image cannot be adequately processed by the software. The image is first manually enhanced and then automatically prepared for particle detection and analysis with Image J [79] 
Higher platelet adhesion was observed on the Si surface than on SiC, and among the SiC polytypes it can be seen that more adhesion occurred for the hexagonal types than the cubic (i.e., 3C-SiC) type. More importantly, when looking at high magnification it was found that the platelets that adhered to the $4 \mathrm{H}-\mathrm{SiC}$ and $6 \mathrm{H}-\mathrm{SiC}$ surfaces had more activation (presence of lamellipodia and filopodia) and presence of clumps than for 3C$\mathrm{SiC}$ and $\mathrm{Si}$. 3C-SiC surfaces showed less aggregation and activation with much more circular shaped platelets that the other surfaces thus indicating an improved hemocompatibility. The former is illustrated in Figure 3.7.
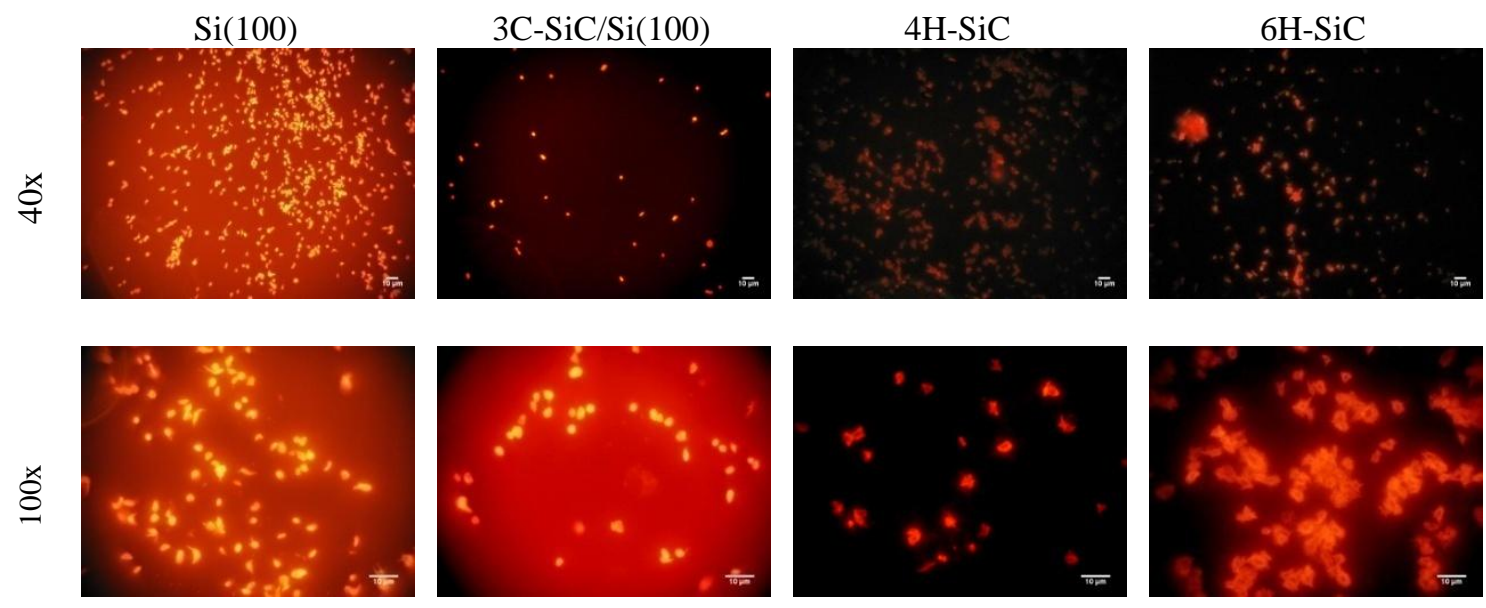

Figure 3.7. Fluorescent micrographs comparing adhered platelets on 3 different SiC polytypes and $\mathrm{Si}$. 3C-SiC clearly shows lower adhesion and high circularity while $\mathrm{Si}$ presented the highest adhesion. $4 \mathrm{H}-\mathrm{SiC}$ and $6 \mathrm{H}-\mathrm{SiC}$ evidenced the presence of clumps and high degree of activation

4H-SiC presented, as shown in Figure 3.8., large-area activated particles and nonactivated/activated platelet clumps and the highest adhesion of all the $\mathrm{SiC}$ polytypes included in this study, exhibiting therefore a thrombogenic behavior that can lead to device failure. 

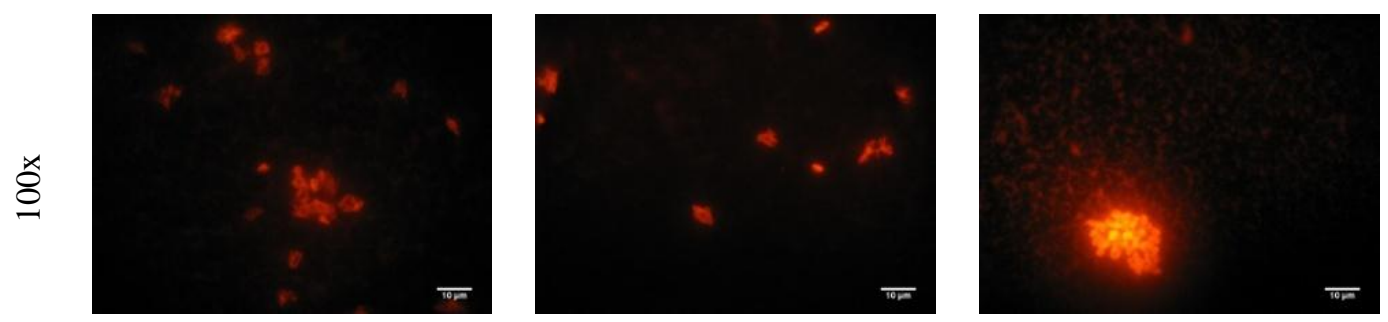

Figure 3.8. Fluorescent micrographs revealing activated platelet clumps (left), nonclumped activated platelets (center) and a large non-activated platelet clump on the surface of $4 \mathrm{H}-\mathrm{SiC}$ samples. Magnification 100x

The results of these experiments were evaluated for statistical significance using analysis of variance (ANOVA) to detect significant differences among all pairs of means of the markers circularity, particle adhesion counts, and particle size (this will indicate if at least one pair of mean values is statistically different). However, this technique does not single out any particular pair of means as being statistically different. In order to address this problem for the cases in which the F-test indicated that at least one of the means was different, a multiple comparison using paired T-tests with Bonferroni adjustment was used. The tests were evaluated for a significance level of $5 \%(\alpha=0.05)$.

Due to the presence of platelet aggregation the resulting statistics cannot be interpreted in a deterministic way in order not to misinterpret particle analysis. For example a very circular clump where platelets cannot be differentiated is going to yield a big size (false platelet size), and in this case circularity is not significant compared to size, that indicates the presence of clumps. Similarly, a low number of counts, but high size, indicates the presence of a few big clumps, where individual platelets cannot be differentiated automatically by the software. A low-thrombogenic material should present low counts of adhered platelets with high circularity and small average size. 
Bar diagrams and ANOVA analysis tables for circularity, adhesion and platelet area (size) are shown in Figures 3.9, 3.10 and 3.11 respectively. Platelet circularity for all the samples was above 0.85 which is considered a high value and indicative of low activation [78]. The highest average value was for 3C-SiC with a confidence interval of $[0.939 \pm$ 0.049] also with the smallest standard deviation. However, when testing for statistical differences a high $p$ value of $p=0.0746$ showed no significant differences among the platelet circularity for the different materials. This also suggests that the samples have similar variances and therefore the presence of outliers in the circularity measurements for $4 \mathrm{H}-\mathrm{SiC}$. This indicates that the results of circularity, particle counts and size should be analyzed together to understand the thrombogenic behavior of this material. $4 \mathrm{H}-\mathrm{SiC}$ presented high circularity but small particle count (comparable to $3 \mathrm{C}-\mathrm{SiC}$ and $6 \mathrm{H}-\mathrm{SiC}$, as confirmed by paired-adjusted test), particles that also presented the highest average size with the highest variance. This can be interpreted as the particles not being individual platelets, but large size circular clumps that the software is not able to differentiate as multiple particles regardless of any image enhancement done previously, leading to platelet miscounts. Looking at the circularity alone, it would lead us to think of $4 \mathrm{H}-\mathrm{SiC}$ as a low thrombogenic material, however this cannot be further from the truth, and a composite analysis of the statistical data confirms the optical results illustrated in Figures

\section{7 and 3.8 .}

Additionally, it can be concluded that mathematically small differences in circularity are good indicators of the initial stages of activation, even though they may not be big enough to translate into drastic statistical indicators of variability among the samples. For example, the confidence intervals of circularity for $3 \mathrm{C}$-SiC and Si were [0.939 \pm 0.049$]$ 
and $[0.885 \pm 0.053]$ which is a small difference with no statistical significance, but optical comparison of $\mathrm{Si}$ and 3C-SiC (Figure 3.12) shows that platelets adhered to $\mathrm{Si}$ are more activated than the ones adhered to $3 \mathrm{C}-\mathrm{SiC}$, however they are in an early stage of activation which must be considered when drawing conclusions from this data.

$6 \mathrm{H}-\mathrm{SiC}$ or $4 \mathrm{H}-\mathrm{SiC}$ had comparable average circularity but also higher variability, which was associated either with the presence of circular clumps or with the presence of deformed clumps or individual highly activated platelets.

Statistical paired analysis of the particle counts indicated no statistical differences between $3 \mathrm{C}-\mathrm{SiC}$ and $6 \mathrm{H}-\mathrm{SiC}$; however platelets that adhered to $3 \mathrm{C}-\mathrm{SiC}$ showed higher circularity and smaller area while $6 \mathrm{H}-\mathrm{SiC}$ evidenced the presence of activated clumps. $\mathrm{Si}$ surfaces evidenced the highest platelet adhesion of all the surfaces with high presence of clumps (large size particles), thus showing consistently a lower level of hemocompatibility. 


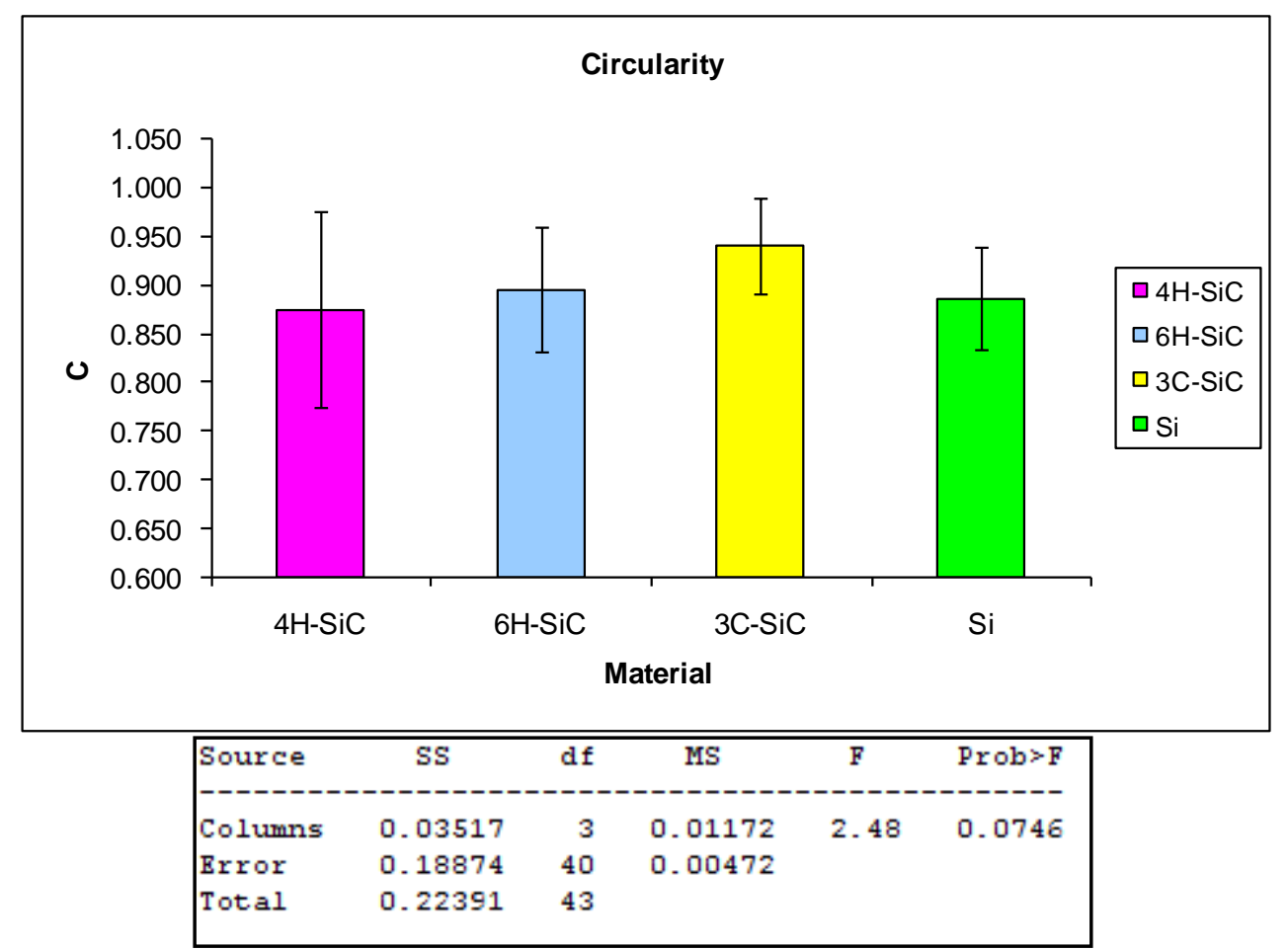

Figure 3.9. Statistical analysis of particle circularity on 3 different $\mathrm{SiC}$ polytypes and $\mathrm{Si}$. Top: Histogram. Bottom: Anova table.

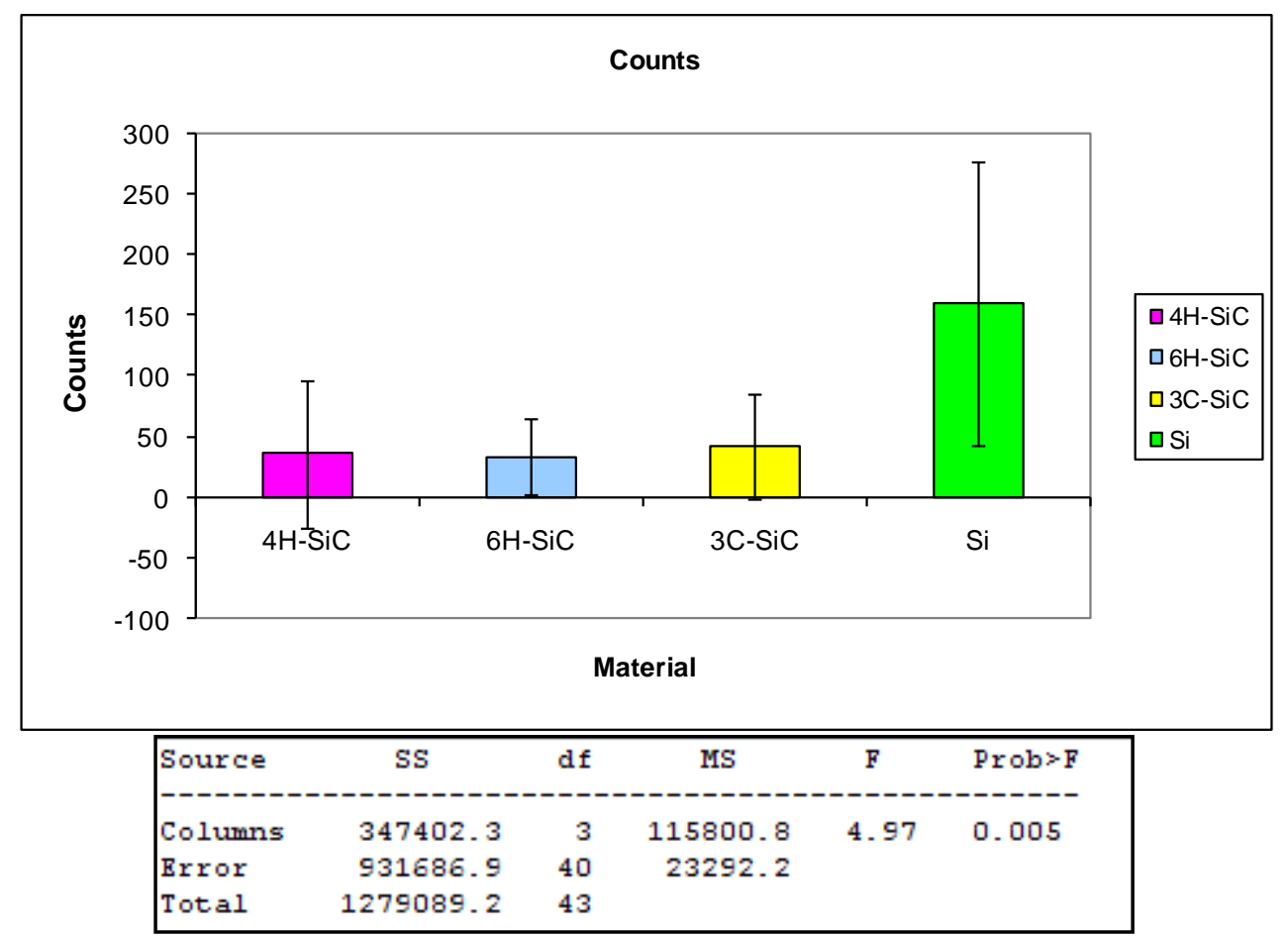

Figure 3.10. Statistical analysis of particle counts on 3 different SiC polytypes and $\mathrm{Si}$.

Top: Histogram. Bottom: Anova table. 


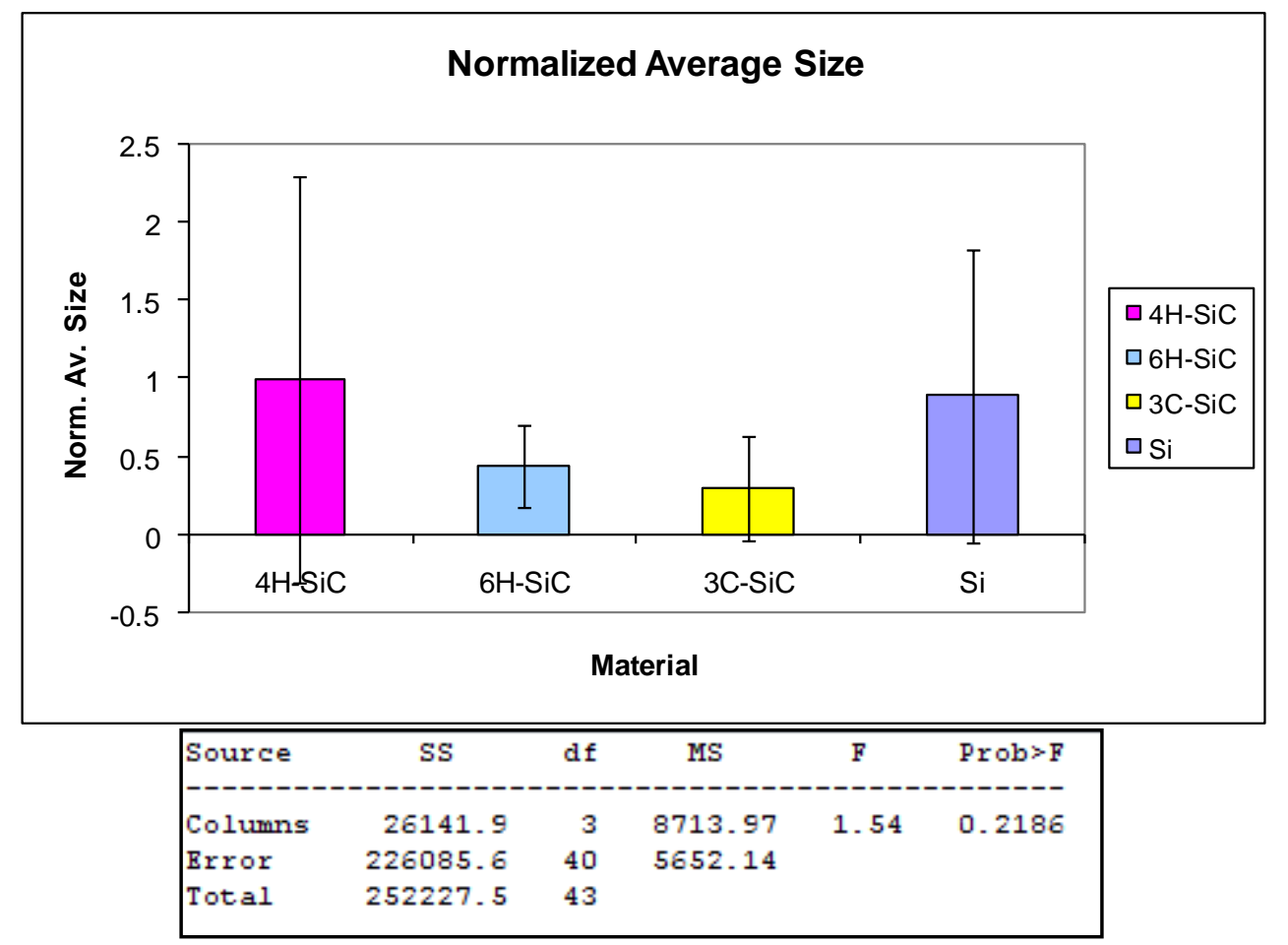

Figure 3.11. Statistical analysis of particle size on 3 different SiC polytypes and Si. Top: Histogram. Bottom: Anova table.
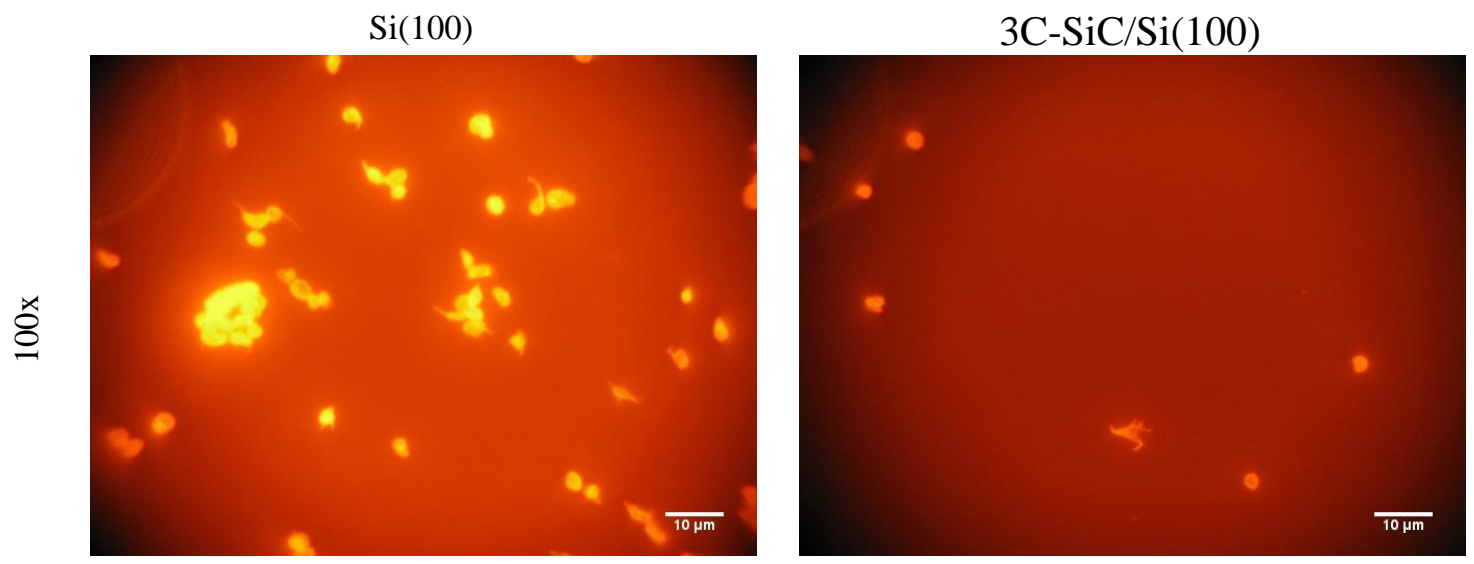

Figure 3.12. Fluorescent micrographs comparing Si (left) and 3C-SiC (right) samples revealing higher degree of thrombogenicity in $\mathrm{Si}$ than in $3 \mathrm{C}-\mathrm{SiC}$. Si samples presented higher adhesion, activation and aggregation than $3 \mathrm{C}-\mathrm{SiC}$ samples. 


\subsubsection{The Impact of Surface Roughness}

Surface roughness is considered a key factor in determining a low-thrombogenic behavior of biomaterials. Although the mechanisms behind hemocompatibility have not been completely understood yet, it is largely accepted that blood cell lysing due to high surface roughness can induce a thrombogenic reaction but more importantly that surface roughness has an impact on surface wettability and protein adsorption [82] [83] [34].

In order to assess the effect of surface roughness on platelet reactivity to $3 \mathrm{C}-\mathrm{SiC}$, several samples of high and low roughness were used, with different degrees of crystallinity and crystal orientation: single crystal $3 \mathrm{C}-\mathrm{SiC}$ samples grown on $\mathrm{Si}(100)$ showing low roughness, Polycrystalline 3C-SiC grown on $\mathrm{Si}(100)$ showing high roughness, and single crystal $3 \mathrm{C}-\mathrm{SiC}$ grown on $\mathrm{Si}(111)$ evidencing both high roughness and low roughness in different parts of the wafer, see Figures 3.13-3.17. Table 3.1 summarizes the range of values used for roughness assessment of the different samples.

The silicon samples were used as controls for comparison and its roughness has average values smaller than single crystal $3 \mathrm{C}-\mathrm{SiC}$ and a small standard deviation, indicating less variability of the surface morphology.

Table 3.1. Summary of samples roughness expressed as [average roughness $(\mu)+$ standard deviation of the mean $(\sigma)]$ in nanometers $(\mathrm{nm})$

\begin{tabular}{|c|c|}
\hline Sample & {$[\mu \pm \sigma](\mathrm{nm})$} \\
\hline Single crystal 3C-SiC/(100)Si & $0.248167 \pm 0.112642$ \\
\hline Polycrystalline 3C-SiC/(100)Si & $62.31167 \pm 17.38315$ \\
\hline $\begin{array}{c}\text { Single crystal 3C-SiC/(111)Si } \\
\text { (low Roughness) }\end{array}$ & $4.215833 \pm 1.525045$ \\
\hline $\begin{array}{c}\text { Single crystal 3C-SiC/(111) Si } \\
\text { (high roughness) }\end{array}$ & $34.0165 \pm 16.6633$ \\
\hline (100) $\mathrm{Si}$ & $0.074 \pm 0.087681$ \\
\hline
\end{tabular}



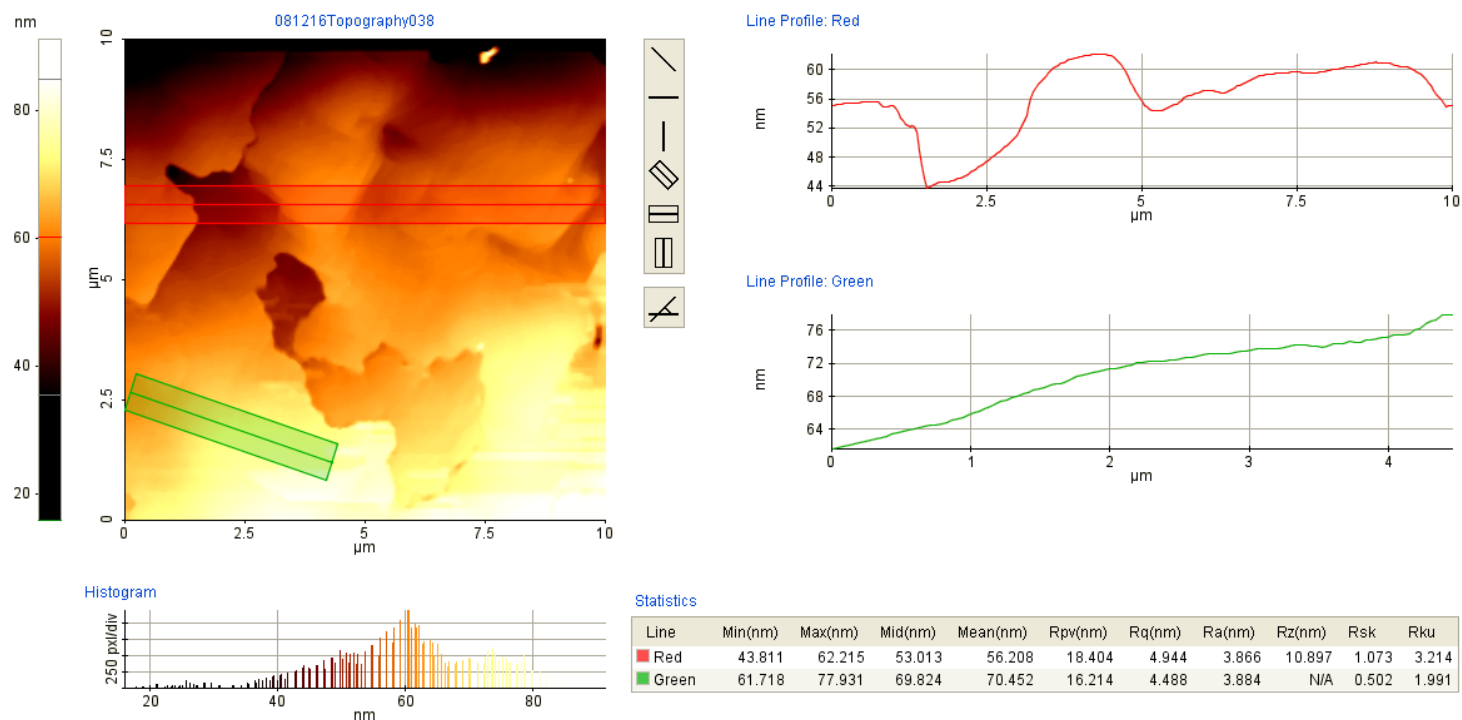

Figure 3.13. AFM micrograph taken in tapping mode. Example of sample with low roughness: single crystal 3C-SiC/(100)Si (from wafer USF1-08-013- die \#9)
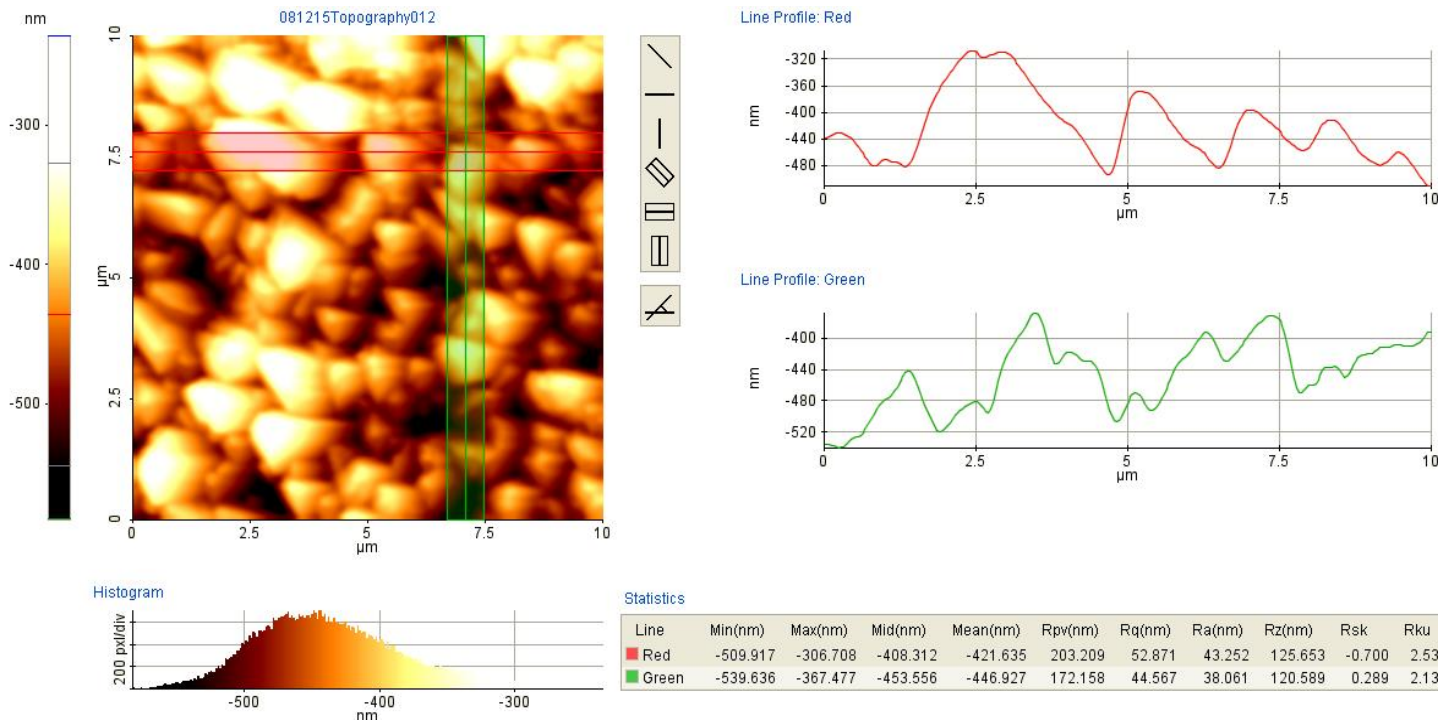

Statistics

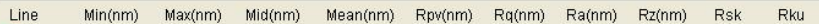
$\begin{array}{lllllllllll}\text { Red } & -509.917 & -306.708 & -408.312 & -421.635 & 203.209 & 52.871 & 43.252 & 125.653 & -0.700 & 2.534\end{array}$ \begin{tabular}{lllllllllll}
\hline Green & -539.636 & -367.477 & -453.556 & -446.927 & 172.158 & 44.567 & 38.061 & 120.589 & 0.289 & 2.139 \\
\hline
\end{tabular}

Figure 3.14. AFM micrograph taken in tapping mode. Example of sample with high roughness: polycrystalline 3C-SiC/(100)Si (from wafer USF2-06-074- die \#4) 

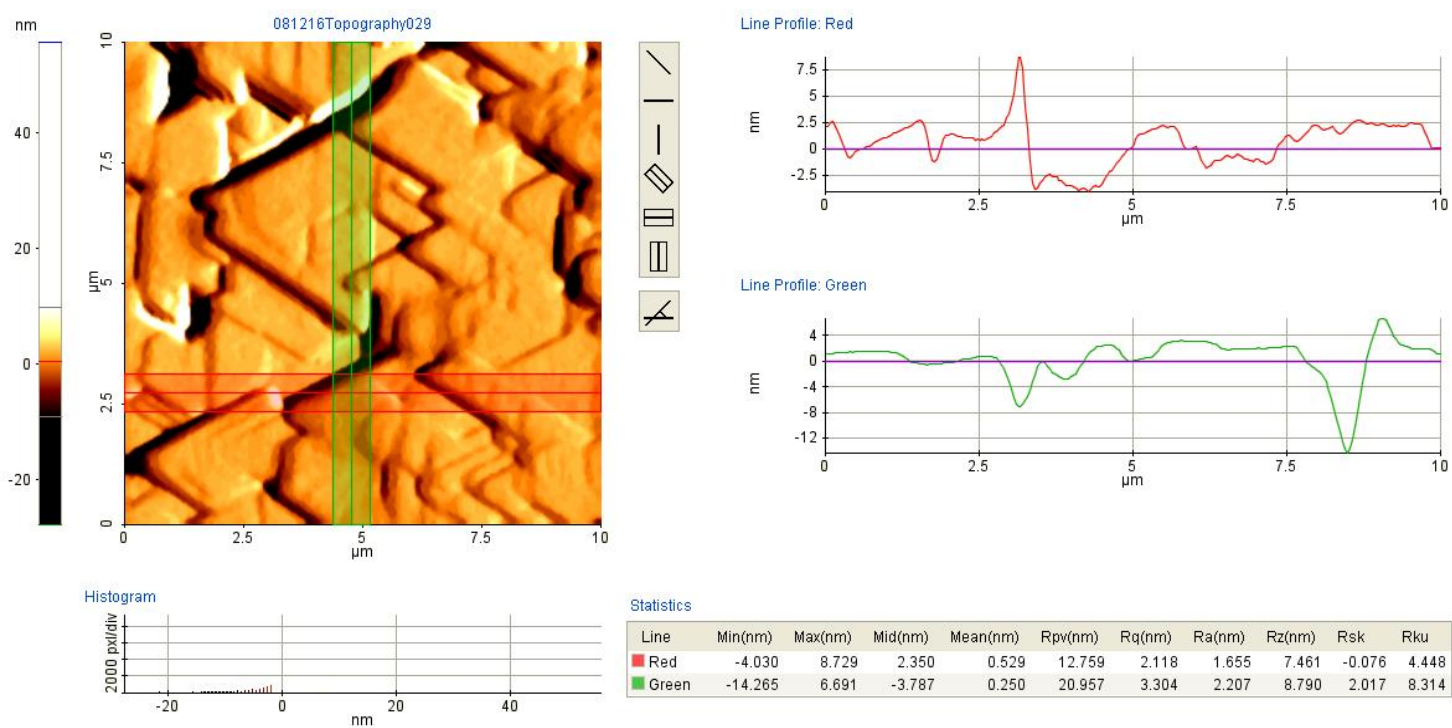

statics

ए

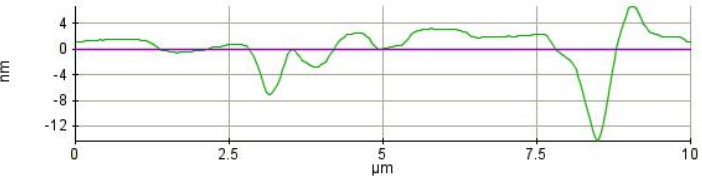

Figure 3.15. AFM micrograph taken in tapping mode. Example of sample with low roughness: single crystal 3C-SiC/(111)Si (from wafer USF -U die \#9)
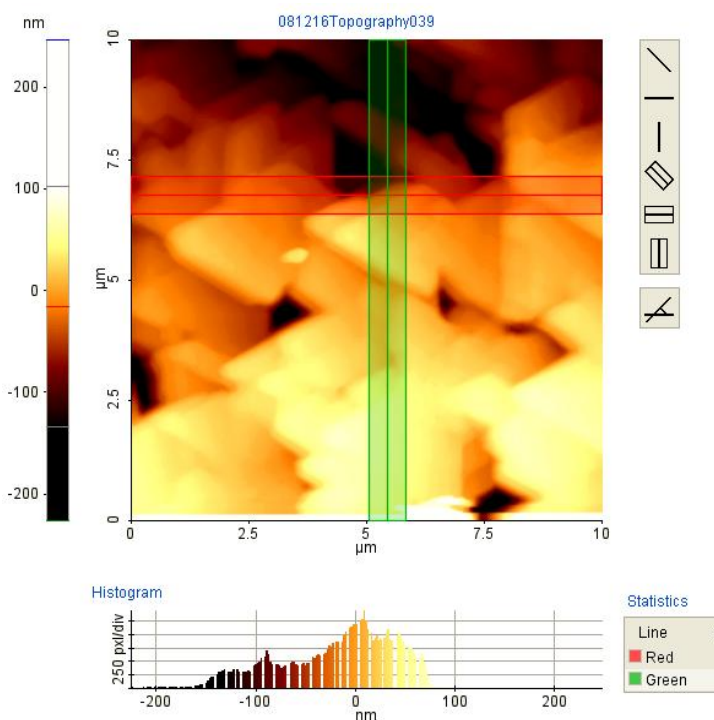

Line Profile: Red

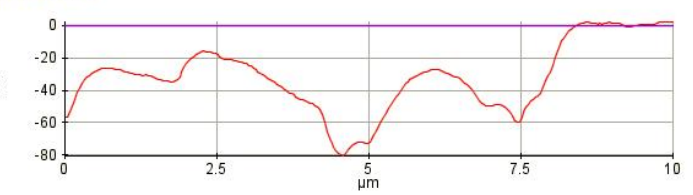

Line Profile: Green

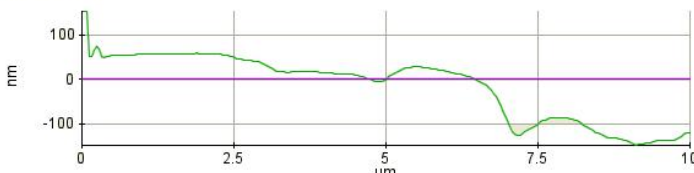

Figure 3.16. AFM micrograph taken in tapping mode. Example of sample with high roughness: single crystal 3C-SiC/(111)Si (from wafer USF -U die \#4) 

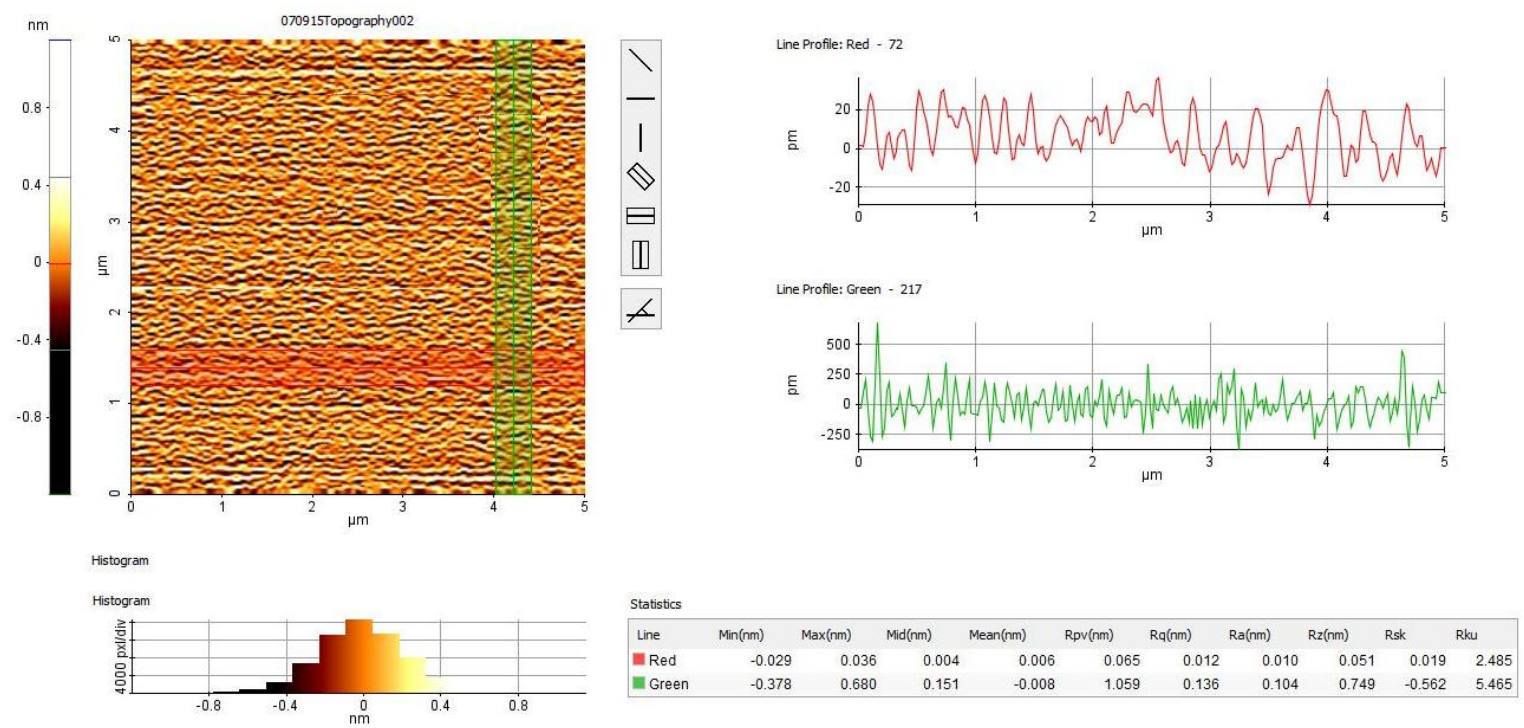

Figure 3.17. AFM micrograph taken in tapping mode. Silicon (100) sample exhibiting low roughness.

The protocol used to evaluate the effect of surface roughness was the same as described in Section 3.3. After fluorescence microscopy of the stained platelets at different levels of magnification, it was observed that there is a high density of clumps for the high-roughness surfaces that is independent of crystal orientation and surface morphology, Figure 3.19.

Low-roughness surfaces on the other hand evidenced interesting results, as shown in Figures 3.18 and 3.20. Figure 3.18 compares two low roughness surfaces, with different orientations, the optical results indicate that for comparable roughness, crystal orientation may have an impact on platelet reactivity. Figure 3.20 shows high platelet adhesion, activation and clump formation on a low-roughness $\mathrm{Si}$ surface; comparison of these images with the left images in Figure 3.18 indicate higher reactivity of $\mathrm{Si}$ versus 3C-SiC, this is, for identical conditions (both single crystal, same orientation and low roughness) which can be explained by the fact that silicon surfaces are considerably more 
hydrophobic than the SiC surfaces [9]; it is a well known fact that adhesion proteins adhere preferentially to hydrophobic surfaces [84].

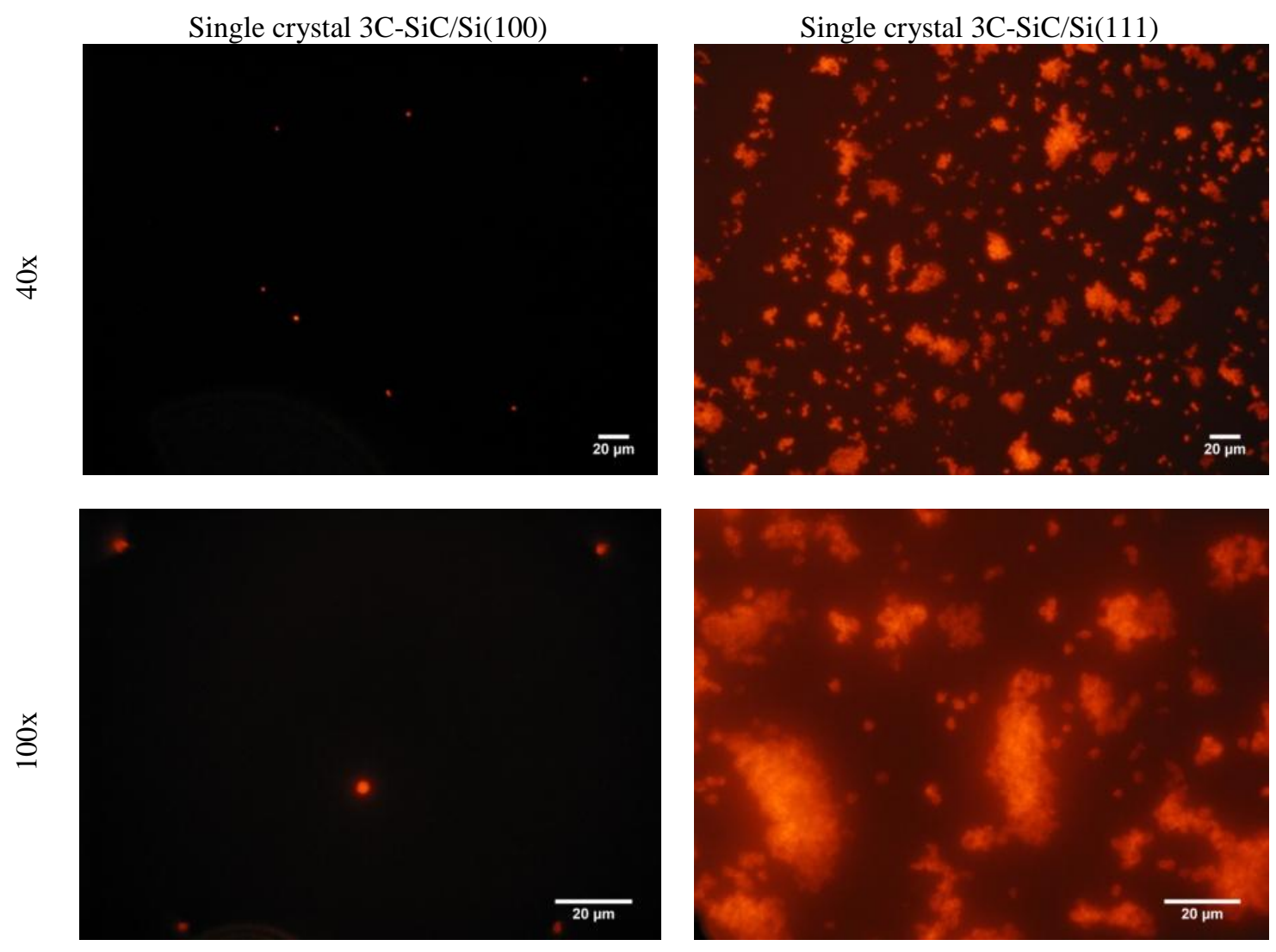

Figure 3.18. Fluorescent micrograph comparison of two low-roughness surfaces. Left: single crystal 3C-SiC/Si(100). Right: single crystal 3C-SiC/Si(111) 

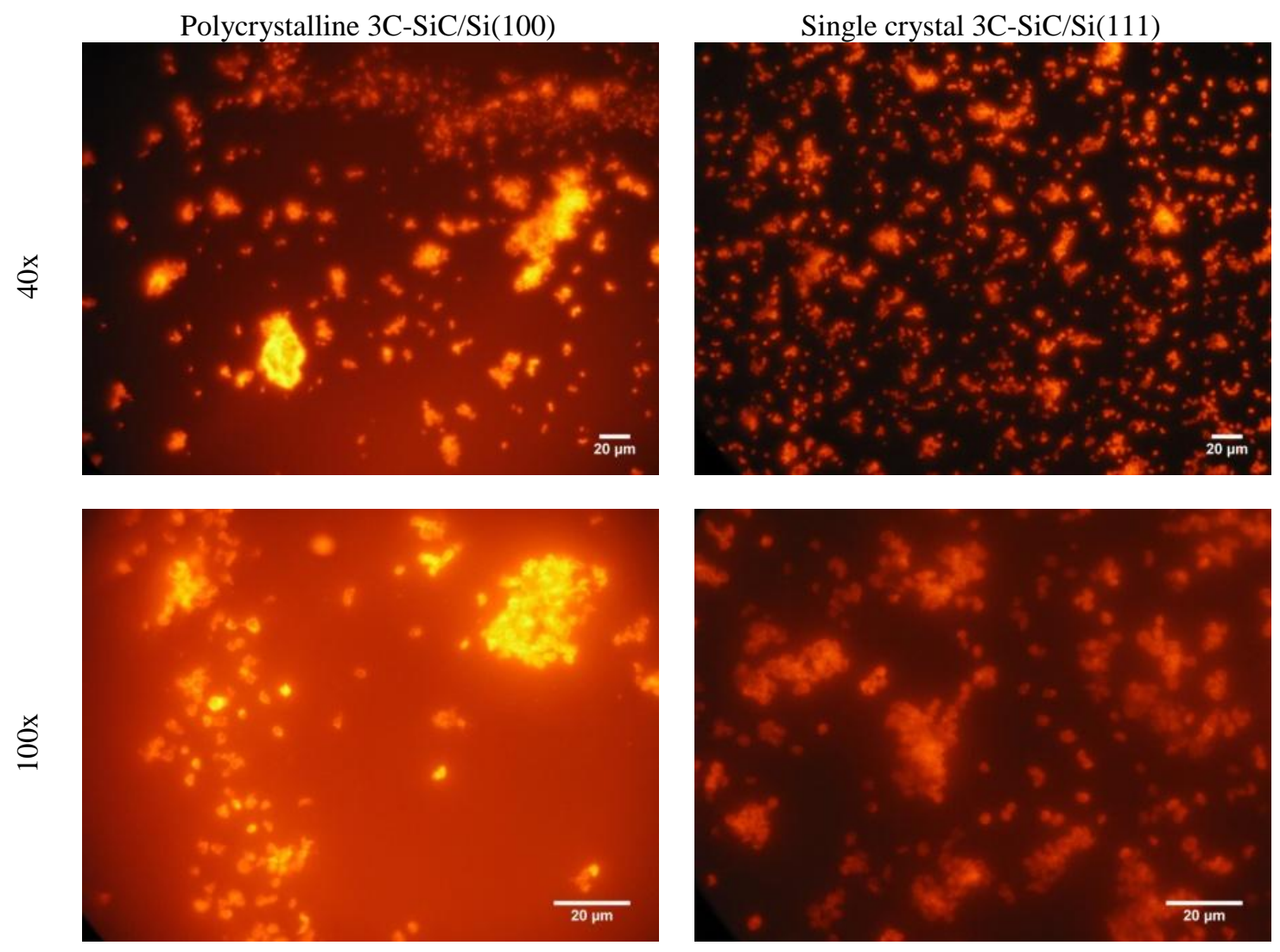

Figure 3.19. Fluorescent micrograph comparison of two high-roughness polycrystalline 3C-SiC surfaces. Left: Grown on a Si(100) substrate. Right: Grown on a Si(100) substrate
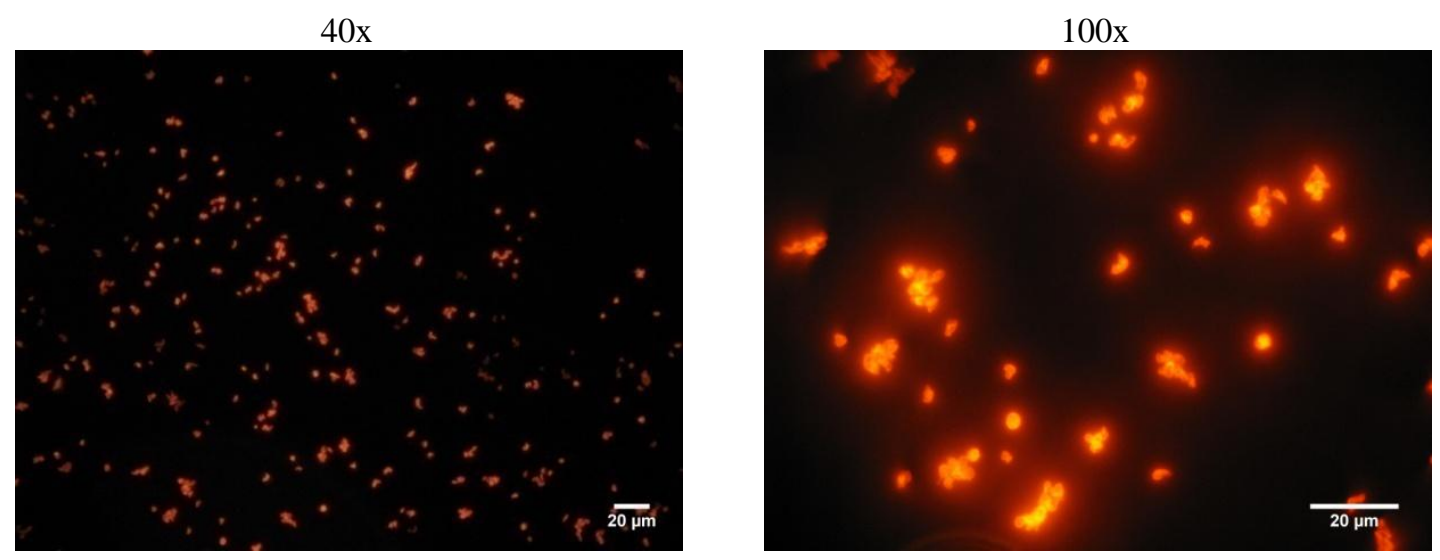

Figure 3.20. Fluorescent micrograph of platelet adhesion on a low-roughness silicon(100) surface 
Unlike the previous experiment, no particle analysis was derived from the images, as the high density of adhesion and aggregation for all the surfaces, except for the single crystal 3C-SiC/Si(100) would only result in falsified statistics.

\subsection{Discussion}

Platelet adhesion and morphology were assessed after the exposure of PRP to different $\mathrm{SiC}$ polytypes, different crystal orientations and surface roughnesses and the results were contrasted to those of $\mathrm{Si}(100)$ wafer die. The information obtained from these experiments was evaluated qualitatively, by optical (fluorescent microscopy) inspection, and quantitatively, by obtaining specific information from the images and then performing statistical analysis.

In each case single crystal $3 \mathrm{C}-\mathrm{SiC}$ grown on $\mathrm{Si}(100)$ substrates had the best performance, with low particle adhesion counts and small-area adhered platelets that also showed high platelet circularity. The former characteristics are highly desirable for cardiovascular applications as they display low thrombogenicity and reduce the chances of catastrophic failure of a device due to thrombi embolization. 


\section{Chapter. 4: $\quad$ Protein Adsorption to Surfaces}

\subsection{The Aggregation and Activation of Platelets}

Platelet aggregation is a key event in the process of thrombus formation, which results from a series of coordinated cell adhesion events. Circulating platelets are initially tethered to subendothelial matrices exposed at the vascular injury site, followed by stable platelet adhesion to the subendothelium, and adherence of additional platelets to the surface of platelets already adhered, leading to platelet aggregation. This sequence is mediated by specific receptor-ligand interactions [85] [5].

Integrin $\alpha_{\mathrm{IIb}} \beta_{3}$ (the same as glycoprotein [GP] IIb-IIIa complex) is the most abundant platelet surface membrane glycoprotein and its expression is specific to platelets and megakaryocytes. This glycoprotein is essential for platelet aggregation, as this event is mediated by the binding of fibrinogen or von Willebrand Factor (vWF) to integrin $\alpha_{\mathrm{IIb}} \beta_{3}$ (see Figure 4.1). Integrin $\alpha_{\mathrm{IIb}} \beta_{3}$ is a heterodimeric receptor that mediates platelet adhesion and signaling by modulating their affinity and avidity for adhesive ligands; this process is known as integrin activation or 'inside-out' signaling [5].

Platelet aggregation is a form of cell- to-cell adhesion that is mediated by the binding of adhesive ligands to GPIIb-IIIa. Even though platelet activation and aggregation is induced by a variety of stimuli, the aggregation response specifically requires the presence of GPIIb-IIIa. Following that logic, GPIIb-IIIa receptor antagonists have been used successfully in clinical trials as antithrombogenic agents [72] [86]. 
GPIIb-IIIa plays a fundamental role in the process of thrombus formation, either physiological (as a response to injury) or pathological (thrombosis).

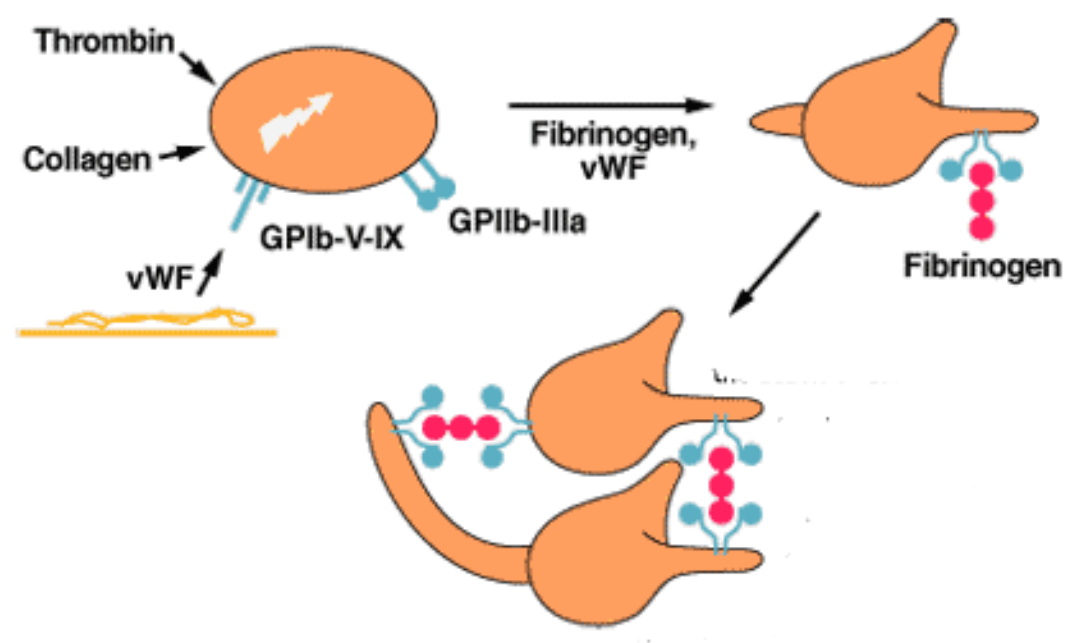

Figure 4.1. Platelet aggregation mediated by the action of fibrinogen and von Willebrand Factor (vWF) [87]

GPIIb-IIIa is expressed on the plasma membrane of the resting platelets, the membranes of their $\alpha$-granules and the open canalicular system as $\mathrm{Ca}^{2+}$-dependent heterodimers. Additionally, it can bind to several macromolecular adhesive glycoproteins (e.g., fibrinogen, vWF, fibronectin, and vitronectin, prothrombin and neural cell adhesion molecule L1). Arginine-Glycine-Aspartic acid, known as RGD, is a sequence present in the ligands that bind to GPIIb-IIIa, that serve as a recognition motif promoting cell-to-cell and cell-to-matrix adhesion [88]. In resting platelets GPIIb-IIIa has a low activity for ligand binding, but when platelets are exposed to a soluble antagonist (e.g. thrombin) or subendothelial matrices, their ability to bind ligands increases rapidly. Stimuli engage specific membrane receptors that induce cytoplasmic intracellular signals that activate GPIIb-IIIa. The ligand necessary for platelet aggregation in vitro is fibrinogen [72] [5]. 


\subsection{The QCM Technology}

The quartz crystal microbalance (QCM) is basically a mass sensing device with the ability to measure very small mass changes on a quartz crystal resonator in real-time. The sensitivity of the QCM is approximately 100 times higher than an electronic fine balance with a sensitivity of $0.1 \mathrm{mg}$ [89]. This means that QCM's are capable of measuring mass changes as small as a fraction of a monolayer or single layer of atoms [90].

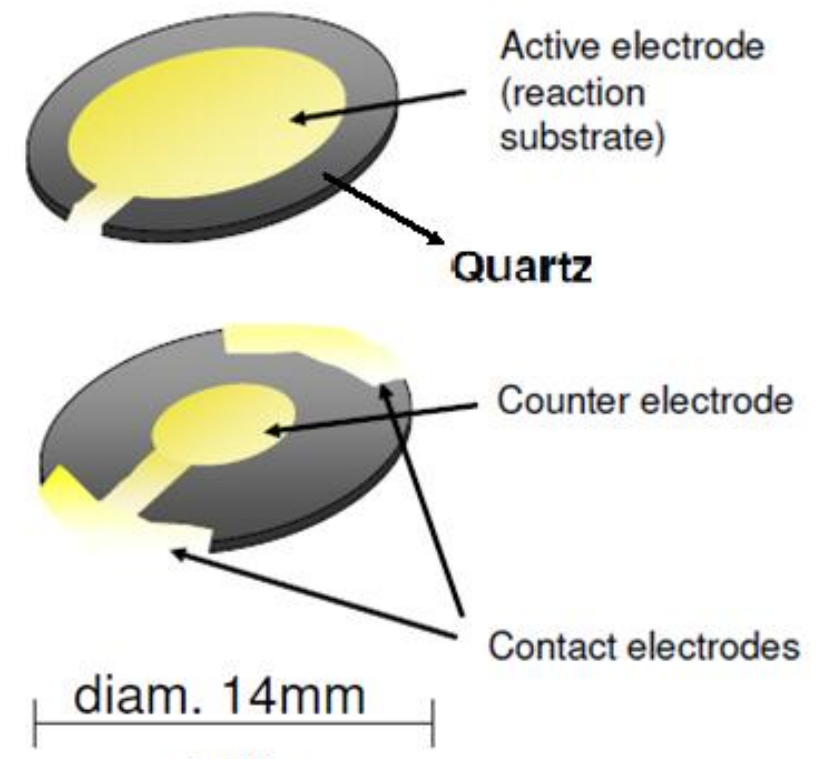

\section{$5 \mathrm{MHz}$}

Figure 4.2. Diagram of a quartz crystal sensor [91]

The high sensitivity and the real-time monitoring of mass changes on the sensor crystal make QCM a very attractive technique for a large range of applications, including its use under vacuum and, more recently its use with fluids or with viscoelastic deposits. The QCM principle of operation is based on a piezoelectric quartz crystal sandwiched between a pair of electrodes (see Figure 4.2) [90] [89]. When the electrodes are connected to an oscillator and an AC voltage is applied over the electrodes, the quartz 
crystal starts to oscillate at its resonance frequency due to the piezoelectric effect. This oscillation is generally very stable due to the high $\mathrm{Q}$ factor.

If a thin, non-dissipative layer is evenly deposited on the active electrode the resonant frequency will decrease proportionally to the mass of the adsorbed layer according to the Sauerbrey relationship [90], where $\Delta f$ is linearly related to the adsorbed mass

$$
\Delta m=C \frac{\Delta f}{n}
$$

where $\mathrm{C}$ is a constant based on the physical properties of the quartz crystal $(C=$ $17.7 \frac{\mathrm{ng}}{\mathrm{cm}^{2} \mathrm{~Hz}}$ at $\left.f=5 \mathrm{MHz}\right)$ and $n$ is the overtone number $(n=1,3,5, \ldots)$.

If the damping of the deposited layers can be considered to be negligible, then the QCM is used in order to study the dissipative processes on the quartz crystal. The Sauerbrey relationship is not applicable for hydrated, highly viscous surface-adsorbed protein layers that result in high dissipation shifts [90]. In those cases, in addition to measuring the frequency, the dissipation is often measured to help with the analysis and the techinique is called QCM-D, where the D stands for dissipation. The dissipation is a parameter quantifying the damping in the system, and is related to the sample's viscoelastic properties. Theorethical modeling of the response using dissipation requires the use of a Voigt model, that characterizes the adsorbed layer using the following parameters: effective density $(\rho)$, shear viscosity $(\eta)$, shear elastic modulus $(\mu)$ and thickness $(\delta)$ [90] [72]. This method has been used mainly to study the interactions of proteins (including blood serum proteins) with film coatings, especially polymeric coatings [88] [92] [93]. 


\subsection{Protein Adsorption Assessment Using QCM-D}

Platelet aggregation is the primary mechanism of haemostatic control. It is widely accepted that the hemocompatibility of a material is highly dependent of platelet activation and aggregation onto its surface, which at the same time is dependent upon the binding of fibrinogen to the surface of the material and of activated platelets which is mainly mediated by platelet receptor GPIIb-IIIa [85]. Adsorption of plasma proteins to materials influences the plasmatic (coagulation and complement) and cellular activation pathways [72] [94].

These adhesive proteins, particularly fibrinogen, adsorb to surfaces within seconds of contact. It has been reported in [95] that platelet adhesion to surfaces, in vitro, and preadsorbed with plasma is mediated exclusively by fibrinogen and does not involve other adhesion plasma proteins. Therefore a better insight into fibrinogen adsorption to surfaces and platelet membrane receptor binding efficiency will provide a better understanding of the hemocompatibility of a material.

QCM-D can monitor the formation of protein layers adsorbed onto the surface of a quartz crystal in real time, by monitoring the resonant frequency shifts. In this study we monitored the binding kinetics of purified GP IIb-IIIa to adsorbed fibrinogen using the methods and protocols described in [72] and [96].

In order to assess the protein adsorption to $3 \mathrm{C}-\mathrm{SiC}$ and compare it to $\mathrm{Si}$, custom made sensors were ordered from Q-Sense® [91]. We obtained four SiC coated sensors, four gold (i.e., standard QCM-D surfaces), four silicon coated and four nanocrystalline diamond (NCD) coated sensors. The gold sensors were used as sample controls, as it is known that gold is used for blood contacting applications, and the NCD sensors to start 
exploring the hemocompatibility of this material due to the interest generated after Dr. Frewin's research [11]. The main purpose was to compare fibrinogen and GPIIb-IIIa adsorption to 3C-SiC vs. Si.

Protein-free TRIS buffer (Tris(hydroxymethyl)aminomethane) was prepared using Trizma ${ }^{\circledR}$ HCL (cat. 1185-53-1), Trizma ${ }^{\circledR}$ Base (cat. 77-86-1) from Sigma ${ }^{\circledR}-A l d r i c h$ and deionized water (with a resistivity of at least $16 \mathrm{M} \Omega \cdot \mathrm{cm}$ ), to obtain a $50 \mathrm{mM}$ solution with a $7.4 \mathrm{pH}$ at $37^{\circ} \mathrm{C}$. Divalent cations were added to the TRIS buffer as they are required for GPIIb-IIIa binding to ligands [72] [5] [97] as follows: $100 \mathrm{mM} \mathrm{NaCl}$ (Sigma®®-Aldrich, cat. S5886-500G), $1 \mathrm{mM} \mathrm{MgCl}$ (Sigma®-Aldrich, cat. M8266-100G), $1 \mathrm{mM} \mathrm{CaCl}_{2}$ (Fisher, cat. S71924) and $1 \mathrm{mM} \mathrm{MnCl} 2$ (Fisher, cat. M87-500).

Human fibrinogen (cat. 341575) and human platelet receptor GPIIb-IIIa (cat. 528240) were obtained from Calbiochem ${ }^{\circledR}$ and prepared to the following final working concentrations: fibrinogen $50 \mu \mathrm{g} / \mathrm{mL}$ and GPIIb-IIIa $10 \mu \mathrm{g} / \mathrm{mL}$.

Bovine serum albumin (BSA) was obtained from Fisher Scientific (Cat. BP671-10) and prepared at a working concentration of $10 \%$ BSA (w/v). BSA was used to block nonspecific GPIIb-IIIa binding to the surfaces.

Hydrogen peroxide (cat. 216763-100) and ammonium hydroxide (cat. 320145$500 \mathrm{ML}$ ) were obtained from Sigma ${ }^{\circledR}$-Aldrich and used to clean the quartz crystal sensors ( $\mathrm{Au}, \mathrm{Si}, \mathrm{SiC}$ and $\mathrm{NCD}$ ) following the protocol A-I from Q-Sense ${ }^{\circledR} .2 \%(\mathrm{w} / \mathrm{v})$ of sodium dodecyl sulfate (SDS) from Sigma®-Aldrich (cat. L4390-100G) was prepared in DIwater in order to rinse extensively the Q-sense instrument chambers before and after every experiment. 
Fibrinogen adsorption and the corresponding binding of the platelet receptor (GPIIbIIIa) to quartz crystals with a fundamental resonant frequency of $5 \mathrm{MHz}$ coated with $\mathrm{Si}$, $\mathrm{SiC}$ and NCD was measured. Frequency shifts versus time curves, induced by sequential adding of protein solutions (human fibrinogen, BSA, human GPIIb-IIIa), were recorded.

Each protein solution was incubated until the binding saturation was reached, followed by a TRIS buffer rinse in order to remove non-bound proteins.

All experiments were repeated six times using the Q-Sense® E4 monitoring system at $37^{\circ} \mathrm{C}$, in TRIS buffer under non-flow conditions and allowing the liquid in the QCM-D chambers to exchange in every step via gravitational flow. $1.5 \mathrm{~mL}$ of solution per chamber (TRIS, fibrinogen, BSA, GPIIb-IIIa) was loaded in every step and was sufficient to fill the chambers and to allow for fluid exchange. All the solutions were degassed before exposure to the chambers and crystal surfaces.

Frequency shifts induced by adsorbed proteins were monitored in real time at three, five, and seven times the crystal's natural frequency of $5 \mathrm{MHz}$. However, the data provided by the first overtone had better stability, higher sensitivity and less glitch-like errors, thus it was the one used for subsequent statistical analysis.

In order to obtain the baseline for the observed frequency shifts, $1.5 \mathrm{ml}$ of degassed TRIS was allowed to sit in each chamber. Once a constant baseline was obtained (and the values compared to the acceptable values provided by Q-Sense $\left.{ }^{\circledR}\right)$ the sensors were exposed to the fibrinogen solution until saturation was reached, then it was followed by TRIS rinsing and BSA incubation for 30 minutes. Next, the BSA was rinsed with a TRIS buffer and the chambers filled with GPIIb-IIIa. The solution was allowed to sit until saturation was reached. The chambers were rinsed thoroughly again using TRIS (see 
Figure 4.3). The measurements were stopped and the sensors and chamber cleaned using SDS.

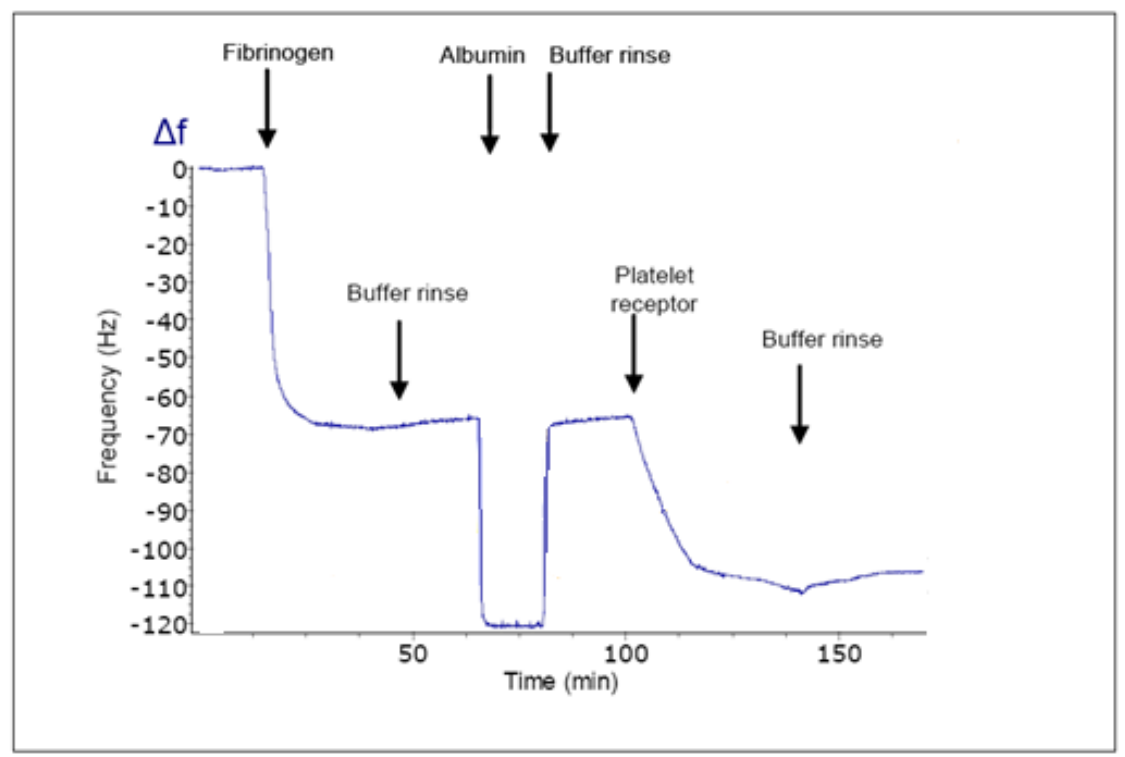

Figure 4.3. Sequence of steps of a typical hemocompatibility assesment using a Q-sense device. TRIS buffer (50 mM TRIS, pH7.4 at $37^{\circ} \mathrm{C}$ containing $100 \mathrm{mM} \mathrm{NaCl}, 1 \mathrm{mM}$ $\mathrm{MgCl} 2,1 \mathrm{mM} \mathrm{CaCl} 2$ ).Fibrinogen concentration $50 \mu \mathrm{g} / \mathrm{ml}$, BSA 10\%w/v, GPIIb-IIIa 10 $\mu \mathrm{g} / \mathrm{ml}$. Adapted from [96].

After every experiment the sensors were cleaned (Q-Sense ${ }^{\circledR}$ 's cleaning protocol A-I) using an UV/Ozone chamber for 10 minutes, followed by dipping the sensor in a $\mathrm{H}_{2} \mathrm{O}_{2}$ (30\%), $\mathrm{NH}_{4} \mathrm{OH}(25 \%)$, and DI-water solution in a 1:1:5 ratio for $5 \mathrm{~min}$ at $75^{\circ} \mathrm{C}$. The sensors were rinsed with DI-water, dried using nitrogen gas and stored in a desiccator, to avoid surface changes due to contact with contaminated air.

\subsection{Results}

The custom made coated quartz sensors were created by sputtering the material of the desired coating onto the surface of existing gold sensors. Unfortunately the NCD films 
peeled off from the gold surface after the cleaning and no measurements were obtained for those films.

Additionally, after XRD, it was found that the $\mathrm{SiC}$ sensors did not correspond to 3C$\mathrm{SiC}$ (as it was requested) but to $4 \mathrm{H}-\mathrm{SiC}$. This unfortunate event did not allow the direct comparison of 3C-SiC versus Si that was desired for this experiment.

Figure 4.4 shows a histogram of the frequency shifts due to the loading of fibrinogen and GPIIb-IIIa for gold, silicon and 4H-SiC. From the statistical results (expressed as the mean \pm standard deviation) it is evident that there is much more fibrinogen adsorption on $\mathrm{Si}$ and $4 \mathrm{H}-\mathrm{SiC}$ than on gold and the opposite is observed for GPIIb-IIIa.

In order to confirm these results ANOVA analysis (see Figure 4.5) and paired T-test with Bonferroni adjustment were performed at a confidence level of $95 \%$ and it was confirmed that the behavior of $4 \mathrm{H}-\mathrm{SiC}$ was not statistically different from silicon. Gold instead displayed significant differences from $4 \mathrm{H}-\mathrm{SiC}$ and $\mathrm{Si}$.

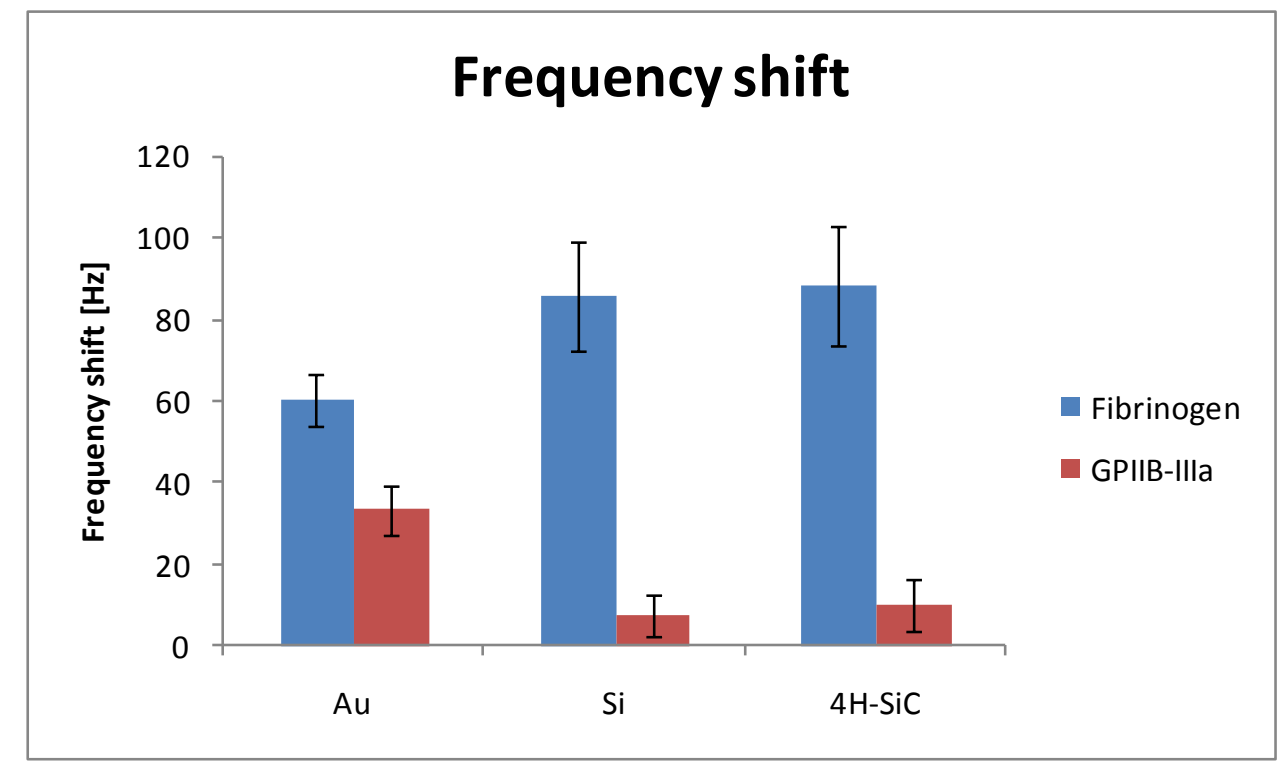

Figure 4.4. Histogram of the fribrinogen and GPIIb-IIIa adsorption to gold, silicon and $4 \mathrm{H}-\mathrm{SiC}$ substrates. Measurements made using a Q-Sense ${ }^{\circledR} \mathrm{E}-4$ QCM-D tool in the USF FCoE BITT laboratory [98] 


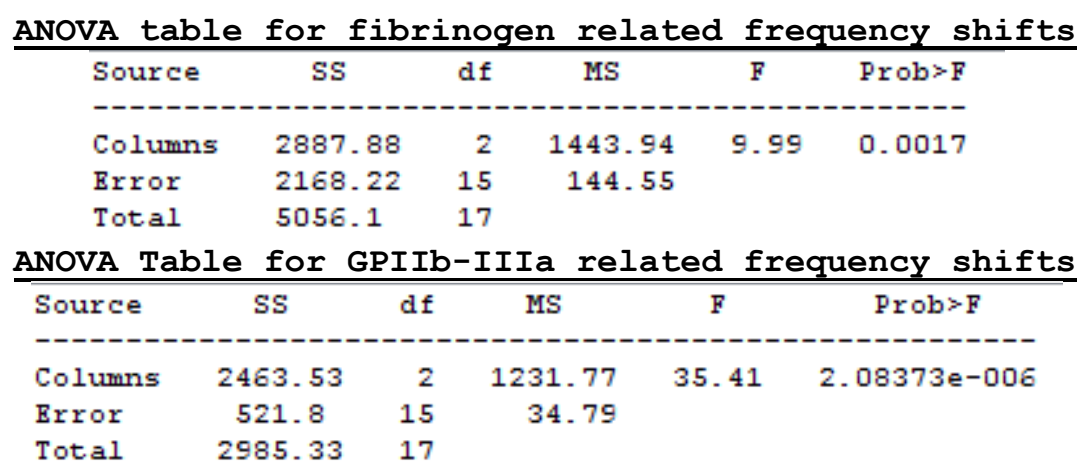

Figure 4.5. ANOVA tables of the statistical data for Fibrinogen (top) and GPIIb-IIIa (bottom). Notice the low $p$ value that indicates that statistical differences exist in at least one pair of means.

Interestingly, $4 \mathrm{H}-\mathrm{SiC}$ and $\mathrm{Si}$ presented high levels of Fibrinogen adsorption to their surfaces. However, the percentage of GPIIb-IIIa that bound to the adsorbed fibrinogen was less than the one that bound to gold.

The purpose of these experiments was to determine which material had higher degree of protein adsorption. The substrates used were hard and non-viscous and the observed dissipation values were negligible (the maximum value observed was $3.4 \times 10^{-6}$ for GPIIb-IIIa on gold,) and therefore Voigt models were not derived. Instead the mass adsorption (expressed in $\mathrm{ng} / \mathrm{cm}^{2}$ ) was derived using the Sauerbrey relationship (See Figure 4.6). 


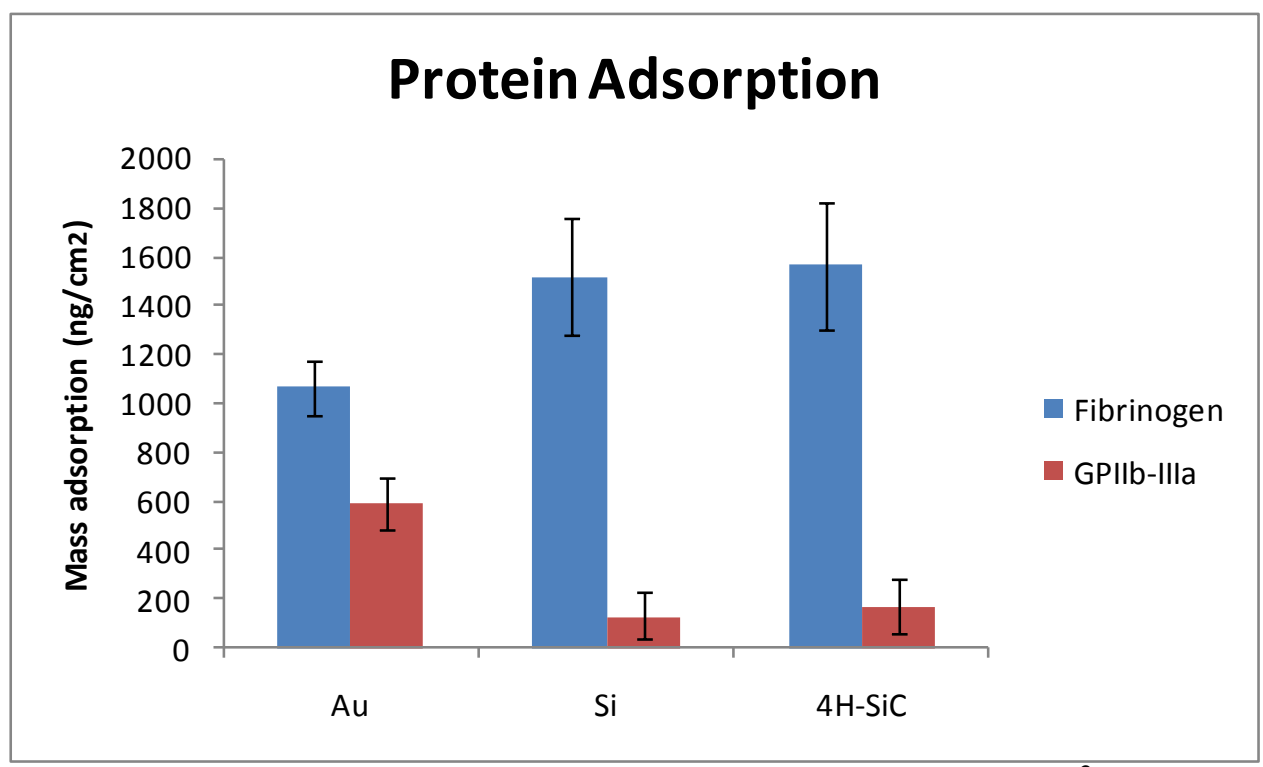

Figure 4.6. Histogram of the fribrinogen and GPIIb-IIIa mass $\left(\mathrm{ng} / \mathrm{cm}^{2}\right)$ adsorption to gold, silicon and 4H-SiC substrates. Measurements made using a Q-Sense ${ }^{\circledR}$ E-4 QCM-D tool in the USF FCoE BITT laboratory [98]

\subsection{Discussion}

From the previous platelet assessment experiment, we know that $4 \mathrm{H}-\mathrm{SiC}$ performs similarly to $\mathrm{Si}$. These results were confirmed by the protein adsorption assessment using QCM technology.

Unfortunately this experiment did not provide the desired information regarding hemocompatibility of $3 \mathrm{C}-\mathrm{SiC}$.

Additionally, as more of the fibrinogen that adhered to gold mediated GPIIb-IIIa binding, this result also implies a higher thrombogenic behavior of the gold surfaces used in these experiments. Further experiments involving the interaction of platelets with these protein layers, in order to determine if these values are directly correlated with higher platelet aggregation to these surfaces in vitro, are required.

The small values for dissipation observed in these experiments contradict the results reported in [99], where the dissipation was not negligible, and because the substrates for 
those experiments were polymeric films, that most likely were being hydrated as the experiments were performed. 
Chapter. 5: Microvascular Endothelial Cell Proliferation on Semiconductor Substrates

\subsection{Microvascular Endothelial Cells and the Vessel Internal Lumen}

Blood supply to the different tissues in the body depends on the blood vessels. The internal lining of the blood vessels is composed of endothelial cells, the natural nonthrombogenic surface of the human body. If the continuity of the endothelial layer is disrupted, this event initiates the activation of the clotting cascade. Endothelial cells form the interface between the cells in the lumen and the vessel wall creating a flat pavementlike pattern that seals the vessel [100]. Endothelial cells are very flat, have a central nucleus, are about 1-2 $\mu \mathrm{m}$ thick and some 10-20 $\mu \mathrm{m}$ in diameter [100], as shown in Figure 5.1.

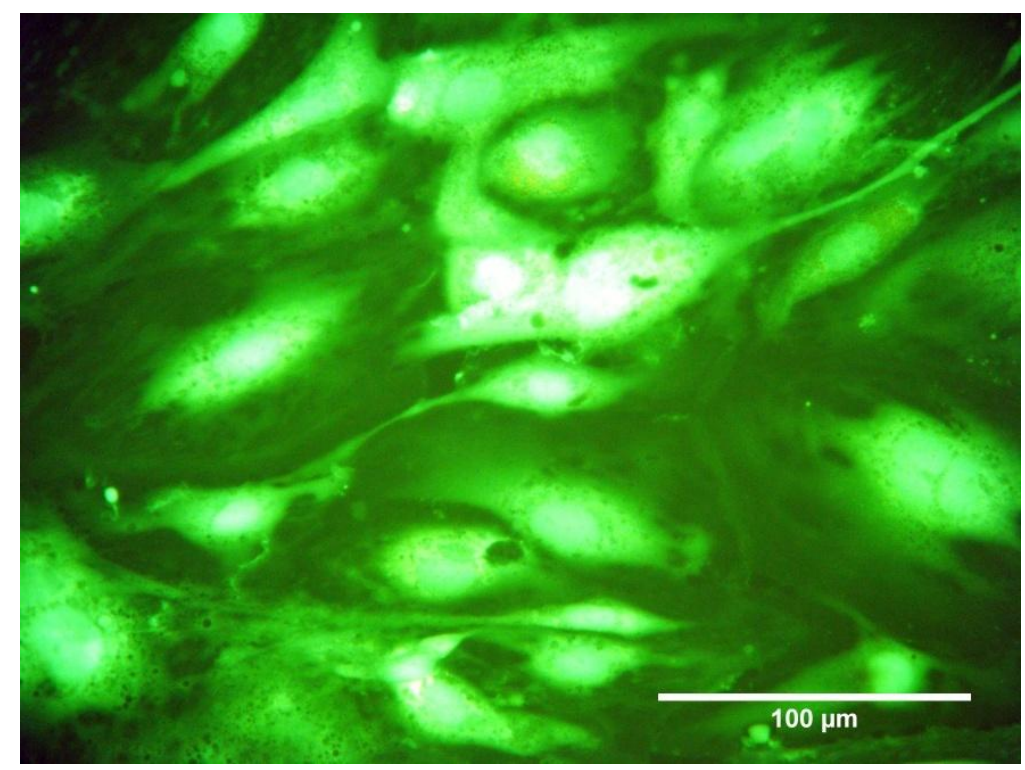

Figure 5.1. Fluorescent micrographs illustrating the pavement-like pattern of the endothelial cells. Endothelial cells were stained using CMFDA cell tracker dye. 
Endothelial cells are considered an adaptable life support system, extending cell migration to almost every region of the body and adjusting their number and configuration to adjust to local requirements [100]. This adjustable capability of the endothelium, the thin single sheet of endothelial cells that lines the vessel wall, is responsible for blood vessel remodeling, growth, angiogenesis (formation of new blood vessels) and repair [100]. Endothelial cells act like selective filters which regulate the passage of gases, fluids and various molecules across their cell membranes through the action of their cell surface-molecule receptors and interaction sites that usually attract leucocytes to the endothelium in the presence of inflammatory states.

Many leucocytes pass through endothelial cells, especially in capillaries as part of their normal life cycle, so that they can monitor foreign agents (antigens) in the tissues. Macrophages travel in the blood and pass through endothelial cells to gain access to various tissues of the body [100] [101]. Endothelial cells also allow large amounts of blood plasma fluids to pass through their intercellular junctions and create edemas as response histamine released after tissue damage.

Another vital function of the endothelial cells is the synthesis of the Von Willebrand's factor, essential for hemostasis [101].

Large blood vessels (i.e., arteries and veins) have a thick wall of connective tissue and many layers of smooth muscle. The lumen of the large vessels is lined by the endothelium, which is separated from the outer layer by a basal lamina, a layer of extracellular matrix found on the basal surface of epithelial cells and secreted by them (see Figure 5.2). The amounts of connective tissue and smooth muscle vary depending on the vessel diameter, but the endothelium is always present. Capillaries are fine vessels 
that are only 10-15 $\mu \mathrm{m}$ in diameter and consist merely of endothelial cells and a very fine layer of basal lamina. Apart from cartilage, every cell lies within a few $\mu \mathrm{m}$ of a capillary, thus making endothelial cells vital for the integrity of almost every tissue of the body.

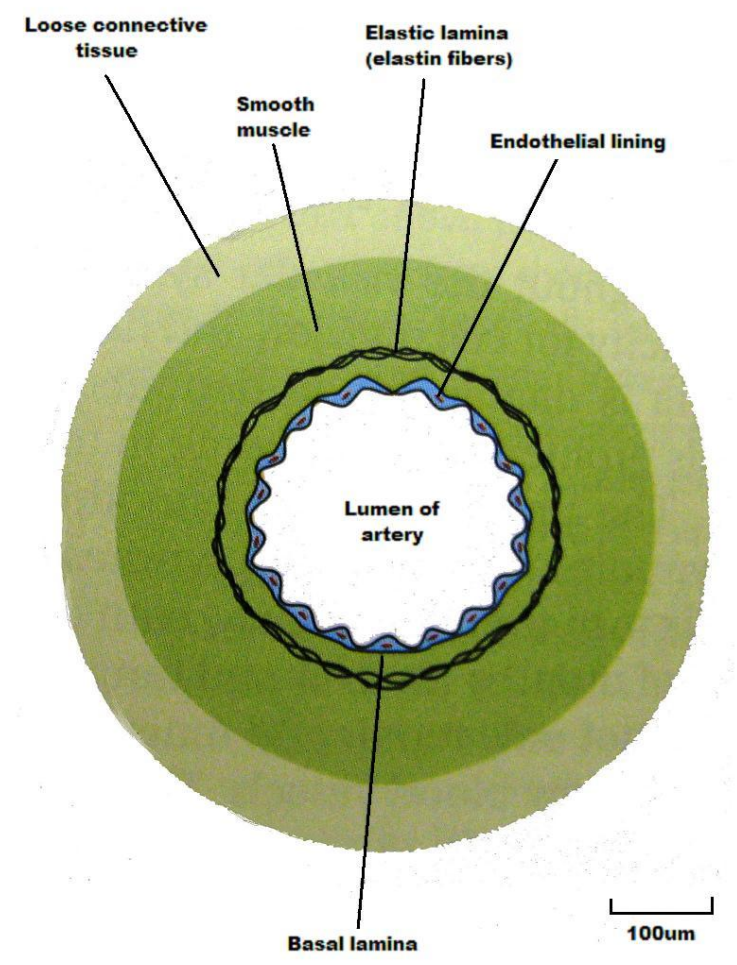

Figure 5.2. Diagram of a small artery in cross section. From [100].

Additionally, endothelial cells have mechanoreceptors that respond to shear stress due to blood flow over their surfaces and, by signaling this information to the surrounding cells, they enable the vessels to adapt their diameter and wall thickness to suit the blood flow [100]. Endothelial cells also respond to neuronal signaling related to blood vessel dilation by releasing NO gas, to make smooth muscle relax in the vessel [100]. The former phenomena of vasoconstriction and vasodilation, mediated by the endothelial cells, are the processes that regulate blood pressure [100]. 
Endothelial cells reproduce by duplication of existing endothelial cells. If a part of the vessel wall is damaged and denuded from endothelial cells, neighboring endothelial cells proliferate and migrate to the exposed area [100]. Endothelial cells not only repair existing vessels but also create new vessels (angiogenesis).

Endothelial cells line the entire vascular system, from the heart to the smallest capillary, thus a material that is biocompatible with them and also displays low thrombogenicity would provide an extra advantage for the development of cardiovascular implantable applications (e.g., sensing devices and vascular grafts).

\subsection{Cell Proliferation in Vitro: Experimental Protocol}

Cells interacting with a biocompatible surface will increase their attachment area and multiply, keeping their normal morphology, thus having greater viability than cells in contact with cytotoxic surfaces [1] [37] [102] [74].

It has been proven that $3 \mathrm{C}-\mathrm{SiC}$ has excellent biocompatible properties, however it has also been shown in [11] that some cells prefer silicon, so in the particular case of hemocompatibility of single crystal 3C-SiC versus silicon, it is necessary to evaluate cell viability and morphology on the substrates of interest. In order to assess the biocompatibility in vitro of 3C-SiC the methods outlined in the standard ISO 10993-1 [2] were used including fluorescent microscopy and measurements of cell proliferation.

Cell proliferation was measured using yellow MTT (3-(4,5-Dimethylthiazol-2-yl)2,5-diphenyltetrazolium bromide, a tetrazole)) assays [9] [11] [103]. Yellow MTT solution is reduced to purple formazan in the mitochondria of living cells. This reduction 
takes place only when mitochondrial reductase enzymes are active, and therefore conversion can be directly related to the number of viable (living) cells [104] [105].

The absorbance of this colored solution can be quantified by measurement at a certain wavelength (usually between 500 and $600 \mathrm{~nm}$ ) by a spectrophotometer [103]. The higher the cell proliferation the higher the amount of synthesized formazan and that translates to an increased absorbance value. The MTT method of cell viability determination is most useful when cultures are prepared in multiwell plates so that statistical analysis can be performed to ensure that the data is significant.

The samples used in these experiments were low roughness single crystal 3C-SiC films grown on $\mathrm{Si}(100)$ substrates and then diced into $8 \mathrm{~mm}$ by $10 \mathrm{~mm}$ die. The samples were selected from those of the platelet adhesion and morphology experiments described in (§3.2) having flat surfaces with an average roughness of $[0.25 \pm 0.11] \mathrm{nm}$, that was estimated from AFM measurements taken in taping mode.

It has been reported that cell proliferation for cells seeded on samples that have been repeatedly cleaned with piranha is reduced over time [106]. It is likely that repeated piranha immersions may decrease the carbon concentration in the near surface region of the SiC samples altering their surface wettability and biocompatibility. Piranha cleans of a specific sample should be limited to a maximum of five as a precaution for cell proliferation [106].

As the samples were used in several experiments that involved piranha cleaning, they were hydrogen etched at 150 Torr pressure flowing 3 SLM of Pd (Palladium membrane)purified hydrogen, for 30 minutes at $1200^{\circ} \mathrm{C}$. in a hot-wall CVD reactor specifically designed for 3C-SiC growth and processing, which is described in [107] as the optimum 
method for 3C-SiC Hydrogen etching. 3C-SiC and $\mathrm{Si}$ die semiconductor samples where cleaned following the protocol described in (\$3.2) prior to any cell proliferation experiment.

A normal human microvascular endothelial cell (HMVEC) line, cryopreserved from adult dermis and capable of at least 16 population doublings, was obtained from GIBCO ${ }^{\circledR}$ Invitrogen ${ }^{\mathrm{TM}}$ (Cat. C-011-5C) [108]. The cells were cultured in Corning ${ }^{\circledR}$ Cellbind ${ }^{\circledR} 75 \mathrm{~mm}^{2}$ culture flasks from Fisher scientific (Cat. 07-202-515) that were coated with attachment factor (GIBCO ${ }^{\circledR}$ Invitrogen ${ }^{\mathrm{TM}}$ Cat. S-006-100) containing gelatin at $0.1 \%$ [109]. The cells were grown using basal Medium 131 (GIBCO ${ }^{\circledR}$ Invitrogen $^{\mathrm{TM}}$ Cat. M-131-500) supplemented with Microvascular Growth Supplement (MVGS) (GIBCO ${ }^{\circledR}$ Invitrogen ${ }^{\mathrm{TM}}$ Cat. S-005-25) [109], containing fetal bovine serum (5\% v/v final concentration), hydrocortisone, recombinant human fibroblast growth factor, heparin, recombinant human epidermal growth factor, and dibutyryl cyclic AMPand, and $1 \%$ penicillin-streptomycin. The cells cultures were incubated in a $37^{\circ} \mathrm{C}, 5 \% \mathrm{CO}_{2} / 95 \%$ air, and humidified cell culture incubator.

When the cultures reached $80 \%-90 \%$ confluence they were collected through trypsination (using Trypsin/EDTA solution and Trypsin neutralizer), centrifuging at $180 \mathrm{~g}$ for 7 minutes and resuspending the cell pellet in supplemented Media 131. The density of the cell suspension was later determined using a hemocytometer.

The cells were seeded then on BD Falcon ${ }^{\mathrm{TM}}$ primaria tissue culture 24-multiwell plates (Fisher Cat. 08-772-4G), with flat bottom and enhanced reproductivity due to a stable modification of the polystyrene surface that allows the proliferation of cell lines 
that grow poorly on standard tissue culture surfaces, and used as controls. Six wells were pre-treated with attachment factor prior to cell seeding.

Six 3C-SiC/Si(100) die and six $\operatorname{Si}(100)$ die were used per experiment and each experiment was repeated 3 times for each of the samples (i.e. three repetitions and 6 sample replicates per experiment). The samples were seeded with HMVEC after sample cleaning and placement in an ultra-low attachment 24-multiwell plate from Corning® (Fisher Cat. 07-200-602), in order to prevent cell migration and growth on the well surface in case this was more biocompatible than the semiconductor samples. The area of the wells used in these experiments was $200 \mathrm{~mm}^{2}$. Figure 5.3 presents a schematic of the sample positioning in the multiwell plates.

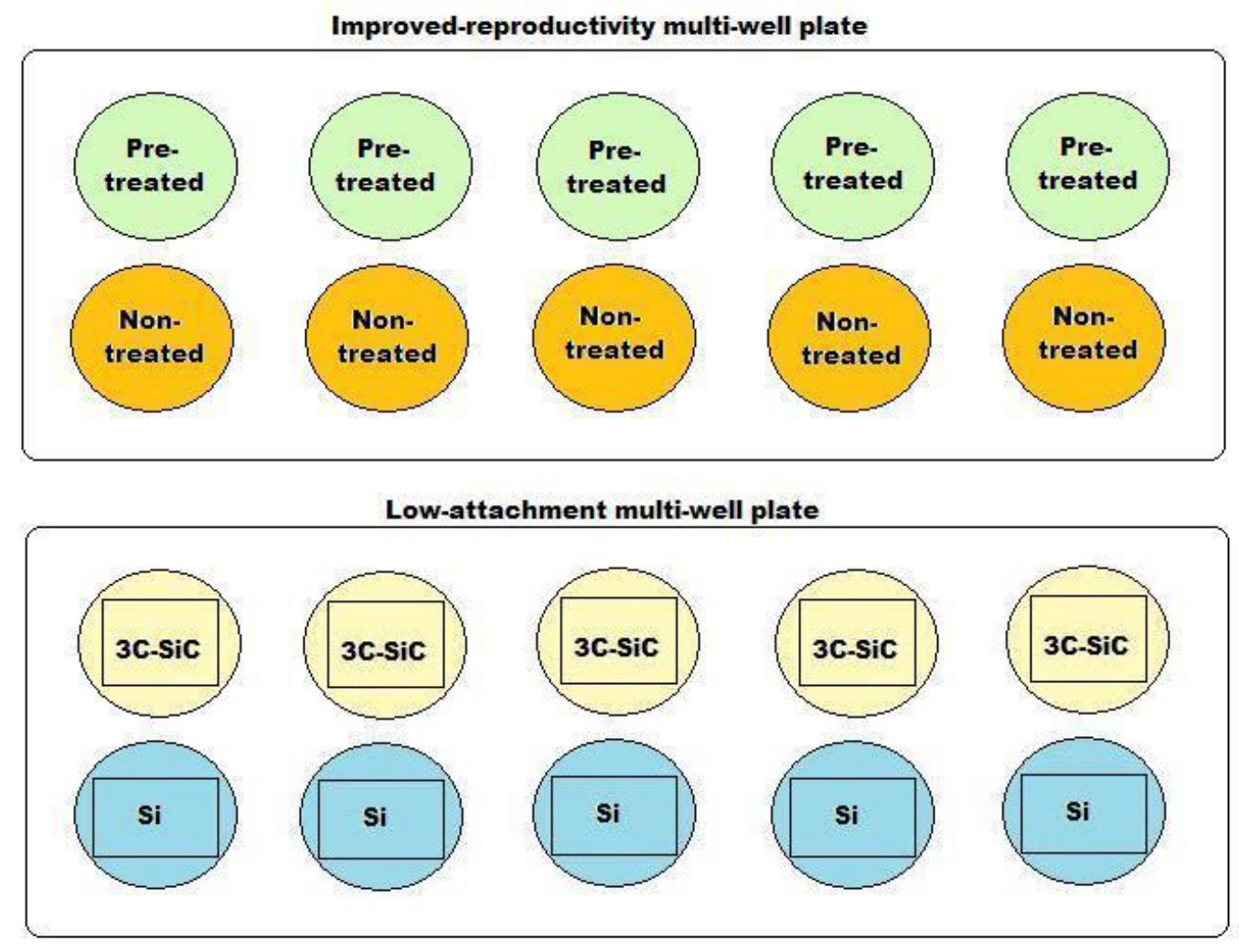

Figure 5.3 Schematic representation of sample position for cell plating experiments. Die size $8 \mathrm{~mm} \times 10 \mathrm{~mm}$. 
The cells were seeded on the samples at a density of $15 \times 10^{3}$ cells $/ \mathrm{cm}^{2}$ (determined experimentally to avoid cell confluence before 168 hours), and the volumes of cell suspension deposited on the samples scaled according to the respective plating areas (200 $\mathrm{mm}^{2}$ for the plates versus $80 \mathrm{~mm}^{2}$ for the semiconductor die), as described in [110], followed with the addition of $2 \mathrm{ml}$ of supplemented Medium 131, that was changed on a daily basis.

After seeding, all the plated cells were incubated at $37^{\circ} \mathrm{C}$ for 72,120 and 168 hours in an air atmosphere containing $5 \% \mathrm{CO}_{2}$ and $95 \%$ relative humidity. Next MTT assays measurements were performed, using the BioTek Synergy 2 SLFA plate reader operating at a wavelength of $540 \mathrm{~nm}$, following the protocols in [34] [106] [103]. In order to reduce sampling error in the absorbance measurement, 3 drawings of diluted formazan were obtained per sample (replicates) and then averaged.

The measurements were normalized with respect to the average of the treated control wells and expressed as sampling distribution of the mean $(\mu) \pm$ standard error of the mean $(\sigma)$. The collected data was compared using ANOVA analysis and paired T-test with Bonferroni adjustment, in order to determine significant differences between the samples (treated wells, non-treated wells, 3C-SiC and $\mathrm{Si}$ ) distributions.

The attached HMVEC were also stained using a fluorescent CellTracker ${ }^{\mathrm{TM}}$ probe (Green CMFDA from Invitrogen, Cat. C2925) at a working concentration of $0.5 \mu \mathrm{M}$ [111]. This probe is retained in living cells, after passing freely through the cell membrane and being transformed into cell-impermeant fluorescent dye. Living-cell staining allowed for cell proliferation, morphology and adhesion quality assessment. Fluorescence microscopy was performed using a Leica DM2000 compound microscope 
for the control wells and a Leica DM IL inverted microscope for the wafer die. The results of the MTT assays and fluorescence microscopy are discussed in section (§5.3).

\subsection{MTT Assay and Fluorescent Microscopy Results}

Figure 5.4. displays the statistical analysis of the MTT readings after 72 hours. No statistical differences were observed among the different substrates and this was confirmed after ANOVA analysis, which yielded a large $p$ value $(p=0.598)$. This result was consistent with the observed degree of cell proliferation on the different substrates, obtained by fluorescence microscopy (see Figure 5.5). The adherent cells showed similar morphology, and good adhesion indicating no preferential adhesion to any particular substrate.

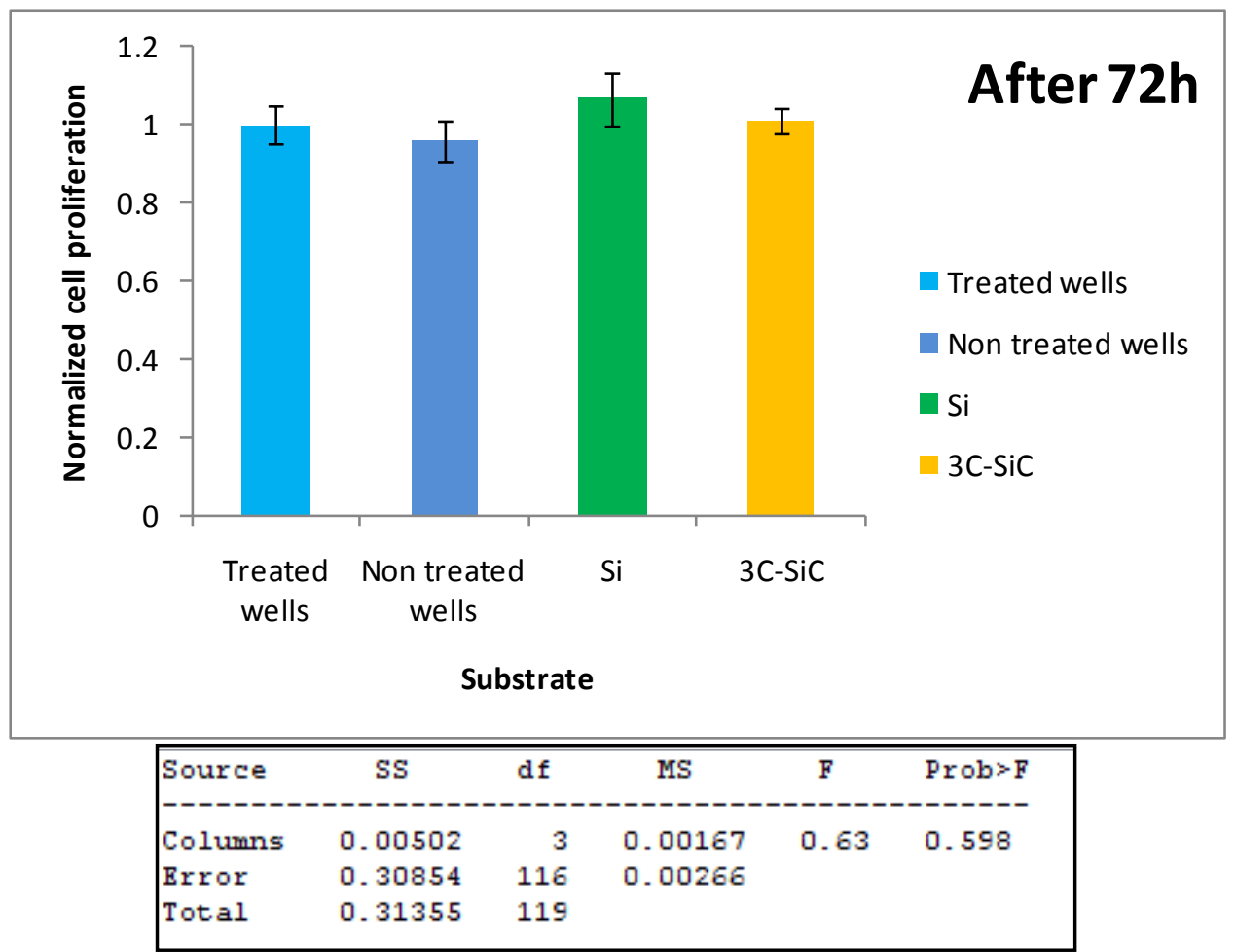

Figure 5.4. (Top) Histogram displaying the normalized results (respect to the treated wells) of the MTT assay after 72 hours. (Bottom) ANOVA table of the measured data. 

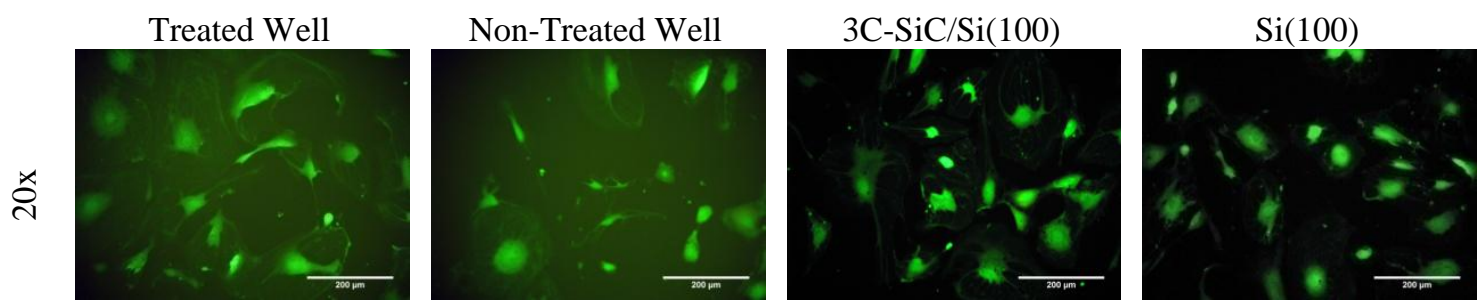

Figure 5.5. Fluorescent micrographs of HMVEC proliferation on various substrates (treated well, non treated well, 3C-SiC and Si) after 72 hours.

Previous research on mammalian cell adhesion to $\mathrm{SiC}$ has shown that significant differences in cell proliferation are typically observed after increasing the culturing time, as long as confluence is not reached [106] [11]. Following the same rationale HMVEC were cultured on the different substrates for longer times (i.e. 120 and 168 hours) in order to determine if the cells had a different proliferation rate with time on any particular substrate.

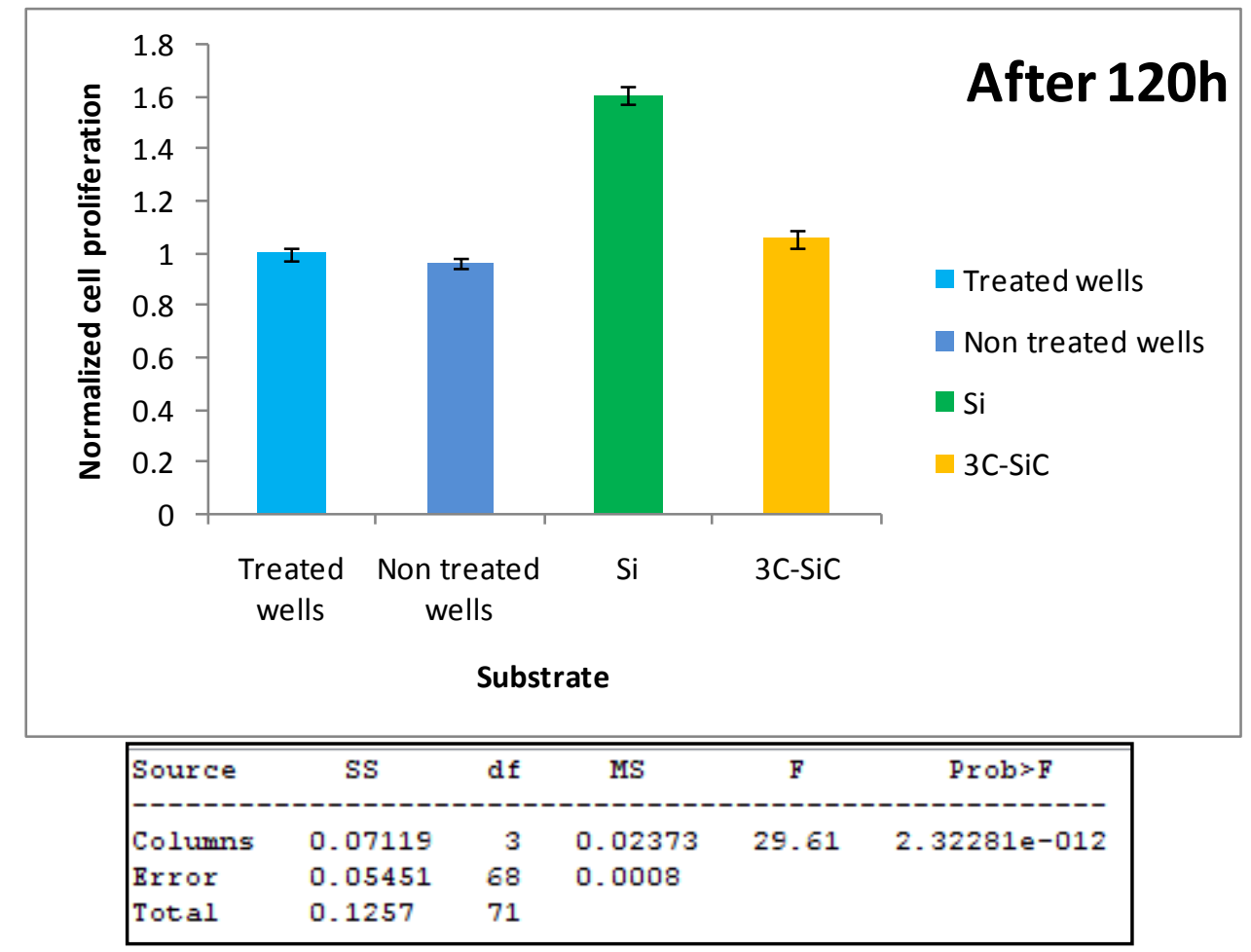

Figure 5.6. (Top) Histogram displaying the normalized results (respect to the treated wells) of the MTT assay after 120 hours. (Bottom) ANOVA table of the measured data. 

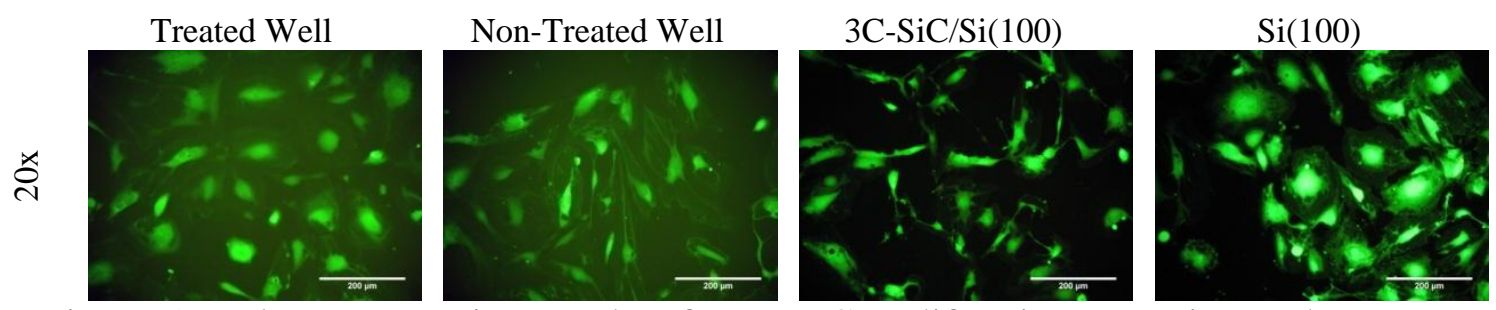

Figure 5.7. Fluorescent micrographs of HMVEC proliferation on various substrates (treated well, non treated well, $3 \mathrm{C}-\mathrm{SiC}$ and $\mathrm{Si}$ ) after 120 hours.

Figures 5.6 and 5.7 show the statistical analysis of the MTT assays and the fluorescent micrographs for adherent cells after 120 hours of seeding. In this case a higher proliferation was observed on silicon and the result was statistically confirmed by the paired test. The wells treated with attachment factor, the non-treated well and 3C-SiC substrates had no statistical differences for the cell viability measurement, however $\mathrm{Si}$ displayed an increased proliferation that was statically different from all the other samples. After well treatment it was expected to have an increased proliferation on these wells than on the non-treated wells. However as the culture insert used for the controls have a high reproductive nature it actually does not make any difference to use the attachment factor. This is completely different from culturing the cells in conventional culture flasks were, if attachment factor is not used, only a small percentage of the cell suspension is attached to flask culture surface. 


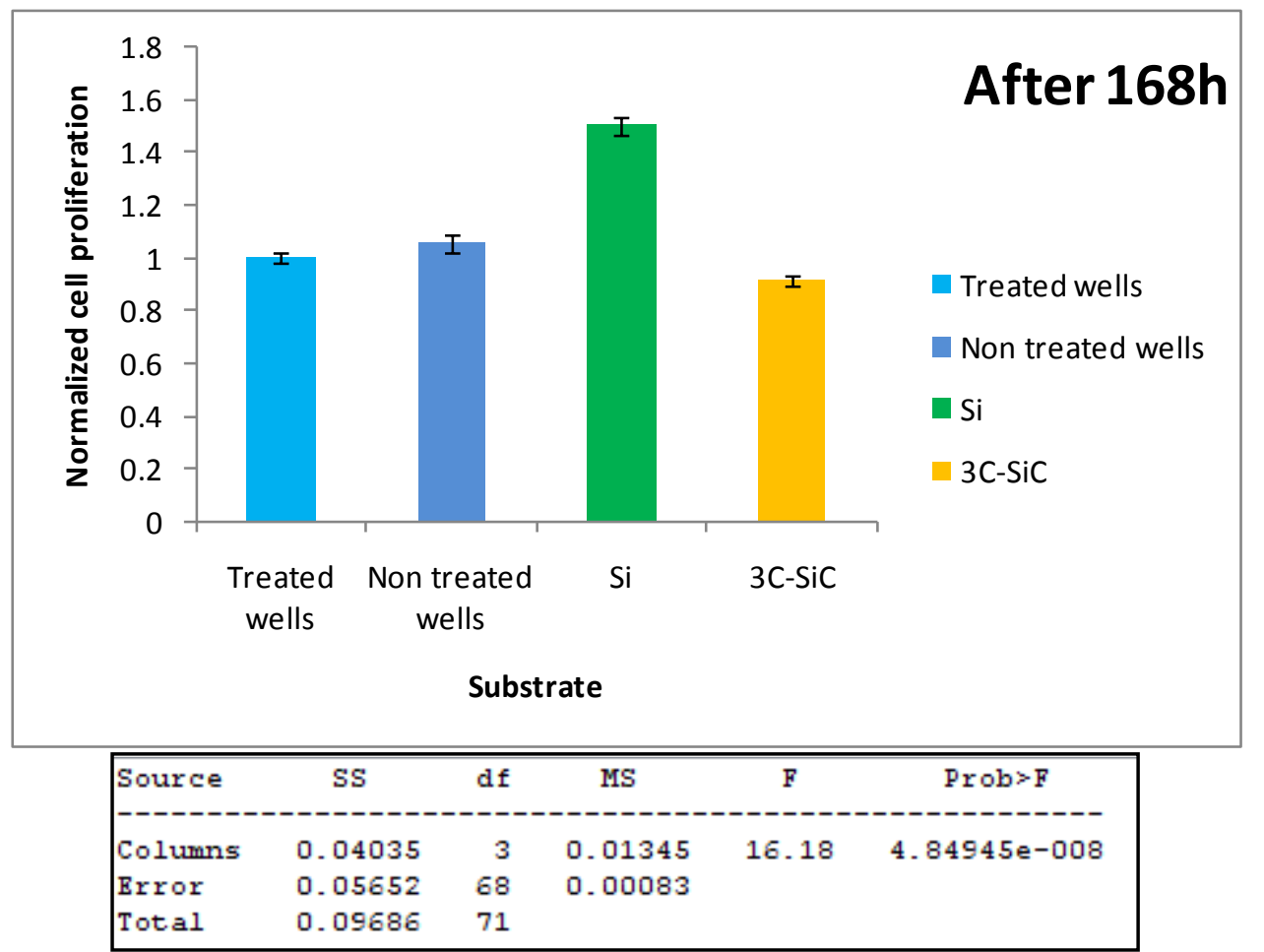

Figure 5.8. (Top) Histogram displaying the normalized results (respect to the treated wells) of the MTT assay after 168 hours. (Bottom) ANOVA table of the measured data.

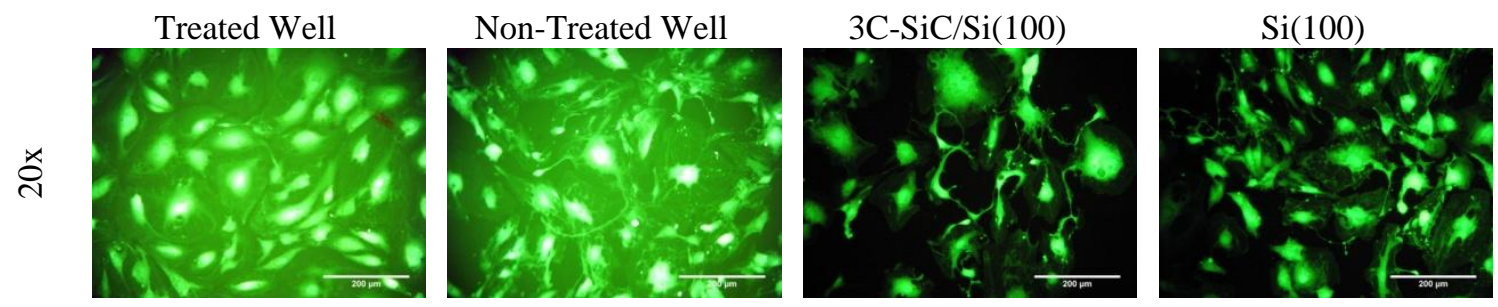

Figure 5.9. Fluorescent micrographs of HMVEC proliferation on various substrates (treated well, non treated well, 3C-SiC and Si) after 168 hours.

The same trend was observed again after 168 hours (see Figures 5.8 and 5.9). A higher cell proliferation was observed on $\mathrm{Si}$, which was as high as $60 \%$ more than the proliferation observed for the other cultures, and statistically different from the other substrates (which display no statistical differences among them).

No morphological differences were observed among the substrates. Healthy elongated endothelial cells proliferate on the substrates creating mosaic-like patterns that had good 
quality of adhesion (flattened cells) and no morphological changes as the culturing time increased.

3C-SiC displayed consistently good biocompatibility that was statistically comparable to high proliferation culture wells. In [11] it was reported that certain cell lines can induce physical damage on the substrate surfaces. The Si and 3C-SiC surface morphology were evaluated before and after culturing (after cleaning) and no differences were observed in surface morphology before and after cell seeding and removal.

\subsection{Discussion}

After the excellent platelet adhesion and morphology assessment results that were obtained for $3 \mathrm{C}-\mathrm{SiC}$, it was very compelling to evaluate its compatibility with the cells that line the cardiovascular system (endothelial cells). An adult human dermis microvascular cell line was selected and cell proliferation was evaluated on 3C-SiC and $\mathrm{Si}$, the leading material for biomedical sensing applications.

After statistical analysis of the MTT assays and morphological evaluation of cell cultures it was found that 3C-SiC had an excellent biocompatibility with this cell line, comparable with the culture inserts treated with attachment factor or equivalent high reproductivity culture wells. However Si displayed a superb proliferation, about $60 \%$ above the culture wells and $3 \mathrm{C}-\mathrm{SiC}$, without affecting cell morphology (cell were flattened, elongated and well spread on the surface), which means that this high proliferation was not the result of cell mutation or accelerated proliferation, but rather the effect of enhanced cell and cell adhesion protein attachment. 
These results may induce us to think of $\mathrm{Si}$ as a superior material with biocompatible characteristics, which for the case of HMVEC appears to be true, but it does not necessarily mean that the material is more hemocompatible. When interpreting these results one must think of the final application, which in this case is the future development of cardiovascular devices. If $\mathrm{Si}$ is coated with a lining of endothelial cells, and implanted in the human body, it is likely that its surface is denuded from cells at some point, exposing a highly thrombogenic surface to the blood stream, activating therefore the clotting cascade and presenting an elevated risk or material debris contaminating the blood stream due to Si's lack of mechanical resilience.

On the other hand, the reason why $\mathrm{Si}$ outperformed $3 \mathrm{C}-\mathrm{SiC}$ is most likely related to the high attachment of adhesion proteins to its surface due to the effect of its hydrophobicity and protein layer-film interfacial tension [84] [112] [113], especially Von Willebrand's Factor, which is produced constitutively by the endothelium and is present in the blood plasma [100]. It has been reported in [114] that substrates coated with Von Willebrand's Factor have higher platelet adhesion and aggregation as this factor is responsible for platelet tethering and translocation. Therefore it must be considered that protein adhesion adsorption onto surfaces requires a compromise, in this particular case the same reason that enhances cell proliferation on $\mathrm{Si}$ substrates is the same reason that makes it perform poorly when in contact with plasma proteins and platelets. 


\section{Chapter. 6: Conclusions and Future Work}

\subsection{Conclusions: 3C-SiC Versus Si}

To date, few crystalline semiconductor materials have been assessed for their biocompatibility. Crystalline semiconductor materials are of special interest for the development of biomedical sensors that can be in intimate contact with the human body. Therefore biocompatible sensing materials are critical to the development of implantable biomedical devices and this dissertation was dedicated to evaluating the biocompatibility of such materials for use in the cardiovascular system.

The development of implantable sensors that are placed in the blood stream has faced many challenges dominated by the hemocompatibility of the materials that can be used for their fabrication. The formation of thrombus on the surface of the semiconductors is of special concern and is a response to the activation of the clotting cascade, and the subsequent embolization of the thrombus. Many polymeric coatings have been developed or modified in order to reduce the thrombogenicity of engineered materials, but these coatings have all degraded over time once they are placed in the human body and thus make long-term cardiovascular implants very difficult to achieve

The former states the necessity of a semiconductor material that is biocompatible, hemocompatible and chemically and mechanically resilient, as the material needs to be in contact with the harsh environment of the body (i.e., bodily fluids). 
Two materials were selected for this research in order to compare their hemocompatibility, namely $\mathrm{Si}$ and $3 \mathrm{C}-\mathrm{SiC}$. Silicon is a material traditionally used for the development of MEMS devices, and is the main semiconductor used for biomedical applications and is known to be biocompatible with certain cell lines.

3C-SiC is a chemically and mechanically resilient wide band-gap semiconductor, very suitable for harsh environments, that has been proven to be biocompatible with several cell lines, but whose hemocompatibility in the single crystalline state has not yet been reported.

To the best of our knowledge this is the first research that directly compares crystalline $\mathrm{Si}$ and $3 \mathrm{C}-\mathrm{SiC}$ for their hemocompatibility. In order to assess the hemocompatibility of these semiconductor materials, three different aspects involved in thrombosis were used to design the experiments (see $\$ 2.3$ ): 1) the platelet adhesion and morphology assessment, 2) the protein adsorption perspective and 3) the human microvascular endothelial cell proliferation perspective.

Platelet adhesion and morphology were assessed after the exposure of platelet-richplasma (PRP) to different SiC polytypes, two different crystal orientations and as a function of surface roughness, and the results were contrasted to those of $\mathrm{Si}(100)$ wafer die (§3.2). In each case single crystal 3C-SiC grown on $\mathrm{Si}(100)$ substrates had the best performance, with low particle adhesion counts and small-area adhered platelets that also showed high platelet circularity. $\mathrm{Si}, 4 \mathrm{H}-\mathrm{SiC}$ and $6 \mathrm{H}-\mathrm{SiC}$ displayed high thrombogenicity and were therefore determined to be non-suitable for cardiovascular applications

A second experiment was designed $(\S 4.3)$ to monitor protein adsorption onto the surface of 3C-SiC, nano-crystalline diamond (NCD) and Si coated quartz crystal sensors 
using QCM-D technology. Unfortunately the NCD coatings peeled off and the SiC sensor coating was $4 \mathrm{H}-\mathrm{SiC}$ instead of $3 \mathrm{C}-\mathrm{SiC}$. However from this experiment it could be confirmed that protein adsorption to $\mathrm{Si}$ and $4 \mathrm{H}-\mathrm{SiC}$ are statistically similar, which confirms the platelet adhesion and morphology results observed on those substrates during the first experiment reported here (\$3.2) It was also found that the viscosity of the protein layers adsorbed to the hard substrates was smaller than for the proteins adsorbed onto polymeric film coatings.

Next, proliferation of human microvascular endothelial cells (HMVEC) on 3C-SiC substrates was directly compared to $\mathrm{Si}$ substrates (§5.2). Cell viability was quantified using MTT assays (\$5.3) and cell morphology inspected using fluorescence microscopy (§5.4).

After statistical analysis of the MTT assays and morphological evaluation of cell cultures it was found that $3 \mathrm{C}-\mathrm{SiC}$ had an excellent biocompatibility with this cell line, comparable with the culture inserts treated with attachment factor or equivalent high reproductivity culture wells. However, $\mathrm{Si}$ displayed higher proliferation than $3 \mathrm{C}-\mathrm{SiC}$ and appears to be more biocompatible with HMVEC.

Cells proliferate on both substrates without altered cell morphology, which is a good indication of non-degenerative interactions at the cell-material interface (good biocompatibility) [115].

It was concluded that even though Si has a higher biocompatibility for microvascular endothelial cells, this does not necessarily imply hemocompatibility, as the cell proliferation was assessed in vitro and in the absence of blood interactions. If a material that displays high thrombogenicity also displays good HMVEC compatibility, one must 
consider the implications of this material being coated with endothelial cells and then being placed in the blood stream. Under those conditions, if the material is denuded from endothelial cells, then the platelet attachment and activation response will be faster than the cell's capability to cover the surface [116], therefore the thrombogenic nature of the base material (as indicated by platelet adhesion assessment) will negate the positive endothelial cell biocompatibility result and makes Si non-suitable for cardiovascular applications in the long term.

The reason why $\mathrm{Si}$ outperformed $3 \mathrm{C}-\mathrm{SiC}$ in cell proliferation assessment is most likely related to the high attachment of adhesion proteins to its surface. Therefore a proper balance of the amount and type of proteins adsorbed to surfaces is required to guarantee hemocompatibility.

3C-SiC demonstrated in vitro characteristics that are highly desirable for cardiovascular applications including low thrombogenicity and good compatibility with endothelial cells. $3 \mathrm{C}-\mathrm{SiC}$ has a better trade off, between cell proliferation and platelet adhesion, in vitro than silicon.

The low thrombogenicity of $3 \mathrm{C}-\mathrm{SiC}$ reduces the chances of catastrophic failure of a device due to thrombi embolization and its resilience reduces the chances of material debris falling into the blood stream.

\subsection{Future Work}

The experiments performed in this research provided insight into the compatibility of 3C-SiC and silicon with blood. However in order to develop implantable sensing devices 
and two aspects should be explored more on detail: the behavior of the material in vivo and the interaction of the material with plasma proteins.

However, in order to address hemocompatibility in vivo, hemocompatibility must be first studied under blood flow conditions.

Additionally, the study of surface-protein interactions is key to truly understanding the mechanisms behind the hemocompatibility of a material and to functionalize surfaces. Surface functionalization is perhaps the most challenging and the last step required to develop an implantable sensing device.

The enzyme-linked immunosorbent assay, also called ELISA, is a technique used to detect the presence of an antibody or an antigen in a sample. This technique can be used in vitro in order to detect and quantize platelet activation by measuring the levels of relevant platelet metabolic products [117] (e.g. alpha granule components such as beta thromboglobulin and Platelet Factor 4) that are specific to platelet release or the presence of the soluble form of the adhesion molecule P-selectin [118] after contact with the semiconductor material surfaces.

Raised levels of soluble P-selectin are found in a variety of thrombotic disorders and its levels do not seem to be influenced by the various anticoagulants and different methods of plasma preparation [68] [119] making it an ideal candidate for further evaluation of the thrombogenicity of blood contacting materials. These types of measurements will provide additional information regarding platelet activation in the presence of material-blood plasma interactions.

In order to detect activated platelets under flow conditions the surface expression of P-selectin can be performed using fluorescence-activated flow cytometry [120]. This 
technique would also involve the detection of antigens on the membrane of activated platelets (e.g., GP IIb-IIIa), platelet surface bound fibrinogen and it would additionally allow the detection platelet changes in shape of activated circulating platelets in contact with the materials [121].

Future work regarding the coating of quartz crystal sensors with 3C-SiC single crystal films would allow the study of fibrinogen and GPIIb-IIIa onto this substrate using QCMD. If this were possible, the QCM-D experiment could be extended to the exposure of flowing platelets to the layer of pre-adsorbed proteins, and quantize the degree of platelet adhesion and activation related to protein adsorption. Following the same rationale, $3 \mathrm{C}$ $\mathrm{SiC}$ could be compared to sensors coated with hemocompatible polymeric films.

Finally, an important step in the development of an implantable sensor would be the study of plasma protein adsorption and platelet activation related to the semiconductor surface energy.

Perhaps the most useful step in the determination of the hemocompatibility of any material would be in vivo biocompatibility studies whereby the material is implanted into the blood stream of a living animal and analyzed following the appropriate amount of time. However this last step is very time consuming and expensive and should only be considered once the previous suggested future work research steps have been completed successfully. 


\section{References}

[1] David F. Williams, "On the mechanisms of biocompatibility," Biomaterials, vol. 29, pp. 2941-2953, 2008.

[2] ISO 10993 Biological evaluation of medical devices- Part 1: Evaluation and testing.

[3] S. C. Bayliss, L. D. Buckberry, P. J. Harris, and M. Tobin, "Nature of the siliconanimal cell interface," Journal of Porous Materials, vol. 7, pp. 191-195, 2000.

[4] ISO 10993 Biological evaluation of medical devices- Part 5: Tests fot in vitro cytotoxicity.

[5] A. D. Michelson, Platelets. San Diego: Elsevier Academic Press., 2002.

[6] Surmodics, Inc., Diagnosing hemo(in)compatibility, from clinical and device consideratins to test bench assessment, 2004.

[7] Surmodics, Inc., Advancements in blood- and tissue-compatible coatings, 2004.

[8] A. Bolz and M. Schaldach, "Artificial heart valves: Improved blood compatibility by PECVD a-SiC:H coating," Artificial Organs, vol. 14, no. 4, pp. 260-269, 1990.

[9] C. Coletti, M. J. Jaroszeski, A. M. Hoff, and S. E. Saddow, "Culture of mammalian cells on single crystal SiC substrates," in Fall Mater. Res. Soc. Meeting Proc 950, Boston, 2006.

[10] A. Pallaoro et al., "Study and characterization of different SiC terminations and their interactions with biomolecules," in XVIII Congresso Nazionale sulla Scienza e tecnologia del vuoto, Florence, Italy, 2007.

[11] C. L. Frewin et al., "Atomic force microscopy analysis of central nervous system cell morphology on silicon carbide and diamond substrates," Journal of Molecular Recognition, vol. 22, pp. 380-388, 2009.

[12] U. Kalnins, A. Erglis, I. Dinne, I. Kumsars, and S. Jegere, "Clinical outcomes of silicon carbide coated stents in patients with coronary artery disease," Med Sci Monit, vol. 8, no. 2, pp. 116-120, February 2002 
[13] M. Reyes et al., "Growth of 3C-SiC on Si molds for MEMS applications," in Materials Science Forum, vol. 527-529, 2006, pp. 307-310.

[14] B. Furie and B. C. Furie, "Thrombus formation in vivo," J. Clin. Invest., vol. 115, no. 12 , p. 3355-3362, 2005.

[15] M. A. Lichtman et al., Williams hematology, 7th ed.: Mc Graw Hill Medical, 2006.

[16] M. Frost and M. E. Meyerhoff, "In vivo chemical sensor: tackling biocompatibility," Anal Chem, vol. 78, no. 21, pp. 7370-7377, November 2006.

[17] S. L. Goodman, S. L. Cooper, and R. M. Albrecht, "The effects of adsorbed albumin on platelet spreading," J. Biomater Sci Polym, vol. 2, pp. 147-159, 1991.

[18] M. Moriau, E. P. Lavenne, J. M. Scheiff, and C. Debeys, "The physiological mechanisms of haemostasis," in Blood Platelets.: Hologramme Ed, 1988.

[19] C. Mao et al., "In vitro studies of platelet adhesion on UV radiation-treated nylon surface," Carbohydr. Polym., vol. 59, pp. 19-25, 2005.

[20] L. Jin et al., "The anticoagulant activation of antithrombin by heparin," in Proc. Natl. Acad. Sci., vol. 94, 1997, pp. 14683-14688.

[21] T.I. T. Okpalugo, A. A. Ogwu, P. D. Maguire, and J. A. McLaughlin, "In vitro blood compatibility of a-C:H:Si and a-C:H thin films," Diamond and Related materials, vol. 13, pp. 1088-1092, 2004.

[22] S. E. Saddow and A. Agarwal, Eds., Advances in Silicon Carbide processing and applications. Boston, MA: Artech House, Inc., 2004.

[23] S. E. Saddow et al., "Effects of substrate surface preparation on chemical vapor deposition growth of $4 \mathrm{H}-\mathrm{SiC}$ epitaxial layers," Journal of electronic materials, vol. 30, no. 3, pp. 228-234, 2001.

[24] C. A. Zorman and M. Mehregany, The MEMS handbook: Introduction and fundamentals, Mohamed Glad-el-Hak, Ed.: CRC Press LLC., 2005, ch. 15.8.

[25] L. Jiang et al., "Fabrication of SiC microelectromechanical systems," J. Vac. Sci. Technol., vol. 21, no. 6, pp. 2998-3001, 2003.

[26] X. Li et al., "Micro/Nanoscale mechanical and tribological characterization of SiC for orthopedic applications," J. Biomed. Mater. Res. B: Appl. Biomater., vol. 72, no. 2, pp. 353-361, 2005. 
[27] A. H. Maine, S. C. Bayliss, P. Barr, M. Tobin, and L. D. Buckberry, "Biologically interfaced porous silicon devices," Phys. Stat. Sol. (a), vol. 182, no. 1, pp. 505-513, 2000 .

[28] X. G. Zhang, Electrochemistry of silicon and its oxide. New York: Kluwer academic/Plenum Publishers, 2001.

[29] J. I. Carrrasso and M. M. Faktor, "Oxidation reactions and potentials of germanium and silicon," in The electrochemistry of semiconductors, P. J. Holmes, Ed. London: Academic Press, 1962, pp. 205-255.

[30] D. Carrié et al., "Initial and follow-up results of the Tenax coronary stent," $J$. Intervent Cardiol, vol. 14, pp. 1-5, 2001.

[31] J. A. Fournier et al., "Initial results and 6 month clinical follow-up after implantation of a silicon carbide coated coronary stent," Rev. Esp. Cardiol., vol. 54, pp. 567-572, 2001.

[32] A. Ogami et al., "Short term effect of silicon carbide whisker to the rat lung," Industrial health, vol. 39, pp. 175-182, 2001.

[33] I. Svensson, E. Artursson, P. Leanderson, R. Berglind, and F. Lindgren, "Toxicity in vitro of some silicon carbides and silicon nitrides: whiskers and powders," American journal of industrial medicine, vol. 31, pp. 335-343, 1997.

[34] C. Coletti et al., "Biocompatibility and wettability of crystalline $\mathrm{SiC}$ and $\mathrm{Si}$ surfaces," in IEEE EMBS Proceedings, 2007, pp. 5849-5852.

[35] A. Naji and M. Harmand, "Cytocompatibility of two coating materials, amorphous alumina and silicon carbide, using human differentiated cell cultures," Biomaterials, vol. 12, no. 7, pp. 690-694, 1991.

[36] R. Yakimova et al., "Surface functionalization and biomedical applications based on SiC," J. Phys. D: Appl. Phys., vol. 40, pp. 6435-6442, October 2007.

[37] T. V. Kumari, U. Vasudev, A. Kumar, and B Menon, "Cell surface interactions in the study of biocomaptibility," trend. Biomater. Artif. Organs., vol. 15, no. 2, pp. 37-41, 2002.

[38] G. Sagvolden, I. Giaever, E. O. Pettersen, and J. Feder, "Cell adhesion force microscopy," in Proc. Natl. Acad. Sci., vol. 96, 1999, pp. 471-476.

[39] C. S. Goodman, "Mechanisms and molecules that control growth cone guidance," Annu. Rev. Neurosci, vol. 19, pp. 341-377, March 1996. 
[40] D. F. Williams, The Williams dictionary of biomaterials.: Liverpool University Press, 1999.

[41] C. Salvagnini. (2005) Thrombin inhibitors grafting on polyester membranes for the preparation of blood-compatible materials. [Online]. http://hdl.handle.net/2078.1/5328

[42] S. R. Hanson, "Blood coagulation and blood-materials interactions," in Biomaterials science, an introduction to materials in medicine;, B. D. Ratner, A. S. Hoffman, and F. J. Schoen, Eds. San Diego, CA: Elsevier Academic Press:, 2004, p. 332.

[43] B. D. Ratner, "Blood compatibility—a perspective," J. Biomater. Sci. Polym. Ed., vol. 11, pp. 1107-1119, 2000.

[44] A. H. Schmaier, "Contact activation: a revision," Thromb. Haemost., vol. 77, pp. 101-107, 1997.

[45] J. Hunt, "Foreign body response," in Encyclopedia of biomaterials and biomedical engineering, g. L. Bowlin and G. Wnek, Eds.: Informa Healthcare, 2004.

[46] M. Szycher and C. P. Sharma, Blood compatible materials and devices: Perspectives towards the 21st century.: CRC, 1990.

[47] Y. Ito, L.-S. Liu, R. Matsuo, and Y. Imanishi, "Synthesis and nonthrombogenicity of polymer membrane with surface-graft polymers carrying thrombin inhibitor," $J$. Biomed. Mater. Res., vol. 26, pp. 1065-1080, 1992.

[48] A. Kishida et al., "Immobilization of human thrombomodulin onto poly(ether urethane urea) for developing antithrombogenic blood-contacting materials," Biomaterials, vol. 15, pp. 848-852, 1994.

[49] D. E. Garfin, "Gel electrophoresis of proteins," in Essential cell biology: Cell structure, a practical approach, J. Davey and M. Lord, Eds. Oxford: Oxford University Press., 2003, vol. 1, pp. 197-268.

[50] U. T. Seyfert, V. Biehl, and J. Schenk, In vitro hemocompatibility testing of biomaterials according to the ISO 10993-4, 2002.

[51] ISO 10993 Biological evaluation of medical devices- Part 4: Selection of tests for interactions with blood, 2002.

[52] J. M. Buchanan, P. J. Upman, and R. F. Wallin. (1998) MD\&DI. [Online]. http://www.devicelink.com/mddi/archive/98/11/009.html 
[53] U. T. Seyfert, V. Biehl, and J. Schenk, "In vitro hemocomptibility testing of biomaterials according to the ISO 1993-4," Biomolecular engineering, vol. 19, pp. 91-96, 2002.

[54] N. Nurdin et al., "Hemocompatibility evaluation of DLC- and SiC- coated surfaces," European Cells and Material, vol. 5, pp. 17-28, 2003.

[55] A. J. Rosenbloom et al., "Nanoporous SiC: A Candidate Semi-Permeable Material," Biomedical Microdevices, vol. 6, no. 4, pp. 261-267, 2004.

[56] J. Y. Chen et al., "Antithrombogenic investigation of surface energy and optical bandgap and hemocompatibility mechanism of Ti(Ta+5)O2 thin films," Biomaterials, vol. 23, pp. 2545-2552, 2002.

[57] G. Kotzar et al., "Evaluation of MEMS materials of construction for implantable medical devices.," Biomaterials, vol. 23, no. 13, pp. 2737-2750, 2002.

[58] B A. Weisenberg and D. L. Mooradian, "Hemocompatibility of materials used in microelectromechanical systems: Platelet adhesion and morphology in vitro," $J$ Biomed Mater Res., vol. 60, no. 2, pp. 283-291, May 2002.

[59] L. A.W. Sanderson, K. Emoto, J. M. Alstine, and J. J. Weimer, "Characterization of Grafted Poly(ethylene glycol) on Si Wafers Using Scanning Probe Microscopy," Journal of Colloid and Interface Science, vol. 207, no. 1, 1998.

[60] G. M.B.F. Snellings, S. O. Vansteenkiste, S. I. Corneillie, M. C. Davies, and E. H. Schacht, "Protein adhesion at Poly(ethylene glycol) modified surfaces," Adv. Mater., vol. 12, no. 24, pp. 1959-1962, 2000.

[61] Y. Takami et al., "Protein adsorption onto ceramic surfaces," J. Biomed. Mater. Res., vol. 40, no. 1, 1998.

[62] N. Ali et al., "Human microvascular endothelial cell seeding on Cr-DLC thin films for heart valve applications," Journal of Materials Engineering and Performance, vol. 15, no. 2, pp. 230-235, 2006.

[63] G. Perego et al., "Functionalization of poly-(L-lactic-co-epsilon-caprolactone): effects of surface modification on endothelial cell proliferation and hemocompatibility [corrected].," J Biomater Sci Polym Ed., vol. 14, no. 10, pp. 1057-1075, 2003.

[64] F. J. Jing et al., "Hemocompatibility of lanthanum oxide films fabricated by dual plasma deposition," Thin Solid Films, vol. 515, no. 3, pp. 1219-1222, 2006. 
[65] E. Ruckenstein, A. Marmur, and S. R. Rakower, "Sedimentation and adhesion of platelets onto a horizontal glass surface," Thromb Haemostas, vol. 36, p. 334-342, 1976.

[66] S. L. Goodman, M. D. Lelah, L. K. Lambrecht, and S. L. Cooper, "In vitro v. ex vivo platelet deposition on polymer surfaces ," Scanning Electron Microsc, vol. I, p. 279-290, 1984.

[67] H. R. Baumgartner, R. Muggli, T. B. Tschopp, and V. T. Turitto, "Platelet adhesion, release and aggregation in flowing blood: Effects of surface properties and platelet function," Thromb Haemostas, vol. 35, 1976.

[68] S. Kamath, A. D. Blann, and G.Y. H. Lip, "Platelet activation: assessment and quantification," European heart journal, vol. 22, pp. 1561-1571, 2001.

[69] Y. Jiang, B. Rongbing, T. Ling, S. Jian, and L. Sicong, "Blood compatibility of polyurethane surface grafted copolymerization with sulfobetaine monomer," Coll. Surf. B: Biointerf., vol. 36, p. 27-33, 2004.

[70] L. F. Brass, L. Zhu, and T. J. Stalker, "Minding the gaps to promote thrombus growth and stability," J. Clin. Invest., vol. 115, no. 12, p. 3385-3392, 2005.

[71] J. G. McFarland and R. H. Aster, "Evaluation of four methods for platelet compatibility testing," Blood, vol. 69, no. 5, pp. 1425-1430, 1987.

[72] N. Weber, H. P. Wendel, and J. Kohn, "Formation of viscoelastic protein layers on polymeric surfaces relevant to platelet adhesion," Biomaterials, vol. 28, no. 35, pp. 5246-5258, 2007.

[73] H. P. Wendel and G. Ziemer, "Coating-techniques to improve the hemocompatibility of artificial devices used for extracorpreal circulation," Eur. J. Cardio-thorac. Surg., vol. 16, pp. 342-350, 1999.

[74] O Chappey, M -P. Wautier, and J. -L. Wautier, "Endothelial cells in culture: a model to study in vitro vascular toxicity," Toxic. in Vitro, vol. 9, no. 4, pp. 411-419, 1995.

[75] B. J. Bain, A beginners guide to blood cells, 2nd ed. Massachusetts: Blackwell Publishing Ltd, 2004.

[76] M. M. Frojmovic and J. G. Milton, "Human platelet size, shape, and related functions in health and disease," Physiological reviews, vol. 62, no. 1, pp. 185-261, January 1982. 
[77] (2003, December) The journal of Biological Chemistry. [Online]. http://www.jbc.org/content/278/51.cover-expansion

[78] K. Park, F. W. Mao, and H. Park, "Morphological characterization of surface induced platelet activation," Biomaterials, vol. 11, pp. 24-31, 1989.

[79] Image J. [Online]. http://rsbweb.nih.gov/ij/

[80] S. Levy-Toledano, J. Maclouf, P. Bryon, and E. H. Savariau, "Human platelet activation in the absence of aggregation: A calcium-dependent phenomenon independent of thromboxane formation," Blood, vol. 59, no. 5, pp. 1078-1085, May 1982.

[81] H. Mani, B. Luxembourg, C. Kläffling, M. Erbe, and E. Lindhoff-Last, "Use of native or platelet count adjusted platelet rich plasma for platelet aggregation measurements," J Clin Pathol, vol. 58, p. 747-750, 2005.

[82] S. J. Hitchcock, N. T. Carroll, and M. G. Nicholas, "Some effects of substrate roughness on wettability," Journal of Materials Science, vol. 16, no. 3, pp. 714-732, March 1981.

[83] J. Israelachvili, Intermolecular and surface forces. London: Academic Press, 1992.

[84] R. I. Freshney, Culture of animal cells: a manual of basic technique, 5th ed.: John Wiley \& Sons, Inc., 2005.

[85] L. J. Yao and K. H. Mayo, "Interactions of integrin GPIIb/IIIa-derived peptides with fibrinogen investigated by NMR spectroscopy," Biochem. J., vol. 315, pp. 161-170, 1996.

[86] Y. Gu, P. Boonstra, A. A. Rijnsburger, J. Haan, and W. van Oeveren, "Cardiopulmonary bypass circuit treated with surface-modifying additives: a clinical evaluation of blood compatibility," Ann. Thorac. Surg., vol. 65, pp. 1342-1347, 1998.

[87] Gladstone. (2009, October) Integrilin: Basic Research Translated into Therapy. [Online]. http://www.gladstone.ucsf.edu/gladstone/site/publicaffairs/section.php?id=1396

[88] M. S. Lord et al., "The effect of silica nanoparticulate coatings on serum protein adsorption and cellular response," Biomaterials, vol. 27, pp. 4856-4862, 2006.

[89] KSV. (2004, October) KSV-QCM techinical note. Electronic document. 
[90] N. Weber, A. Pesnell, D. Bolikal, J. Zeltinger, and J. Kohn, "Viscoelastic properties of fibrinogen adsorbed to the surface of biomaterials used in blood-contacting medical devices," Langmuir, vol. 23, pp. 3298-3304, 2007.

[91] Q-sense. (2009) Q-snese QCM-D technology. [Online]. http://www.qsense.com/index.asp

[92] M. Rodahl and B. A. Kasemo, "A simple setup to simultaneously measure the resonant frequency and the absolute dissipation factor of a quartz crystal microbalance," Rev. Sci. Intrum., vol. 67, no. 9, pp. 3238-3241, 1996.

[93] K. A. Marx, "Quartz crystal microbalance: a useful tool for studying thin polymer films and complex biomolecular systems at the solution-surface interface ," Biomacromolecules, vol. 4, no. 5, pp. 1099-1120, 2003.

[94] B. Osterud, "Activation pathways of the coagulation system in normal haemostasis," Scan. J. Haematol, vol. 32, pp. 337-345, 1884.

[95] W. B. Tsai, J. M. Grunkemeier, C. D. McFarland, and T. A. Horbertt, "Platelet adhesion to polystyrene-based surfaces preadsorbed with plasmas selectively depleted in fibrinogen, fibronectin, or von Willebrand's factor," J. Biomater. Res., vol. 60, no. 3, pp. 348-359, 2002.

[96] Q-Sense. Hemocompatibility of hydroxyapatite (Application note QS405-12-1). electronic document.

[97] J. W. Smith, Z. M. Ruggeri, T. J. Kunicki, and D. A. Cheresh, "Interaction of integrins alpha v beta 3 and glycoprotein IIb-IIIa with fibrinogen. Differential peptide recognition accounts for distinct binding sites," J. Biol. Chem., vol. 265, no. 21, pp. 12267-12271, 1990.

[98] FCoE BITT. (2009) USF FCoE BITT. [Online]. http://www.bitt.usf.edu/

[99] N. Weber, H. P. Wendel, and J. Kohn, "Formation of viscoelastic protein layers on polymeric surfaces relevant to platelet adhesion," Journal of Biomedical Materials Research Part A, vol. 72A, no. 4, pp. 420 - 427, 2005.

[100] B. Alberts et al., Molecular biology of the cell, 4th ed. New York: Garland Science, 2002.

[101] J. McGeachie. (1998, February) Blue histology- more about endothelial cells. [Online]. http://www.lab.anhb.uwa.edu.au/mb140/MoreAbout/Endothel.htm 
[102] R. G. Richards, "The effect of surface roughness on fibroblast adhesion in vitro," Injury, vol. 27, no. Supl 3, pp. S-C38-S-C48, 1996.

[103] T. Mosmann, "Rapid colorimetric assay for cellular growth and survival: application to proliferation and cytotoxicity assays," Journal of immunological methods, vol. 65, no. 1 , pp. 55-63, 1983.

[104] D. M. Spinner, "MTT Growth Assays in Ovarian Cancer," in Ovarian Cancer: Methods and Protocols, M. S. Bartlett, Ed.: Humana Press, Inc, pp. 175-177.

[105] S. Ahmadian, J. Barar, A. A. Saei, M.A. A. Fakhree, and Y Omidi. (2009) Cellular Toxicity of Nanogenomedicine in MCF-7 Cell Line: MTT assay.JoVE. 26. [Online]. http://www.jove.com/index/details.stp?id=1191

[106] C. Coletti, Silicon carbide biocomaptibility, surface control and electronic cellular interaction for biosensing applications, 2007, Ph.D.E.E. dissertation.

[107] C. L. Frewin, C. Coletti, C. Riedl, U. Starke, and S. E. Saddow, "A comprehensive study of hydrogen etching on the major SiC polytypes and crystal orientations," Materials science forum, vol. 615-17, pp. 589-592, 2009.

[108] Cascade Biologics. Inc. Human Microvascular Endothelial Cells (adult dermis). Document. [Online]. http://www.cascadebio.com/product_files/doc20.8\%20HMVECad.pdf

[109] Cascade Biologics. Inc. Medium 131, MVGS and AF: Instructions for storage and use. Document.

[110] C. C. Perry and T. Keeling-Tucker, "Aspects of the bioinorganic chemistry of silicon in conjunction with the biometals calcium, iron and aluminium," J. Inorg. Biochem., vol. 69, no. 181, 1998.

[111] Invitrogen. (2008, February) CellTracker ${ }^{\mathrm{TM}}$ Probes for Long-Term Tracing of Living Cells. Document.

[112] Barry Arkles. (2006, October) Hydrophobicity, hydrophilicity and silanes. Paint \& Coatings Industry Magazine.

[113] L. Mirenghi, P. A. Ramires, R. E. Pentassuglia, P. Rotolo, and A. Romito, "Growth of human endothelial cells on plasma treated polyethyleneterephthalate surfaces," Journal of material science: materials in medicine, vol. 11, pp. 327-331, 2000.

[114] S. Kulkarni et al., "A revised model of platelet aggregation," The journal of clinical investigation, vol. 105, no. 6, pp. 783-791, March 2000. 
[115] A. J. García, "Intefaces to control cell-biomaterial adhesive interactions," $A d v$. Polym. Sci., vol. 203, pp. 171-190, 2006.

[116] P. Zilla, M. Deutsch, and J. Meinhart, ""Endothelial cell transplantation," Semin. Thromb. Hemostais., vol. 12, pp. 52-63, 1999.

[117] M. Fisher, P. H. Levine, and A. L. Fullerton, "Marker proteins of platelet activation in patients with cerebrovascular disease," Arch. Neurol., vol. 39, pp. 692-695, 1982.

[118] A.D. Blann and G.Y.H. Lip, "Hypothesis: is soluble P-selectin a new marker of platelet activation?," Atherosclerosis, vol. 128, pp. 135-138, 1997.

[119] B.H. Chong et al., "Plasma P-selectin is increased in thrombotic consumptive platelet disorders," Blood, vol. 83, pp. 1535-1541, 1994.

[120] L. Corash, "Measurement of platelet activation by fluorescence-activated flow cytometry," Blood Cells, vol. 16, pp. 97-106, 1990.

[121] A.H. Lazarus, J.F. Wright, V. Blanchette, and J. Freedman, "Analysis of platelets by flow cytometry," Transfus Sci, vol. 16, pp. 353-361, 1995. 


\begin{abstract}
About the Author
Norelli Schettini was born on December $7^{\text {th }} 1982$ in Barranquilla (Atlántico), Colombia. In 2005, she earned her bachelor's degree in Electrical Engineering from the Universidad del Norte (Barranquilla, Colombia). She graduated with honors and received the scientific merit award for her research work on speech recognition in cotton-top tamarins (saguinus oedipus), an endemic endangered species from the north coast of Colombia.

In 2005 she was selected as a scholar by Universidad del Norte, to become part of the faculty after acquiring her Ph.D. degree at University of South Florida (USF) in Tampa, FL (USA), as part of a special program to improve education and research in South America.

During her Ph.D. studies at USF, she was awarded the FCoE BITT (Florida Center of Excellence, Biomolecular Identification and Targeted Therapeutics) fellowship to conduct her research on hemocompatibility of Single crystal 3C-SiC.
\end{abstract}

